University of Massachusetts Amherst

ScholarWorks@UMass Amherst

Doctoral Dissertations 1896 - February 2014

$1-1-1981$

\title{
The effects of reasoning workshops on the teaching strategies of secondary science teachers.
}

Anne S. Lombard

University of Massachusetts Amherst

Follow this and additional works at: https://scholarworks.umass.edu/dissertations_1

\section{Recommended Citation}

Lombard, Anne S., "The effects of reasoning workshops on the teaching strategies of secondary science teachers." (1981). Doctoral Dissertations 1896 - February 2014. 3693.

https://scholarworks.umass.edu/dissertations_1/3693

This Open Access Dissertation is brought to you for free and open access by ScholarWorks@UMass Amherst. It has been accepted for inclusion in Doctoral Dissertations 1896 - February 2014 by an authorized administrator of ScholarWorks@UMass Amherst. For more information, please contact scholarworks@library.umass.edu. 
THE EFFECTS OF REASONING WORKSHOPS

ON THE TEACHING STRATEGIES OF SECONDARY SCIENCE TEACHERS

A Dissertation Presented

By

ANNE S. LOMBARD

Submitted to the Graduate School of the University of Massachusetts in partial fulfillment

of the requirements for the degree of

DOCTOR OF EDUCATION

February 1981

Education 
(c) Anne S. Lombard 1981

All Rights Reserved 
THE EFFECTS OF REASONING WORKSHOPS

ON THE TEACHING STRATEGIES OF SECONDARY SCIENCE TEACHERS

A Dissertation Presented

By

ANNE S. LOMBARD

Approved as to style and content by:
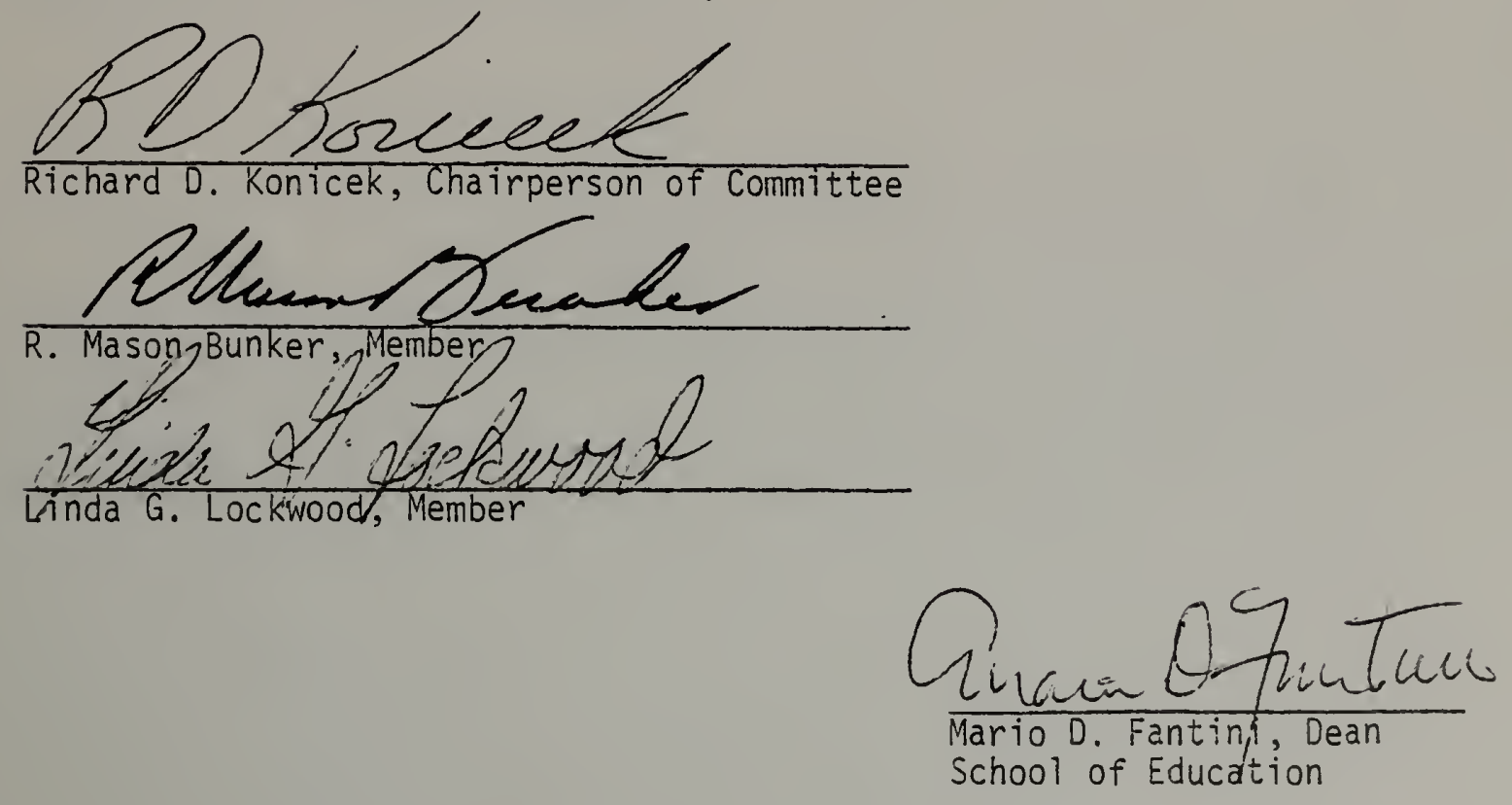
ACKNOWLEDGEMENTS

I would like to thank those who assisted in so many ways in the development and preparation of this dissertation:

-- Dr. Richard Konicek, Chairperson of my Committee, for encouragement, support, and friendship, for the many hours spent carefully reviewing and analyzing this work, and for good productive times working together throughout my graduate career;

-- Or. R. Mason Bunker, whose concerns for the needs of inservice teachers influenced the design of this study and stimulated me to probe for meanings beneath the surface;

-- Dr. Linda Lockwood, who asked clarifying questions and whose environmental outiook has provided me with a larger perspective;

-- Dr. Klaus Schultz, for his encouragement in writing the proposal and starting the project which culminated in this study;

-- The Science teachers, who generously and enthusiastically provided time in their crowded days for interviews, and who shared materials which were vital to this study;

-- Nancy Kaminski, for her excel lent advice and competent preparation of the final draft of this dissertation;

-- My parents, Frances and George Sanborn, who have encouraged me throughout my life in my pursuit of knowledge;

-- Ada Lombara, for her support and help, especially in times of crisis;

-- My daughters, Karen and Pam, for managing so competently at home and in their own lives and for making me realize that this was worth doing; 
-- And, most importantly been strong in his belief in band, Don, who has support and love have helped me ability. His goa 1. 


\section{ABSTRACT}

The Effects of Reasoning Workshops

on the Teaching Strategles of Secondary Science Teachers

$$
\text { (February, 1981) }
$$

Anne S. Lombard, B.A., Mount Holyoke College

$$
\text { M.S. University of Rochester }
$$

Ed.D., University of Massachusetts

Directed by: Professor Richard O. Konicek

The purpose of this study was to determine the effects of Science Teaching and the Develomment of Reasoning workshops on the attitudes and classroom behavior's of teachers who attended. The study aiso determined the nature and extent of changes made which were consistent with the intent and philusophy of the rorkshop and identified what factor's the teachers perceived either facilitated or hindered their ability to make changes.

Data from the following sources were collected and ana-

lyzed:

1. An evaluation questionnaire, developed and pretested by the researcher, sent to all secondary science teachers (approximately 200 ) who have participated in scierice Teaching and the Deveiopment of Radschitig workstiops exceeding three hours in Tength in New England.

2. Interviews with twenty secondary science teachers who responded to the questionnaire and indicated that they had used the ideas from the workstiop in their classroom.

3. Telephone interviews with twenty secondary science teachers who did not retunn the questionnaire to assess their ateitudes and use of the workshop ideas. 
4. The Stages of Concern Questionnaire administered to twenty-one participants of a fifteen holir course, assessing changes in concerns and perceptions of changes in teaching behaviors as a result of the course, Scierice Teaching and the Development of Reasoning.

5. Teacher-prepared materials such as tests, laboratory outlines, and review questions that illustrated the effects of the workshop on teaching.

The changes reported by teachers respording to the questionnaire, by those who were interviewed, and those who provided materials they had developed, feli into three categories: attitudinal changes, curriculum innovations, and sharing of the workshop ideas with colleagues.

Eighty-nine percent reported an increased awareness of the reasoning processes of their students; seventy-nine percent felt that they snould teach their courses differently as a result of the workshop. Interviews revealed that these teachers were aware that their teaching was too formally oriented, and were looking for ways to adapt it to the reasoning capabilities of their stucients. The extent of curriculum innovation reported by the teachers, in order from greatest to least, occurred in the presentation of new topics, and concepts, testing procedures, laboratory design, and use of texts. Three-fourths of the interviewed teachers had shared the ideas from the workshop with their professional colleagues. Fifteen of the twenty had met with other faculty members at their school in meetings or on a one-to-one basis. Two had organized workshops at their school for other faculty and five had presented workshops or courses at other schools, meetings, or conferences. 
These results show that a single workshop or short series of workshops can result in modifying teaching behaviors in the classroom. Analysis of the interviews and curriculum revealed considerabie variation in interpretation of concrete and formal operational reasoning as well as the concept of "exploration." In addition, the Stages of Concern Questionnaire showed high "informational" and "personal" concerns for the new users of the workshop ideas.

The teachers perceived the following. factors as important in facilitating or hindering their ability to make changes reiated to inis workshop in the classroom:

1. Agreement with the content and theoretical basis of the workshoo.

2. Time during and after the workshop to assimilate the concepts preserited.

3. Voluntary attendance.

4. Administrative and colleague support.

Recommendations regarding the conducting of future science Teaching and the Development of Reasoning workshops are given. Additional conclusions and recommendations for both the researcher and practitioner are offered. These include the need for studies to clarify the characteristics of formal operational thought with respect to the domains of science as well as the development of a realistic, research-based pian which will increase the impact of inservice programs promoting the development of reasoning. 
TABLE OF CCNTENTS

\section{PFGE}

ACKNOWLEDGEMENTS ..........................

ABSTRACT OF DISSERTATION ......................

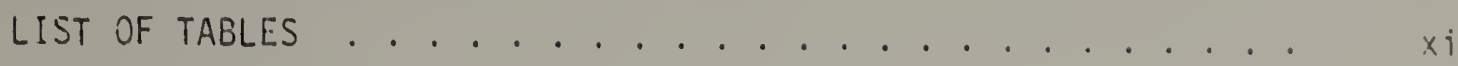

LIST GF FIGURES . . . . . . . . . . . . . . . . . . . . . . . . . .

Chapter

I. BACKGROUND OF THE PROBLEM AND FOCUS OF THE STUDY .... . i

Introduction ..................

Statement of the Problem . . . . . . . . . 2

Background of the Study . . . . . . . . . . 15

Purpose of the Study . . . . . . . . . . . . . . 21

Significance of the Study . . . . . . . . . 22

Methodology . . . . . . . . . . . 23

Delimitations of the Study . . . . . . . . . . 25

Chapter Outtine ............. . . 26

II. REVIEW OF THE LITERATURE . . . . . . . . . . . . 28

Introdustion . . . . . . . . . . . . 23

Formal Operational Thought . . . . . . . . . 29

An Application of the Theory of Equilibration

to Secondary Science Education: The Learning

Cycle . . . . . . . . . . . 43

Humaristic Psychology: A Conceptual Basis for

Modern Inservice Progranis . . . . . . . . . 51

Application of the Change Process to Inservice.... 55

The Positivist and Phenomenological Approaches

to Evaluation ................ 72

Teachers'Perceptions as a Source of Data . . . . T 76

Summary ...................... 81 
Chapter

II I. METHODOLOGY $\ldots \ldots \ldots \ldots$

Introduction ..................... 84

Instrumentation ard Data Collection ............... 84

workshop evaluation questionnaire ...... 85

User interviews . . . . . . . . . . . . . 37

Materials submitted by teachers . . . . . . . . 92

Telephone interviews by non-responders ....... 93

The Stages of Concern Questicnnaire (SoCQ)..... . Q3

Workshop evaluatior.s by subcenter directors

and workshop participants ........... 95

Organization and Use of the Data ........... 95

IV. DESCRIPTION AND ANALYSIS OF DATA ......... 105

Introduction .............. . . 105

Reported Utilization of Workshop Ideas ........ . 106

Interview Analysis . . . . . . . . . . . . . . . 1i0

Factors Affecting Teacher Change . . . . . . . . . 20

Teacher decision-making and choice....... 121

Characteristics of the workshop . . . . . . . 125

Administrative and peer support . . . . . . . . 130

Concerns of teachers . . . . . . . . . . . 137

Additional factors. . . . . . . . . . . 146

Impact of Innovations on the Students ....... . 146

Telephore Interviews with Non-Responders . . . . . . 149

Summary .............. 151

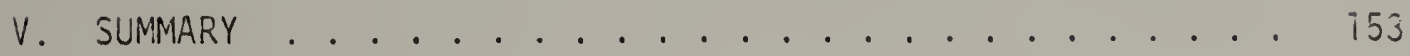

Introduction ................. 153

Conclusions ............. . . . . . 154

Recommendations Regarding Future

Science Teachina and the Development of

Reasoning Worksnops ............ 150

Implications and Suggestions for Future Research . . . 161

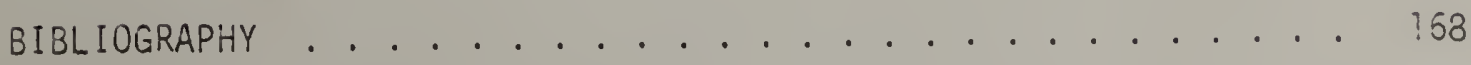

APPENDICES ............................ 178 


\section{LIST OF TABLES}

\section{TABLE}

i. Location, Dates and Number of Particioants of the Science Teaching and the Develooment of Reasoring Workshops Used in the Study ............

2. Data Regarding the Teachers who Responded to the Questionnaire ..............

3. Effects of Science Teachina and the Development of Reasoning Workshops .............

4. Applications of the Ideas of Science Teaching and the Developmerit of Reasonina Workshops in Laboratory Design, Use of Textbooks, Intrcducirg New Topics, Presenting Concepts, and Testing

5. Changes in Topic Preseritation/Concept Introcuction and Laboratory Design and Procedure in the Secondary Science Classroom as a Result of Attending Science Teaching and the Development of Reasoning Workshops .............

6. Changes in Textbook Usage and Evaluation Procedures in the Secondary Science Classroom as a Result of Attending Science Teaching and the Development of Reasoning Workshops .............

7. Factors Mentioned by Teachers During the Twenty User Interviews Which Limited Their Ability to Apply the Ideas of the Workshop in Their Classrooms

8. Teacher Decision-Making and Choice .........

9. Statements Related to the Content and Theoretical Basis of the Science Teaching and the Development of Reasoning Workshop..............

10. Statements Describing the Manner in Which the Workshop Was Conducted 
11. Issues Related to Administrative Support ........ 131

12. A Comparison of Teachers' Perceptions of Change in Laboratory Design Following Science Teachina and the Development of Rea soning Workshops, Depending on whether They look It as a

Department or Individually ............

13. Listing of Individual Stage of Concern Percentiie Scores for a Curriculum Innovation: The Learning Cycle Approach . . . . . . . . . 139

14. Frequency of Highest Concerns Stage for Individuals Displayed in Table $13 \ldots \ldots$. . . . . . .

15. Science Teaching ard the Development of Reasonina workshop Evaluation Questionnaire Resuits... 


\section{LIST OF FIGURES}

FIGURE PAGE

1. Three-Phased Model of Hypothetical-Deductive Thought . . . . . . . . . . . . . . 46

2. Definitions: Stages of Concern About the Innovation . . . . . . . . . . . 64

3. Concerns Profiles for Non-Users and Users in the Worcester Workshop ............ 143 


\author{
C HAPTER I \\ BACKGROUND OF THE PROBLEM ANO FOCISS OF THE STUDY
}

The desire to change, if it is to be consequential, must come from within. . Nothing we can invent in the way of content or method will be worth very much unless it is used ingeniously. Inservice education should not be, as it has sometimes been, merely another theatre for puppets. It should set a stage for growth in the tradition of the Comedia del Arte, where actors do not memorize, tut improvise their lines (Rubin, 1978, p. 31).

\title{
Introduction
}

New ideas in the structure of the mind only become real as they interact with the physical environment. Likewise, educational theory can only be understood and clarified as it bounces against the educztional practice of our learning environments. Innovation frequently does not succeed because it is carelessiy put into practice. The success and failure of innovation in teaching relate to factors that can be studied and evaiuated. If a fraction of the resources that are currently being spent to change educational practice were spent in finding out how to succeed in making such change, a great deal would thereby be saved. Until that happens, many hours of time and courtless millions of dollars will be spent in abortive efforts to modify educational practice.

With the intent of taking a step towards solving this problem, this study was made evaluating an inservice workshop approach for 
secondary science teachers. The purpose of the study was to determine whetiner teachers who participated in Science Teaching and tre Development of Reasoning workshops in New England in 1978 and 1979 felt that they had utilized the ideas of the workshop in changing their teaching style and methods. The nature and extent of changes which were made consistent with the intent and philosophy of the workshop were explored and factors identified which the teachers perceived either facilitated or hindered their ability to make changes.

\section{Statement of the Problem}

Every science teacher has experienced students who seem unable to grasp abstract concepts, as well as other students who understand these same concepts readily. The interest of science educators is now becoming focused on the student who is unable to understand and retair. certain concepts, who uses inappropriate reasoning strategies, and who is unabie to transfer methods of solving problems to new situations.

In the past decade, much research has been done applying the theories of Jean Piaget, a Swiss epistemologist, to the developmental thinking processes of students in the United States. John Renner, Anton Lawson, Robert Karplus, and others have been involved in research attempting to determine, in light of Piaget's theories, how secondary students learn science concepts.

Piaget theorized, based on his observations of Swiss children, that people go through stages of cognitive development. These have been designated as sensorimotor, pre-operational, concrete operational, 
and formal operational. He suggested that children naturally progress through the different stages if certain processes occur; namely, maturation, experience, social transmission, and equilibration, or self-regulation.

Traditionally, intellectual ability was measured quantitatively in terms of achievement and aptitude. Now, as a result of Piagetian influence, many such assessments are qualitative; the important question may concern tre reasoning strategies that a person has, not just how much intellectual ability. The general techniques for acquiring and processing intormation are as important as any specific content or information.

Formal operations. The leveis of cognitive development of particular interest to secondary science teachers are the concrete and formal operational. In general, the difference between these two is that a concrete operational thinker uses concrete, empirical data and centers on the content of a problem, while a formal operational thinker is able to generalize and organize ideas separate from concrete appearance--in other words, is able to move between reality and possibility and conceptualize what might be in addition to what is. Specific forma? operationa? abiitities include the derivation of a proportion from t:vo or more variables, the combination and separation of variables in $a$ hypothetical-deductive framework (if this is true, then that will occur), and prediction. The ability to think of all possible solutions to a problem is another characteristic of formal thinking. Flavell (1963) provides a more general statement of formal thought: 
. not so much this or that specific behavior as it is a generalized orientation, sometimes explicit and sometimes implicit towards problem solving; an orientation towards organizing data (combinatorial analysis), towards isolation and control of variables, towards the hypcthetical, and towards logical justification and proof (p. 211).

Piaget has set the age for the beginning of formal thinking at twelve to fifteen years. Recent research, however, with high school and college science students in the United States suggests that not more than $50 \%$ are at the formal operational reasoning stage (Piaget, 1972; Lawson and Renner, 1974; Keasey, 1970; Eikind, 1961 ; Towler and Wheatley, 1971). Chiapetta (1976) also concludes, after reviewing the studies of cognitive development relevant to the instruction of science at the secondary arid college level, that most adolescents and young adults in the United States do not appear to use formal operationa? thinking in solving science problems. Kuhn (1079a) thinks that the stage of formal operations may be the most important to consider because of the fact that it is the only stace in the secuence that a significant number of individuals never attain. This fact has important implications for science teaching at the secondary level, and may soon alter the reality that formal operations and the transition from concrete to formal has been the least studied of the stage levels in Piaget's theoretical sequence.

Competence and performance. Studies concerning formal operational thinking are complicated by evidence of a large difference between competence and performance in the population. Raven (1974) found, after seven years of research studies with elementary and junior high 
students, that the "level of reasoning used for inquiry and concept acquisition by every individual is substantially below his/her capacity" (p. 259). Studies reported by Chiappetta (1976) indicated that large numbers of science students function below their inte?lectual potential. Many students who perform at a formal level on Piagetian tasks, function at the concrete operational level when dealing with science concepts in the classroom.

The content, the nature of the information processed, must also be considered. cross-cultural studies have shown that individuals use formal operations more frequently in subject areas with which they are familiar (Sinnott, 1975). With adults, formal operational thinking may be evident in everyday activity, but not in abstract logical problems. It is necessary to relate any cognitive theory to the connection between cognitive activity and cultural conditions (Riegel, 1973; Youniss, 1974).

Linn (1977) also found that before logical thinking can be taught, even if that is possible, the relationship between logical reasoning mechanisms and the information they are applied to must be studied. She delineated three context factors concerning the characteristics of a task which influence whether subjects use a certain reasoning mechanism to control variables: salience (the perceptual obviousness of the task), the relevance of the task to their lives, and the perceived goal of the task.

Piaget (1964, 1972) stated that a person moves through stages of development in a consistent order, and in order to progress throuah 
these stages, must be presented with activities and situations which s/he understands at his/her present level. A thinker who uses primarily concrete operational reasoning does not move into formal usage by being confronted with formal operationai tasks and concepts; ratiner, s/he must be exposed to concrete situations which stretch his/her thinking ability and aid progress to higher levels.

A tenth grader, for example, meets many formal concepts: ecosystems, the structure of DNA, density, the propositional logic of Euclidean geometry, etc. Yet, if more than $50 \%$ of tenth graders are primarily concrete operational thinkers, for these students much of the subject matter is not appropriate (Kunn, 1979a). Lawson (1973) found that students of biology, chemistry, and physics, who think concretely, are unable to understand concepts which are categorized as formal.

What does this imply for our educational system? The curricu1 um needs to be reshaped to reflect concrete objects, events, and situations, rather than abstract mental images and rules in the teaching methods and materials used (Piaget, 1972; Karplus, 1979; Lawson, Blake and Nordland, 1975). The recent new curricula for secondary science courses have frequentily produced alterations in the sequence of material and crowding in of more content to be "covered." The techniaues by which this knowledge is transmitted, however, have generally remained the same; laboratories are still largely of the cookbook variety, and self-directed learning rarely occurs. 
It has been thought that simply explaining to secondary school students an abstract concept, such as how to set. up and carry out a controlled experiment, is sufficient. Research suggests that this is not so (Lawson, Black, and Nordland, 1975). Even students who have talked about and performed experiments before do not understand such a fundamental concept as controlling variables. According to these researchers, a variety of concrete experiences and sufficient time to enable the student to resolve by himself the problem being considered, whether it be controlling variables or understanding ecosystems, are required. Secondary schools are often lacking these two factors.

Science Teaching and the Development of Reasoning. Evidence suggests that the level of thought of children of all ages is changed when they are exposed to inquiry-centered experiences in science (Lawson and Wollman, 1975; McKinnon and Renner, 1971; Stafford and Renner, 1970). In work done by Robert Karpius and Associates, under a National Science Foundation Grant, SED 74-18950, an instructional program was develooed incorporating Piagetian theory. These workshops for secondary science teachers attempt to give them the skilis to assess their students' reasoning levels, to become aware of the types of reasoning used in science texts, to become familiar with Piaget's theories of developmental reasoning, and to apply Piaget's ideas to instructional methods (Karplus, 1977; Karplus, et al., 1977).

These Science Teaching and the Development of Reasoning workshops model a three-phased learning cycle which includes exploration, concept introduction, and concept application. This learning cycle, 
originally used in the elementary school science program, developed by the Science Curriculum Improvement Study (SCIS) at. the University of California at Berkeley, has been found to be an effective teaching approach for adults as well as for children of all ages (Karplus, 1979).

During the first or Exploration phase, students are encouraged to explore new ideas and materials. Because the learning is done through their own actions and reactions in a new situation, guidance and expectations are limited. New experiences with concrete materials raise questions not answerable by former patterns of reasoning.

The second phase, Concept Introduction, includes the presentation of a new concept or principle which guides the students in applying new patterns of reasoning to their experiences. This relates directly to the exploration activities and leads towards selfregulation.

In Piagetian terms, when a learner is exposed to new information for which $s /$ he does not have the available mental structures to allow its assimilation, $s / h e$ is in disequilibrium. The role of the teacher at this point then can be to suggest ways of ordering the experience by introducing a new concept. This may include a new term such as "food chain" or "ecosystem."

During the workshop, teachers model the "learning cycle" approach by doing several problems involving proportion and control of variables followed by an examination of student responses to these problems. Only following this "exploration" are they introduced to the 
concept of "reasoning patterns" by learning to identify and distinguish those used most frequentiy by secondary science students.

In the last phase, Concept Application, further activities are presented which involve the same conceptualization. As an example, the workshop participants apply the concept of "reasoning patterns" by dividing student responses into categories and examining texts and other curricular materials in termis of cognitive requirements. Thus, the application phase reinforces the new concept.

In the Science Teaching and the Development of Reasoning materials, the workshops for teachers are organized into the following modules, which model the "learning cycle" as described above:

Part I: Reasoning Patterns

1. How Students Think

2. Concrete and Formal Reasoning Patterns

3. Formal Reasonirg Patterns

4. Science Texts and Reasoning Patterns

Part II: Teaching for Self-Regulation

1. Self-Regulation and the Learning Cycle

2. The Laboratory and Self-Regulation

3. Concrete and Formal Concepts

4. Tests and Self-Regulation

Part III: What Can You Do?

1. Teaching Strategies and Goals

2. Suggested Reading

It is felt by this researcher that there are three important reasons why secondary science teachers can benefit from the opportunity to participate in development of reasoning workshops. First is the great need to make teachers aware that the large number of their students who think concretely are unable to achieve when confronted oniy 
with instruction at the formal level. Second, the "learning cycle," as described above, is one of a variety of methods that can produce a temporary disequilibrium in a student, part of a process which can lead to a different level of cognitive equilibrium.

Third, this theory of learning also pertains to teachers themselves, who grow and change as a result of being presented with ideas which are new but not too dissonant with their current level of thinking. As adults, the factors facilitating cognitive development and growth must exist: maturation, interaction with the physical environment, social interaction, and equilibration (Piaget, 1964).

Staff development: a path to change. Educators in science are continually seeking ways to revitalize discouraged, burnt-out teachers and improve teaching for students. New programs have been funded and developed, but increase in the content of each course rather than change in teaching strategies has been the primary result. Teachers tend to use the new materials in traditional ways.

Secondary school curricula have tended to be much less innovative than those of elementary schools (Goodlad, 1975). Departmentalization characteristics of secondary schools lead to increased rigidity, and teacher as well as administrative resistance to change is high (Hawkins, 1968).

Many factors have a bearing on the facilitation of change in educational settings. Arbuckle (1977) states that the success (i.e., continued implementation) of an innovation is determined by four basic factors: 
1. Characteristics of the innovation itself;

2. Characteristics of the users of the innovation;

3. Characteristics of the school systems sponsoring the irinovation;

4. Interactions between the innovation, the users, and the setting and changes that each undergo in the process of implementation. (p. io)

Within this general framework, a variety of factors stard out as necessary ingredients of continued successfut innovation. These are:

1. Congruence of project and teacher values and goals;

2. Strong administrative support;

3. Training and ongoing follow-up assistance;

4. Limited target populations;

5. Provision of released time for training and assistance;

6. Projects which replace and/or improve existing practices;

7. District support;

8. Availability of existing materials;

9. Organizational climate supportive of educational improvement and growth. (p. 138)

Christopher (1978) found, after interviewing one hundred and thirty science teachers in New York State, that these teachers perceived the following factors in their school environment to influence their desire and ability to be innovative:

1. Small class size (sixteen to twenty-four);

2. A good student-teacher relationship;

3. Psychic rewards of observable pupil involvement; 
4. Expected behavioral and academic performance that teachers have of students;

5. Principals' attitude towards and support or nonsupport of teacher innovativeness;

6. Teachers' feeling of job security;

7. Teachers' access to usable support facilities;

8. Free time;

9. Small amount of spending money.

In addition to environmental factors, user capability is a critical factor for innovation. According to Fullan (1972), to have significant educational change, the attitudes and organizational structure must provide opportunity and expectation for change, users must be receptive to change, and users must have or develop the skills and competencies to perform new roles. Lack of effective change is mainiy a result of failure of attention to these factors (p. 10). Fullan (1972) points out:

The tendency is to view teachers as resistant, incapable or unwiiling to change and to ignore the possibility that teachers' inadequacies in knowledge, understanding and skills are partiy a result of their not having had the opportunity and support to develop these competencies in their past and present social situations. The question, then, may not be whether teachers are currentiy capable of innovation and change, but whether they can come to be capable if the situation is a? tered to support this development (p. 13).

This leads to the importance of inservice training to facilitate teachers' changing roles. If new teaching methods and styles are required, strategies must be developed and used which provide teachers with the necessary skills and knowledge. Although inservice training is widely accepted as a necessary ingredient for change (Goodlad, 1975; 
Scanlon, 1973; Heathers, 1972), much dissatisfaction has been evident with the current staius of inservice education. Bunker (1977) expresses the present state of frustration in terms of three questions:

Why do these teachers and administrators feel so dissatisfied with their inservice experierces?

What needs to be done to help the teachers become excited, committed participants in their own professional growth?

How can the administrators use their cood intentions and leadership skilis to support the staff development which encourages continuous professional growth? (p. 16)

Theories about necessary and desired changes to improve inservice education abound. Lawrence (1974), in his review of research on inservice education, summarizes important patterns for successful programs :

1. Individualized programs are more likeiy to accomplish their objectives than programs that have the same activities for ali participants. Individualization, furthermore, should be understood not to be limited to variations merely in pace and sequence of materials.

2. Programs in which teachers take some active role (e.g., generating a set of instructional materials) are more likely to be successful than those in which teachers are limited to a passive or receptive role.

3. Programs based on a demonstration of materials or techniques, combined with a supervised trial followed by some form of ieedback, are more likely to be successful than those in which information or instructions are learned and stored for future application.

4. Programs in which teachers provide mutual assistance are more like?y to be successful than those in which teachers work entirely on their own.

5. Programs occurring as part of an overall staff development plan or general effort of the school are more likely to be successful than one-shot efforts. 
6. Programs of emergent design, in which teachers themselves choose at least some of the goals and activities, are more likely to be successful than programs which are entirely preplanned.

7. School-based inservice programs that emphasize selfinstruction by teachers have a strong record of effectiveness. (pp. 8-15)

From these patterns, from the humanistic movement, as well as experience with numerous inservice programs, including the Integrated Day Program at the University of Massachusetts and the Amherst Secondary Staff Development Project, Bunker (1977) has derived $\underline{A}$ Belief System to Guide Staff Development Proarams. From the tenets of

this belief system, the following needs for inservice are expressed:

What seems to be needed are voluntary programs that include teachers in the planning, implementing, and evaluating of their own professional growth. Program activities must be individualized and provide for an active role. Inservice must deal with concrete problems and provide feedback. Sys tematic evaluation of both individual components and total programs must be instituted so successes and failures can be documented and analyzed.

Participants' perceived needs must receive priority. Teachers teaching teachers in school-based programs are necessary. Participant talents and competencies should be tapped, strengths identified, and supported. The formation of teams, task forces, committees--human support systems--will do much to alleviate the concept of the isoiated teacher. Administrative support is necessary for leadership and for providing sufficient time and finariciai assistance (Hruska and Bunker, 1978, pp. 9-10).

To summarize, the increased emphasis on content in secondarylevel science courses, on concepts which demand a level of cognitive development which many students have not reached, continues to result in frustration on the part of teacher and student. Secondary science teaching needs to reflect and respond to the varieties of levels of 
reasoning met in the classroom. Teachers also need to know how to facilitate active learning processes on the parts of their students rather than passive absorption of facts and concepts if we assume that the interactionalist theories of learning of Piaget and other construc. tivists are correct.

It also follows from this assumption that teachers learn by the same processes as their students, that as adults we can continue the active learning process of our youth. Any inservice training must model the teaching approaches we are advocating in the classroom. It must incorporate the basic elements necessary to deveiopment: awareness of different maturation levels (individualization), contact with the physical environment, social interaction, and equilibration. it must refiect a humanistic approach which allows each individual to discover personal meaning (Combs, et al., 1971).

This study is an attempt to evaluate a workshop approach for secondary science teachers which incorporates many of these elements. Has a workshop so designed resulted in changes in teaching strategies of teachers which will in turn facilitate the development of thinking in students? If so, this will lead towards a major goal of science education, the development of scientifically literate individuals with a high competence for rational thought and action.

\section{Gackground of the Study}

A description of the project. The project, The Development of Reasoning Ability in Science Students: A Goal for Secondary Science 
Teachers (Schultz and Loribard, 1978), the evaluation of which constitutes this study, was funded by the National Science Foundation and covered the period from September 1978 through December 1979. The project consisted of two overlapping phases: (1) the trainir.g of leaders in science education in New England to give Science Teachino and the Development of Reasoning workshops in their geographic areas. and (2) the presenting of the workshops to science teachers throughout New England.

Directors' conference. The initial phase of the project began with a three-day conference, held at the Willits-Hallowell Conference Center in South Hadley, Massachusetts, on November 5-8, 1978. This conference resulted in the dissemination of the project information from the Center for the Development of Reasoning at the University of Massachusetts, Amherst, to tivelve subcenters located in the six New England states. * The staff at the conference consisted of:

Or. Klaus Schultz and Dr. Richard Konicek: Co-Directors

Ms. Anre Lombard: Project Coordinator

Dr. Leverne Thelen: Subcenter Coordinator

Tiventy carticipants, twelve of whom became the directors of the tivelve subcenters, attended the conference.

* University of Scuthern Maine, University of New Hampshire, University of Vermont, Salem State College, Weston High School, Worcester State College, Sridgewater State Teachers College, Eastern Connecticut State College, Taft School, Stamford Public Schools. Westfield State Teachers College, Rhode Isiand College. 
Ouring the first two days of the directors' conference, the participants worked through the science ieaching and Development of Reasoning materials with the staff actively participating and facilitating discussion. (See Appendix A for the detailed schedule.) Plans for dissemination of the ideas from the workshop to teachers in the various subcenter areas were discussed on the third day. This included developing and sharing various workshop models, deciding on the most effective pubiicity for each subcenter, and developing a support system between the subcenters, so that they could help one another with the initial workshops given by each. Each subcenter director had the opportunity to begin to plan his own dissertation projects.

Written evaluations were requested frum each participant in the conference. These were completed at the conciusion of the conference. A summary of ideas from these evaluations follows:

1. The participants felt prepared, as a resuit of this conference, to organize workshops in their own areas. Those who represented the only person from their subcenter generally ielt the need for assistance from the staff or other subcenter directors during their first workshop.

2. Strengths of the workshop:

Staff cooperation and facilitation, enthusiasm Good pacing of activities Excellent location and facilities Well organized Opportunity to interact and share ideas with other particioants Good staff-participant ratio Relaxed a tmosphere

3. Suggestions for improvement:

A wider variety of points of view about reasuning. 
Too short a time to read and assimilate the materials and concepts

More time for discussion; less for reading

Too concentrated; more breaks reeded

During the conference, each participant was given a set of

Science Teaching and the Development of Reasoning mancials covering each of the five subject areas: Physics, Chemistry, Biology, Earth Science, and General Science, as well as a packet of materials which included: schedule of the conference, an orientation module, publicity brochures, brochures for ordering materials, and articles reiatirig to the conference subject matter. At the conclusion of the conference, each subcenter director received a set of reusable laboratory kits, sufficient for a workshop of twenty-five to thirty people.

The following ideas for the project were suggested by participants. These were implemented by the Center for the Development of Reasoning at the University of Massachusetts.

1. A newsletter from the Center to subcenters for communicating new developments, workshop ideas, etc.

2. Sending out articles describing research that pertains to the Development of Reasoning.

3. Distribution to subcenters of informational sheets which they can submit to be published in statewide science teacher and supervisor association newsletters.

4. During the follow-up conference in April, spend some time with further materials on concept development and reasoning, i.e., Ausubel, and the relationship of affect to logical thinking.

5. Some readings by Piaget and Karplus available before workshops to assist in assimilation of new material. 
Publicity. Publicity for Science Teaching and the Development of Reasoning workshops, sponsored by the University of Massachusetts' Center for the Development of Reasoning and its subcenters, included brochures, articles and notices in professional journals and local newspapers.

Brochures describing the workshops were distributed through mailings, conferences, and Science Teacher Association meetings in the New England states. Approximateiy one thousand secondary science department heads and science supervisors in New England were sent brochures. Early mailings in December 1979 indicated that contacting science department heads and science supervisors was more effective than mailing brochures to superintendents and principals, because the former generally iritiated and organized inservice workshops for their science faculty.

Approximately two hundred individuals contacted the University of Massachusetts or the subcenters directly by returning the returnabie portions of the brochure. They were sent information about workshops being given in their area.

Articles and notices about the project in local newspapers included:

The Amherst Record (October 25, 1979)

The University of Massachusetts Alumnus (November 1978)

The University of Massachusetts Contact (November 1978)

The Springfield Republican (October 1979)

The Hampshire Gazette (October 4, 1978; November 3, 1978; October 1979) 
The Greenfield Recorder (October 1979)

"Spring Forum" Brochure (March 1979)

Articles in professional journals and Science Association Newsletters included:

The Science Teacher (September 1979; May 1980)

Common Focus (Center for Early Adolescence, University of North Carolina, July 1979)

Massachusetts Association of Science Teachers' Newsletter

Hampshire Educational Collaborative Inservice Newsletter (January 22, 1979)

Focus (Newsletter of the Amherst Area Teacher Center, December 1978)

Chem 13 News (May 1979, No. 105)

Western Massachusetts Department of Education Newsletter (January 1979)

Project activities. A newsietter was produced and distributed regularly to the subcenters throughout the course of the project. Information was exchanged, articles distributed, and communication among the subcenters remained strong. Subcenter directors cooperated in the giving of workshops in their areas.

On April 6, 1979, a secord conference was held at the WillitsHallowell Conference Center in South Hadley, Massachusetts, attended by twenty persons, including subcenter leaders, others who had participated in the November conference, and those who had expressed interest. At this time, each subcenter representative gave a report, ideas were exchanged, and progress assessed. The meeting was taped and important 
suggestions and information were sent to all subcenters in a newsletter.

A third meeting of the subcenter directors was held on October 26, 1979, at the Hartford-Sheridan in Hartford, Connecticut, during the Regional Science Teachers' Asscciation Conference. At that time, the focus was on how the project would continue its work.

Summary of the project. During this project, more than one thousand secondary science teachers participated in Science Teaching and the Development of Reasoning workshops throughout New England. (See Appendix A for a list of workshops.)

In addition to considerable amounts of federal funding for the developing and disseminating of these workshops, a large amount of teacher release time has been invested. It is, therefore, of importance to study the effects of these workshops on the teachers who have attended them.

\section{Purpose of the Study}

The aims of this study were three-fold, which included the following:

1. To determine whether teachers who darticipated in Science Teaching and the Development of Reasoning workshops during 1978 through 1979 felt that they had utilized the ideas of the workshop in changing their teaching style and methods.

2. To determine the nature and extent of changes made which were consistent with the intent and philosophy of the workshop. 
3. To identify what factors the teachers perceived either facilitated or hindered their ability to make changes.

A list of factors beileved to affect change in teaching behavior as identified from the literature and consistent with the constructivist learning theory of Jean Piaget was used as a guide in the determination of data to be collected:

1. Teacher decision-making and choice in the planning, implementing, and attendance of inservice programs.

2. Characteristics of inservice progräms as perceived by participants.

3. Administrative and peer support during the development of new skills necessary for innova-. tion.

4. Concerns of teachers regarding irnovations.

5. Additional factors.

These factors will be expanded upon in the following chapter.

\section{Significance of the Study}

Schools with funding for inservice training are continually seeking outside resources to provide one or a series of workshops for their teachers. Evidence exists that one-shot workshops are not conducive to change; that follow-up is necessary (Berman and McLaughi in, 1974). Yet schools continue to spend funds in this manner.

It is important to clarify what changes are possible as a result of workshops provided by outsiders, so that schoois can assess whether funds spent in this manner are accomplishing their goals. Is it sufficient that one or two teachers become excited about a ne'w idea 
and attempt to make some changes?

The Science Teaching and the Development of Reasoning workshops are particularly appropriate for this study because they possess many of the characteristics important to successful learning as determined from the humanistic education literature upon which current inservice theory is based and from Piaget's constructivist theory of cognitive growth.

The results of this evaluation may serve to influence those who design inservice programs in the future. it will serve as a guide for the development of a model for a more intensive longer-term inservice project based on the same content.

\section{Methodology}

A review of the literature to provide a rationale for the development of reasoning as a goal for secondary science study wâs made. Research concerning the nature of successful inservice was explored, and from this investigation a list of factors which facilitate the use of new ideas from workshops was compiled.

To gather evidence to accomplish the aims of this study, data from the following sources were collected, analyzed, and synthesized:

1. An evaluation questionnaire, developed and pretested by the researcher, was sent to all secondary science teachers (two hundred and ten) who could be located and who participated in Science Teaching and the Development of Reasoning workshops exceeding three hours in length in ilew England. 
2. Interviews with twenty secondary science teachers who responded to the questionnaire and indicated that they have used the ideas from the workshop in their classroom. These aided in assessing how much of the workshop content the individual commands as we 17 as self-reports of the impact of the materials prepared on students.

3. Telephone interviews with twerity secondary science teachers who did not return the auestionnaire to assess their attitudes and use of the workshop ideas.

4. The Stages of Concern Questionnaire administered to twenty-one participants of a fifteenhour course in Worcester. Massachusetts, assessing changes in concerns and perceptions of changes in teaching behaviors as a result of the course, Science Teaching and the Development of Reasoning. The Stages of Concern Questionnaire (SOCQ) (Ha11, George, and Rutherford, 1977), a thirty-five item psychometrically sound instrument which measures the concerns of teachers about a particular innovation, was used. The SOCQ has been used in huridreds of schools and university sites for research and evaluation purposes and to monitor and facilitate change efforts. This questionnaire is one dimension of the Concerns-Based Adoption Model which measures the feelings, perceptions, motivations, and attitudes of individuals as they first become exposed to an innovation and make decisions about its use. Seven Stages of Concern have been identified and can be measured.

5. Teacher-prepared materials, such as tests, laboratory out ines, supplementary exp? anations, or review questions that illustrate the effects of the workshop on teaching. These provided data to determine the nature and extent of changes made, which were consistent with the ideas of the workshop.

The following additional sources also provided information for the study: 
1. The project proposal, The Development of Reasoning Ability in science Students: A Goal for Secondary Science Teachers (Schultz and Lombard, 1978).

2. The final technical report of the project.

3. Evaluations of the materials and project by the subcenter directors.

4. Workshop evaluations written immediately following selected workshops for administrators.

Limitations of the methodology. The researcher developed the proposal for the project, coorainated the project, in addition to conducting a considerable number of the workshops being evaluated. Association with the administrators and teachers being questioned and interviewed could influence the interviewee responses.

The researcher is the collector of data and the evaluator of that data. This creates the possibility of researcher bias which is not controlled in the evaluation design.

\section{Del imitations of the Study}

1. Science Teaching and the Development of Reasoning workshops are gradually increasing in number throughout the country. Although this is the first evaluation of the perceived effects of these workshops, the researcher chose to limit the evaluation to New England, the region covered by this project. This was done so that persona? contacts would increase the likelihood of questionnaires being returned and so that follow-up interviews would be practical. As a result, a regional rather than a national sample was obtained. 
2. Because the population from which data were obtained for the study was limited to those science departments who chose to have workshops presented at their school or to teachers who voluntarily registered for workshops, the population does not represent secondary science teachers as a whole. Conclusions from the study must necessarily be limited to that select group.

3. Workshops were carried out by different leaders. The effect of the leadership of the workshop could well have influenced the participants' use of the ideas of the workshop. This factor was not studied.

4. This study focused on the teachers' perceived use of the workshop ideas and factors influericing this use. No attempt was made to evaluate the intrinsic value of the workshop ideas or the effects of these ideas on the students taught by teachers participating in these workshops.

\section{Chapter Outline}

This chapter provided an introduction to the study by presenting one of the significant problems in secondary science education today: the crowding of more content into courses with too little attention to how this knowledge is transmitted. A project designed to help teachers change this orientation was introduced and the development and dissemination of this project in New England described. The aims and methodology of the study evaluating the project were briefiy introduced. 
Chapter II reviews several areas of literature central to the study:

1. Philosophical rationale for development of reasoning as a goal for science study.

2. Humanistic psychology as a conceptual basis for inservice programs.

3. Research concerning the nature of successful inservice programs.

4. Positivist and phenomenological approaches to evaluation.

This chapter synthesizes these areas of research into a framework which provides a rationale for evaluating these particular inservice workshops.

Chapter III describes the procedures used to accomplish the aims of the study. Methods for selecting the population to be studied, data collecting procedures, and the evaluation instrumentation are presented.

Chapter IV presents the results of the evaluation and interpretation of the data.

Chapter $V$ presents conclusions, discusses the implications and significance of the findings, and includes recommendations for further study. 


\section{CHAPTER II \\ REVIEW OF THE LITERATURE}

\section{Introduction}

The first section of tris chapter presents a rationale for the development of reasoning as a goal for science study. This includes a discussion of formal operational thought, the fourth arid ?ast stage of cognitive development described by Jean piaget, the one that should be of considerable interest to secondary school teachers. Controversies deriving from recent research based on this model are presented. The question is posed whether formal operational thought can be promoted by certain teaching techniques, and if so, whether this is an important and valid goal. "The Learning Cycle," an approach to science teaching developed by Robert Karplus and Associates at the University of California, currently being advocated as a method to promote reasoning development in the science classroom, is discussed and analyzed.

The second section of this chapter reviews the literature regarding teacher innovation. Humanistic psychology provides a conceptual basis for modern inservice programs, and new theories and research about the change process with respect to teaching provide this study with certain factors necessary for consideration if change is to take place. These are discussed in turn. 
Formal Operational Thought

The unified theory of formal operations. Formal operational thinking has been the least studied of Piaget's developmental stages, perhaps due to the fact that Inhelder and Piaget (1958) in The Growth of Logical Thinking from Childhood to Adolescence, one of the original theoretical discussions of adolescent thinking patterns, include such a difficult pattern of formal logic that few have understood it. Many have questioned whether this formal system of sixteen logical operations is relevant to adolescent and adult thinking. Inhelder and piaget used a variety of tasks for measuring formal operational thinking, tasks which required proportional reasoning, controlling variables, combinational tasks, and separating variables from others.

At that early point, Piaget thought that new cognitive patterns appeared at adolescence and that these strategies measured one basic structure which had certain mathematical attributes. Piaget also stated that formal thinking had nothing to do with the type of interaction with the materials or the type of questioning done by the experimenter or teacher. If a person's answers were influenced by these factors, $s /$ he was not reasoning formally.

Many questions have arisen concerning Inhelder's unified theory of formal operations, that formal reasoning patterns have a logical organizational structure. Are the particular reasoning patterns that indicate formal operational thinking related to one underlying model, i.e., the one that Inhelder and Piaget postulate? Is there a different 
underlying model? Or do they just need to be studied separately as characteristics of formal? Can any model account for these diverse strategies?

A study in seven different countries showed that the frequency of formal reasoning patterns such as proportional reasoning and control of variables can be affected by different types of instruction, i.e., that there is not a single operational structure underlying all formal reasoning patterns (Karplus, et a1., 1975). The implication of this in the classroom is that a teacher cannot label a student as concrete or formal, but must allow that individuals use different reasoning patterns on different problems, and even on similar problems but in different contexts.

Other studies (Lovei1, 1961) have shown that adolescents chance their reasoning patterns on the particular tasks studied by Inhelder and Piaget. A major problem is the varying methods researchers use to administer and score the criteria for the Piagetian tasks. Since there is no standardization, results differ, and there is little agreement on ages.

Bady (1978) warns that the statistics indicating that most adolescents and many adults have not attained the ievel of formal operations need to be examined closely. He asks two questions. If only one or several tasks are used, can one say that a person reasons formally? In other words, is one task, such as the balance beam, a reliable measure of a scheme (proportion)? In that case, all proportion tasks must be highly correlated or have high intertask reliability. Secondiy, if 
a subject possesses one scheme, can we say s/he is formal operationai in his/her thinking? Is there one underlying mechanism that indicates formal operational thinking? Bady's research attempts to answer the first question; to what extent do tasks claiming to test the same scheme measure the same thing?

Sixty-six subjects from ninth grade through college were tested on five proportion tasks and five combinatorial tasks. The highest intertask agreement was $80 \%$. Bady concluded from these moderate intertask reliabilities that tasks which supposedly test a single scheme are not just testing that scheme, but are measuring something else.

Every subject succeeded on at least one task for each scheme. If we chose one particular task and measured it for success, few would be formal. If we said success on any one task would mean formal thinking, then ail would be formal. Success on one task indicating the presence of a scheme is not a very good predictor of whether success will occur on another task testing the same scheme. Bady corcludes that a person cannot be labeled on the basis of a few tasks whether or not he has a particular scheme.

Kuhn (1979b) provides a further critique of the stage theory with regard to formal operational thought. She states that the usual cognitive strategies developed by Inhelder and Piaget (1958), for example, proportionality and isolation of variables, have only been used for assessment in particular tasks related to the domain of physics. How would the strategies show up in other contexts? An operational definition of formal reasoning which relates to real life situations is 
necessary. Figuring the percentage of adults who possess formal operational reasoning must await appropriate techniques of assessment, as use of this stage is dependent upon the degree of familiarity with the content domain.

Feldman (1980) supports this view, stating that stages must be moved "out of kids' heads and placed conceptually within various domains of knowledge acquisition" (p. 3). Logical thought, which Piaget and Inhelder tested, would represent one domain, and other fields of knowledge would also have tests to indicate level of mastery. The staqes of each domain would be ideal types against which actual performance would be measured. Change in one domain could occur independently of change in other domains.

Applications of reasoning patterns. Karplus (1979) also has moved from Piaget's theory of developmental stages in which the individual's reasoning is governed by underlying mental structures to the idea that the application of these reasoning patterns has a developmental aspect. For example, the ability to conserve or seriate can be applied to coins, liquid, energy, or economic assets. The conservation of the number of coins demands a different level of reasoning from that of energy. So a concrete level of thinking is not a characteristic of the reasonina pattern, but is determined from whether the application involves objects with observable qualities or hypothesized or idealized objects, logical, mathematical or other complex relationships, or assertions contrary to experience. 
This idea that there is a developmental level within each reasoning pattern, that a student can move from non-application of a reasoning pattern to a continuum of applications, at the formal operational level as well as at the concrete level, also supports the teacher who understands the specific reasoning pattern being used as well as the context in which it is applied.

From this discussion, it is evident that the concept of reasoning patterns, particularly at the formal operational level, is being studied from several points of view. Piaget himself, however, moved considerably from his original position in 1958 that $\equiv 11$ fourteen and fifteen-year-olds have reached the stage of formal operational thinking (Piaget, 1972). In more recent works, he stated that formal operations appear between eleven and twenty, but that individuals reach the stage at different ages according to aptitude and interest. He leaves us with a question which remains to be answered:

Can one demonstrate, at this level of development, as at previous levels, cognitive structures common to all individuals, which will, however, be applied or used differently by each person according to his particular activities (p. 9)?

The promoting of formal operational thought. The evidence so far discussed indicates that a certain proportion of the population will reason formally on most of the tasks they encounter in their daily lives which require that sort of thinking, others will reason formally only in areas of familiarity to them, and some wili not reason formally at a11. Are the characteristics of formal thinking desirable, and if so, should teachers attempt to promote that sort of reasoning? 
Before we explore these complex questions, another related question is relevant. Why do other cultures seem to have a smaller or larger proportion of individuals thinking formally than our own? Other than the contextual issues already discussed, there exists the possibility that formal thought increases when there is a demand for it (Dulit, 1972; Dasen, 1972). Neimark (1970) theorizes that survival in an urban, technical society depends on individuals storing more information in their heads. For this information to be useful, systems for organizing and retrieving this information in our brains are necessary. Strategies of formal operational thinking, such as proportional logic and combinatorial reasoning, are effective ways to code and use this information productively.

Individuals in other societies as well as our own who have no need to use large quantities of complex information, do not gain the experience necessary to express problem-solving strategies in a formal operational manner. The potential for formal thought may be there. This theory suggests that as a society becomes more complex and tecinnical, the demand for formally operational adults increases. This also indicates that formal thought is more dependent on cultural and social experience than concrete thought, a fact for which we have already shown evidence. Does this mean that formal thought is actually more advanced or is it simply a characteristic that seems to be of value in Western cultures?

In our society with the increasingly complex decisions we should and need to be making daily, the strategies characteristic of 
formal operational thought are indeed desirable. If, therefore, there are effective ways to increase this mode of thinking among students of all ages, it is a worthwhile goal.

Can formal operational thought be promoted? Can certain learning conditions shorten the interval between successive stages of cognitive development? If so, do these conditions speed up development uniformly? Different systems of operative schemes characteristic of different moments in cognitive development may not be equally sensitive to environmental pressure or to experimental training techniques. Since cognitive development is one of the many expressions of biological growth, it is also temporal and causal. Even though we believe that the causal mechanisms for both biological growth and cognitive growth are similar, these are not yet known specifically enough for clear explanation. Inhelder, Sinclair, and Bovet (1974) rightly caution that any experiments we might do with children to determine the answers to these questions affect the developmental process itself. They made great efforts in their studies on conservation transition mechanisms to use experimental conditions which were as natural as possible. This was one reason they thought it not valid to quantify their results.

The above authors concluded from their experiments, looking at transitions between the preoperational and concrete operational stages, that their experimental procedure did not change the reasoning processes of the students, and could be used to observe the processes or operations. They believed that their procedures could present new, unexpected situations, develop curiosity, and lead to questioning of 
previously seen reality.

They also discovered, in respect to what facilitates the transition from preoperational to concrete operational, that the particular teaching technique used was less of a determining factor in the transition than the child's initial level of cognitive development as measured by a pre-test. The techniques they used were verbal training, conflict-discrepancy between prediction and outcome, and demonstration, such as pouring liquid back and forth into the original glass (conservation of liquid).

John Renner and various associates at the University of Oklahoma Science Education Center have done a variety of studies which suggest that the "inquiry approach" does lead to higher levels of logical thought than traditional approaches to science teaching (Märek and Renner, 1979; McKinnon and Renner, 1971). By "inquiry" he means the learning cycle approach advocated by Karplus and Associates (1977). Although he has completed studies in different disciplines, his experiments need to be replicated by others before firm conciusions can be drawn .

Kuhn and Ho (1978) encourage the developing of anticipatory schemes as a method of encouraging new reasoning strategies. They have found that students are better able to make use of data from experiments, i.e., assimilate it into their theoretical framework, if they reconcile an observed set of events with a theory previously constructed to account for these events. Discrepancies between anticipated and observed outcomes lead to constructive development, although little 
is known about how this actually occurs. To analyze this process, her new research monitors a child's self-directed activity in problem solving situations with the goal of isolating important components of this process.

Raven (1974) assumed that the reasoning level of students was below capacity and found that logical operations could be facilitated by the proper teaching, which in this case was programmed instruction. As Raven put it:

The ourpose of the instructional strategy then is to give the individual repeated practice in making responses that operate on the content of problems in a specified fashion. The student sees the way a problem is solved and then uses the same rule to solve related problems ( $p .254$ ).

This quote illustrates that al though Raven supports Piagetian theories about cognitive development, the strategies and materials he designed for teaching cognitive operations followed the empirical approach. This was programming for reasoning development. It was also not clear from his research whether the cognitive strategies developed by these methods carried over into other content areas or were maintained over a period of time.

Raven's ideas are further developed by Walter, Hendrix, and Mertens (1980) who believe that a successful teaching technique, providing repeated practice in making responses that relate to the content in a specific way, will move students towards formal thought. They decided that a considerable number of college students remain at the concrete operational level with regard to biology because of a deficiency of experiences to reinforce formal reasoning. 
Since the traditional formal operations of proportional logic, combinatorial logic, and hypothetical-deductive reasoning are necessary in studying genetics, they inferred that a teaching strategy which encourages the development of Piagetian formal thought in these areas will increase students' level of achievement in college genetics.

A sequenced, linear, programmed self-study guide was developed with the goal of facilitating students using formal operational thought in genetics problems. The researchers felt that this programmed instruction was different from the traditional because it did not focus on memorizing results, but on "guiding students through the inductive process that allows them to derive these conclusions independently" (Walter, Hendrix, and Mertens, 1980, p. 104). The goal was to produce mild states of disequilibrium.

The finding was that the sequenced instruction did significantly increase students' performance on a problem-solving test in Mendelian genetics that used Piaget's formal operational reasoning patterns. These researchers suggested that application of Piagetian theory is important for college instructors and that if our goai is to produce students who can critically analyze complex data, then instruction should emphasize the "form of systematic sequential thought appropriate to the analytical procedures applied in the discipline" (p. 108).

It is important to note that these researchers did not suggest that formal thought in general was increased, but applied the ir conclusions to their particular cognitive domain of genetics. 
Frequency of exposure to problems requiring formal thinking has been found to be effective in promoting formal operational thought (Kuhn and Angelev, 1976; Kuhn and Ho, 1978). This agrees with some of the cross-cultural studies which were discussed earlier. Ninety-one fourth and fifty grade non-formal students were part of a fifteen-week training program, during which they were given problems requiring formal operational thought (the pendulum problem; the chemicals problem). The more frequent the exposure to the problems (once every week, twice every week, once every two weeks), the greater the acivancement.

Demonstrations were not found to be effective in this regard, no more so than exposure once every two weeks. Of those involved in frequent problem solving, the subjects at the concrete operatiorial stage in regard to these problems moved to a transitional stage, and those initially at transitional, moved towards formal. The intervention in this case produced a problem environment so that subjects could use their existing cognitive strategies and in so doing reorganize them into more advanced structures. This agrees with the theoretical point of view of constructivism, that we build our own more advanced structure through auto-regulatory mechanisms. It also suggests that we should spend more time observing how individuals act and less time on external demonstrations and training which leads to restricted solutions. These experiments successfully produced change, but did not explain how that change occurred. Kuhn concludes that we need to observe more closely what cognitive strategies a student uses during interventions. 
Lawson and Wollman (1975) trained fifth and seventh graders after giving them a pre-test (individual interviews using conservation of weight problems, volume, and bending rods). The experimental group had four sessions of individual training of thirty minutes each while the control group went to their regular classes. The training was effective in developing formal reasoning, but only in tasks similar to those used in the training. Non-specific transfer of training, the ability to do tasks using formal reasoning other than the trained ones, was not significant. They found that the first appearance of formal thought was intuitive. Students began to get a feeling for a "fair experiment" but could not verbalize the concept of isolation of variables.

In another experiment, seventh grade students in two average classes were put in two training groups to learn proportional reasoning (Wollman and Lawson, 1978). One group used physical materials and learned to solve problems in different ways without learning any algorithms. The second group was algorithm-oriented using the traditional verbal techniques and standard texts. The importance of physical action in concept formation was being tested. The active group was superior in the development of concept formation after the training and remained so at the time of a post-test one month later. These authors concluded as a result of their work that instruction should start with concrete, manipulative materials in an action-oriented setting, to be followed by symbolic presentation. 
The question of whether the use of concrete examples and models facilitates new conceptual understanding on a formal level was explored by Goodstein and Howe (1978). They found that students reasoning at a concrete operational level on the problems given did not benefit from concrete models, but that students reasoning at a formal level did progress to greater understanding. The conclusion that the technique used is less influential than the stage at which a person is reasoning, that students reasoning at a concrete level will not master formal concepts no matter how they are taught, until they are developmentally ready to proceed, agrees with the findings of Inhelder, Sinclair and Bovet (1974), even though the latter did experiments with children at a different stage of reasoning.

These experiments show that it is not yet possible to conclude which kind of training, if any, is most effective in developing more advanced modes of thinking. One group (Marek and Renner, 1979; Raven, 1974; Lawson and Wollman, 1975) be? ieve that successful transitions are promoted by instruction of various sorts, i.e., organization of a task corresponding to the reasoning level of the child and active involvement of the children so that they can use their logical operations to construct activities. Proof does not exist at this point that these studies have resulted in actual structural change (Kuhn, 1979a). And even if they have resulted in changes in the laboratory, does this carry over into other domains?

Inhelder, Sinclair, and Bovet (1974) focused on the actual intervention rather than pre-test, post-test changes, and noted that 
new structures came from the integration and coordination of existing schemes. They cannot say from these "microgenetic" process studies, however, what specific conditions lead to acceleration of cognitive development any more than others, only that any training procedures must resemble natural situations in which mental development takes place.

From the current research emerge two theories which relate to the application of transition mechanisms to education (Kuhn, 1979b). The "optimal mismatch" theory states that developmental charige results from exposure to situations slightly more advanced than one's current developmental level, but not so advanced that assimilation cannot occur. Knowledge about how this optimal mismatch leads to developmental charae is not yet available. In the "constructivist" view, higher stage stimuli do not play a role. Disequilibrium produced from inadequate structural organization leads to higher-level reequilibration. Each new level has the highest probability of emerging from lower levels. From these two theoretical approaches emerges the question of whether the next higher structure is invented from within the person or whether it is incorporated from outside as the most available and fitting thing. Most likely it is an interaction between environmental and internal cognitive strlicture. Understanding the mechanism of the transition is important to teachers if they are to know how to intervene in the child's learning environment.

If we accept Piaget's theory that cognitive development results from the interaction between subject and object, we tend to believe 
that the more active a subject is (mental activity included) the more successful the learning. Intellectual activity is most likely to occur if this activity (actual physical acting, observing, discussion, mental activity) occurs at the person's level of development.

New cognitive structures are formed from integration and coordination of existing schemes. Uncoordinated schemes which result in being unable to isolate variables should not be considered errors to be eliminated by coercion. The choice of information from which a child makes a deduction is a characteristic of a certain phase of development. Inadequate schemes are used as a foundation for construction.

Applying this to the transition between concrete and formal operations, the individual gradually finds that the concrete operations with their emphasis on reality and visual perceptions are not enough and is ready to move into the realm of possibility (Inhelder and Piaget, 1958). The gradual realization that the world consists of multiple variables which must be ordered to make sense of what is happening makes the isolation of one-dimensional observations seem inadequate.

\section{An Application of the Theory of Equilibration \\ to Secondary Science Education: The Learning cycie}

Many of the so-called applications of Piaget's ideas to education have borne little resemblance to his theories. His works are difficult to understand and his ideas twisted by American interpreters to fit in with their own ideas of education. 
The first phase of the educational application of his ideas was the naive use of tasks he had designed in the classroom (Gallagher, 1978). Then teachers became preoccupied with his stage theory, misinterpreted it, ignoring the individuality of all learning. Forgotten was the fact that each child is in process, and is not a category or a state. The science curricula of the 1960's, based on Piagetian theory, resulted in "confusion between the structure of logical organization of collective knowledge and the logical structure of the child's mind" (Elkind, 1978). An adult distilling the essence of a science, scientific method, or math, in order to present it to a child, uses logical thought. A child, in attempting to understand, uses whatever ievel of thought s/he is capable of. For example, set theory and isolating variables require formal operational thought, and moving them into elementary curricula may not be fruitful.

A third stage is now beginning, and Piaget's theory of equilibration is being applied to teaching and learning. Now, at the secondary level, the concentration is on different sequencing, and different ways of presenting material. Instead of thinking that Piaget's ideas will produce a new curriculum, it is now realized that it is tools for analysis of current curricula that he provides (Elkind, 1978). A useful framework is provided from which teachers can observe students as they solve problems. The discovery approach to teaching now has a firmer theoretical base.

The learning cycle: description and theoretical base. Of the many applications of Piaget's ideas to the classroom, one will be analyzed 
in detail. This is the three-phased learning cycle, originally used in the elementary school science program developed by the Science Curriculum Improvement Study (SCIS) at the University of California, Berkeley. It has now been shown to be an effective instructional approach for adults as well as children of all ages.

The learning cycle, with its three phases (exploration, concept introduction, and concept application), as described in Cnapter I, will be analyzed in terms of the theory of equilibration. Emphasis will be on its effectiveness at the concrete, transitional, and formal levels of cognitive development.

Karplus has attempted to provide a theoretical basis for the learning cycle by developing a three-phased model of hypotheticaldeductive thought (Karplus, 1979), as illustrated in Figure 1. These three phases go on spontaneousiy in all learning situations outside the artificiality of a laboratory, and the learning cycle is one of the few strategies which allows for these phases within a formal learning setting. Karplus believes that the term "hypothetical-deductive" better describes the abilities which appear during adolescence, than formal, and that it provides a link between the schemes, such as proportions, correlations, and probability, which appear at this time. If our goal, then, is hypothetical-deductive thought, schools need to provide students with opportunities to generate their own hypotheses.

Anaiysis of the learning cycle as a method of fostering cognitive development. The exploration and concept introduction phases of the learning cycle will now be analyzed in terms of their effectiveness in 

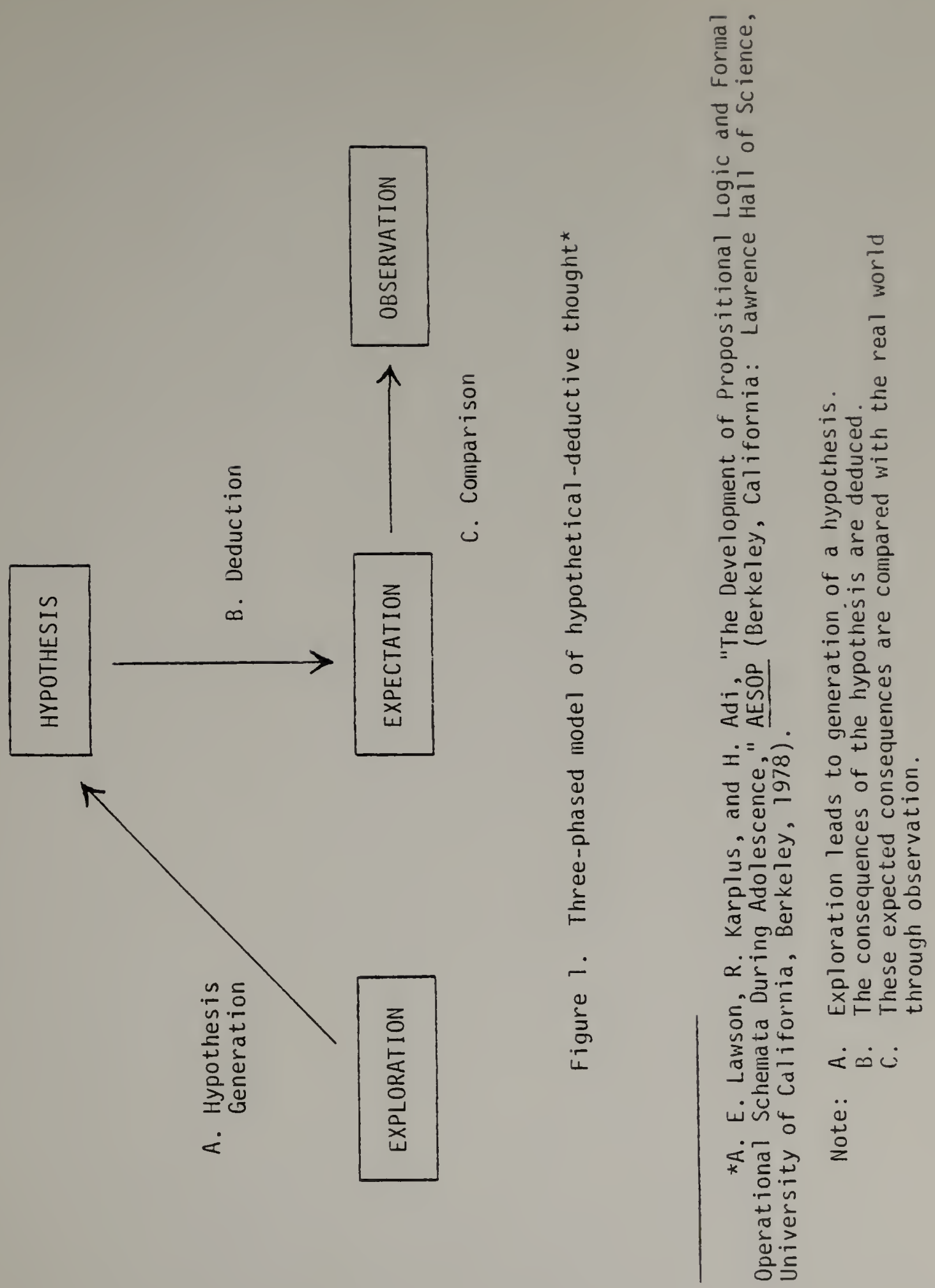
fostering cognitive development. The concept application phase is not discussed separately, because the same issues which arise in considering the first two phases continue to exist.

Exploration. Although the exploration phase is one in which high student autonomy is encouraged, it is also a time during which considerable activity is required of the teacher. As Kuhn and Angelev (1976, p. 705) summed up, "the observational study of subjects' selfinduced changes in strategies for dealing with a problem will ultimately provide the clearest insight into cognitive structural development." To be effective in achieving its goals of opening up a variety of possibilities for the student, the expioration phase must include an active teacher learning phase. This includes intense observation, finding out what students know, individualizing and focusing on the student. The communication skilis of the teacher are particularly important at this stage.

The key to the exploration phase is the designing of good exploration activities (Karplus, 1979). Because the majority of secondary and college courses allow very little student autonomy, few have been developed. The difficulty of getting college and secondary teachers to understand what is meant by "exploration" and to design exploratory activities was evidenced in workshops for science teachers at the University of Massachusetts. Most of the so-called exploratory activities designed by teachers at these workshops were traditional 1aboratory exercises thinly disguised. The concept of exploration was foreign to many of them. 
It has been found that the amount of information available during the exploration phase of a task can determine the sophistication of reasoning skills. Too much information ieads to coniusion. As we grow, we can process more information simultaneously. A good exploration activity will contain within it means of isolating relevant information (Kuhn, 1979b).

Although the exploration phase may include all of the above, the questions still remain as to what is meant by the word "exploration." Is it discovering solutions to problems or actually discovering one's own problem? Is it inventing new solutions to old problems or rediscovering old ones? However it is interpreted by various teachers according to their cwn needs and interests, it must be more than a simple manipulation of objects.

Concept introduction. Although we have emphasized the exploration phase because it contains so many opportunities for selfregulation, the second phase of the learning cycle, that of concept introduction, has given rise to some controversy. Because concept introduction implies a verbal discussion or presentation of concepts which have been previously explored, the question of language and its influence on the reasoning process should be considered.

In experiments with children at the concrete operational level, Inhelder, Sinclair, and Bovet (1974) found that the language of conserving children differed from that of non-conserving children. They asked two questions: Can non-conserving children be taught the verbal expressions for quantitative comparisons that are spontaneously used by 
conservers? If so, will a change in verbal abilities lead to a change in conservation answers? The answer was "yes" to the first question and "no" to the second. Work with deaf children has alsc shown that verbal concepts are not necessary for the development of thought. So, although verbal development does not seem to facilitate cognitive development, there does exist a parallel between developing the cognitive operation and the language needed to express that cognition.

Since language training does not influence operational level, how important is the concept introduction stage? Kauman and Konicek (1974) think that aduit concepts which usually are presented at this stage may be inhibitory, confusing, and certainly do not follow from Piaget's theory of equilibration. Children oniv really understand what they construct themselves from their own inferences and experiences. Therefore a concept presented by a teacher is of no use unless an application activity to change the concept into something personally meaningful occurs afterwards.

In response to these arguments that the concept introduction phase is non-Piagetian in that it is imposing knowledge from the outside, knowledge that the students have not necessarily constructed for themselves, Karplus (1979) responds that as long as concept introduction follows exploration no problem exists. Concept introduction is a "social transmission contribution to development." Self-regulation is the relating of new concepts to what has previously been observed in exploration. The key to the whole process is starting with explcratory activities. 
It has been shown (Furth, 1969) that young children do not need the verbal statements of concepts to have an understanding of what they have explored. Does this change with adolescents and adults? As we grow, we become more dependent on the verbal nature of our Western society. We have previously stated that confusion is conducive to cognitive growth. Is there a point beyond which confusion is so anxiety provoking that it deters cognitive growth? As we mature, we may develop a verbal dependency, such that discovery learning with concept introduction is more effective in promoting formal thinking than exploratory activities alone. Our society is a iabeling one; we like to label and categorize students as well as concepts. Gut often knowing the label substitutes for understanding the concept.

Little research has been done indicating whether the concept introduction phase is important for the cognitive development of children. Of course, many variables, such as the student-teacher interaction and the extent of student autonomy in the classroom, need to be controlled before definite conclusions can be drawn.

This concludes a discussion of the theoretical basis of the Science Teaching and Development of Reasoning workshops for secondary science teachers. The ideas upon which these workshops are based are derived from developmental theory, with cognitive development, specifically the development of formal operational thought, as a goal. This search of the literature revealed that formal operational thinking has different meanings for different researchers. For the purpose of this study, however, the assumption is made that the promoting of thought 
processes generally agreed on as formal operational is a valid goal. In addition, the "Learning Cycle" approach described and modeled in these workshops is one possible method of achieving this goal.

\section{Humanistic Psycholocy: A Conceptual Basis for Modern Inservice Programs}

As Piaget's theory of cognitive development provides a rationale for the development of reasoning as a goal for science study, so humanistic psychology has formed a conceptual framework for the inservice workshops with which this study is concerned. The common theme in both fields is interaction: the theory that a person is essentially formed as a result of interaction with the environment.

This environmental view reflects the influence of Kurt Lewin (1942) who saw the individual as a part of a larger whole, a gestalt, a life space. Change results both from differentiation within the person and the environment. This interaction results in "cognitive structures" within the person from which the world is perceived. When one goes to a new city, it is first seen as an unstructured whole, which gradually, with increased familiarity, becomes differentiated into parts and subparts. A cognitive structure is changed by seeing a connection between areas not previously seen as related, ard this process leads to problem solving and insight. So differentiations lead to changes within the person, changes in the cognitive structure, and finally a more structured, meaningful world. Changes in needs, tensions, attitudes, and expectations result. 
Changes are determined by both central and peripheral aspects of a person. Peripheral aspects are closer to the action level and thus easier to change, while central aspects are private and less accessible to change. Central issues involve deeply held beliefs and values and can result in deep resistance to change. Both the cognitive and affective aspects of an individual are involved.

From these influences and the work of Abraham Maslow (1962) and Carl Rogers (1969) in humanistic psychology come the important conclusions that each of us has a unique reaction to the world and that both the individual and the environment must be observed and understood. Individual goals involve developing our potential by our own efforts, choosing our own direction of growth and values. Reality, according to Rogers, is our perception of our environment, our reaction to our world of experience. Learning, therefore, becomes a process, not an end.

Combs, important for his applications of humanistic psychology to education, considers learning in terms of the development of personal meaning (Combs, et al., 1971). First comes the exposure to new information and ideas followed by the discovery of the personal meaning these have for the individual. Therefore, not only do we as teachers expose people to new ideas and information, but we help this information translate into personal meaning.

If learning is the process of "meaning change" as Combs outlines in his book, Helping Relationships: Basic Concepts for the Helping Professions, what affects the discovery of meaning? What factors are involved in its change? 
1. Long-term changes in behavior will occur if the new behavior suits the learner's needs. Interest is an important factor.

2. Change in behavior is more likely to occur if an individual feels challenged rather than threatened. When innovation becomes a threat, it is not easily attempted.

3. Learning results from solving problems. A goal of teaching is to help ciarify the problem as well as assist in the search for solutions.

4. Learning is an active process; the learner must do something with the learning in order to incorporate it.

5. Learners need ongoing feedback to stimulate the development of rew learnings.

6. The learner needs to have the freedom and responsibility. to test the consequences of his acts in a safe atmosphere.

7. Learning takes time. Meaning from new experiences is discovered from a series of smal1 steps.

(Combs, et al., 1971, pp. 103-120)

Robert Blume, who also has applied humanistic theory to education, adds the following to the above points:

1. People learn most effectively from choices they make. These may be based on alternatives which are available as well as needs and interests.

2. People must make the link between new information and their own lives and experiences. This is the "personal meaning" mentioned by Combs.

3. Teachers teach the way they have been taught.

4. Teachers must feel positive about themselves. (Blume, 1971, pp. 146-148)

Humanistic psychology and institutional change. At about the same period during which humanistic psychologists were providing a conceptual basis for learning, other theorists were also analyzing the change 
process, particularly in institutional settings. The ideas of interaction and differentiation appear again and again. When disequilibrium between the "tension systems" of the individual and the surrounding social field occur, equilibrium is restored by changing either the individual or the surrounding environment (Coffey and Golden, 1957).

Roles within institutional settings can become very fixed and not amenable to change. When roles in which people have security, roles which have resulted from interactions between individual motivation and social pressures, are threatened, change is difficult.

Coffey and Golden (1957) have stated the following as conditions which facilitate institutional change:

a. Democratic Leadership -- Group members should participate in the decision-making process.

b. Norms must be established in which change is an expected part of institutional growtr.

c. Change must be made without jeopardizing a person's membership within the group.

d. When a group is concerned with satisfying member needs, there will be a sense of belongingness in the group.

e. Individuals can be encouraged to take leadership by helping formulate goals and participate in implementation and evaluation.

f. Group cohesion can be developed so members can test new roles, try out new behaviors and attitudes without risk.

g. Change must be supported by the administrative structure. 


\section{Application of the Change Process to Inservice}

The idea of continuing improvement of teachers' professional behavior is more than a century old in this country. The earlier idea of inservice as "getting people to follow directions" (Corey, 1957, p. 8) gradually altered, at least for leaders and conceptualizers of staff development, to the more modern idea of inservice as a cooperative, problem-solving venture. This resulted from the new ideas on human motivation and learning theory. By 1957, the Fifty-Sixth Yearbook of the National Society for the Study of Education was totally devoted to the topic of inservice education. This yearbook supported a different type of organization--one that would provide the opportunity for teachers and administrators to:

a. Identify the particular problems on which they want to work;

b. Get together to work on these problems in ways that seem most productive to the group;

c. Have access to a variety of needed resources;

d. Try out in reality situations whose modifications in practice give a priori promise; and

$€$. Appraise and generalize from the consequences. (Corey, 1957, Pp. 8-9)

Parker, one of the leaders in inservice education who contributed to the yearbook, formulated a series of guidelines for successful inservice programs. These guidelines were derived from the following sources: current concepts of inservice education; growth needs of teachers, supervisors and administrators; the psychology of change; 
research in the field of inservice education; and the experience of schools with inservice programs and activities. They comprise a summary of the thinking of experts in the field in 1957, and indicate that humanistic approaches have not just recentiy appeared on the scene (Parker, 1957):

1. People work as individuals and as members of groups on problems that are significant to them. Significant means:
a. A person can become emotionaily as well as intellectually involved in a problem.
b. The problem can be seen as a basis for action.
c. A solution is needed for the situation.
If work is done in groups, effectiveness often increases.

2. The same people who work on problems formulate goals and plan how they wili work.

3. Many opportunities are developed for people to relate themselves to each other.

4. Continuous attention is given to individual and to group problem-solving processes.

5. An atmosphere is created that is conducive to building mutual respect, support, permissiveness, and creativeness.

6. Multiple and rich resources are made available and are used.

7. The simplest possible means are developed to move through decisions to actions.

8. Constant encouragement is present to test and to try ideas and plans in real situations.

9. Appraisal is made an integral part of inservice activities.

10. Continuous attention is given to the interrelationship of different groups. 
11. The facts of individual differences among members of each group are accepted and utilized.

12. Activities are related to pertinent aspects of the current educational, cultural, politicai, and economic scene. (pp. 104-124)

Herrick (1957) states that a need exists to think about the nature of change in individuals, the nature of the problem around which the inservice program is focused, and the nature of the organization within which this program exists. These are interrelated and any evaluation of change in an individual teacher needs to consider the problem being addressed and the institutional context.

In the same vein, Arbuckle (1977) states:

Implementation of change involves interaction among the innovation, the user, and the institutionai setting. A full understanding of the process of implementation will emerge only through an analysis of characteristics of these three components and the interrelationships between them (p. 9).

Both the approach from humanistic psychology and the constructivist theory of cognitive development emphasize the interaction between the user, the teacher in this case, and new information. If user capability is accepted as one of the critical factors for effective implementation of new ideas, then the following must exist:

1. Users must be involved in the decisions for new programs and be allowed to make their own choices.

2. Users must be receptive to change.

3. Users must have the skills and competencies to perform new roles. New programs must build on their strengths.

4. The attitude and organizational structure of the authorities must provide the opportunity and expectation for change. 
Each of these aspects will now be discussed in turn.

Decision-making and choice in inservice. Studies of the role of the teacher in educational change indicate that change is much more likely to occur when the user or teacher is closely involved at all stages of the process (Ful1an, 1972; McKague, 1976; Edwards, 1975; Russe11, 1974 ; Mahan, 1972). Implementation is higher when projects are initiated with a problem-solving approach and in response to local need. The alternative, the developing of innovations outside the school and then transmitting them to the teachers because funding happens to be avaitable, leads to less significant results for those involved.

Fullan (1972) states:

There is a misplaced emphasis in the innovative process in that those affected by the changes are dependent on the process instead of the process being dependent on them. This has led to top-down attempts at changes which at best modify one or another aspect of the situation witrout radicaliy changing it.

In a study of over two-hundred teachers, Edwards (1975) found that teachers desire input into decision-making about relevant inservice for classroom application, and cooperative planning and programming by teachers and administrators. There is need for an open inservice environment that encourages participation through questioning and exchanging ideas. Teachers' negative perception and attitudes about past inservice educational experiences continues to hinder development of inservice education as a means of positive professional growth.

Voluntary participation in inservice activities appears to have an important relationship to curricular change (Russe11, 1974; Mahan, 
1972). Russell studied attitude change and use of computer terminals following a workshop. Over $90 \%$ of the subsequent users took the workshop voluntarily. The objectives of the program were not accomplished with the non-volunteers.

Since the choices of teachers have been recognized as being of importance and relevant to the gains and changes made as a result of inservice programs, studies have been done to determine teachers' preferences (McKague, 1976; Kagan and Tamir, 1977). McKague found in a survey that the inservice format teachers preferred, in order of rank, were workshops, seminars, special projects, institutes, conferences, and conventions. Their preferences for consultants were, in order of rank, practicing teachers, subject experts, department of education consultants, professional development staff, university faculty, and lastiy, princioals.

The development of new skills. New programs will not succeed without attention to the individuality of teachers. Teachers, even when interested in the same topic, have a variety of backgrounds, beliefs, concerns, knowledge, management expertise, and teaching style. Teaching environments may vary from innovative departments with administrative support to traditional, inflexible, content-oriented, secondary science courses.

When teachers are expected to create a new curriculum that individualizes instruction and produces students with more responsibility and maximum rational functioning, teachers run up against problems in coordinating staff and student schedules to build in the extra 
time needed. Additional difficulties include the fact that most students are not capable of functioning in a program emphasizing student responsibility. Fullan (1972) concluded that because of the uncertainty of teachers in respect to learning new roles, the necessary time and resources must be built into the implementation process if change is to occur.

The learning of new roles leads to confusion and feelings of inadequacy. Joyce (1969) calls this issue "the need to feel competent."

Every innovation--every change, even slight on the surface-requires the members of an institution to adjust by learning new behaviors. To some extent, all adjustments that require learning involve some risk of a feeling of incompetence. In teaching, the risk can be considerable, particularly because the average school provides no place where the teacher can develop new competence in private ( $p .20)$.

Sarason (1971) uses new math development as an illustration of the way change is usually introduced into the school culture. This innovation, its conceptualization, development and packaging, came from the university community. During summer workshops, two main problems emerged:

1. Nobody had formulated the problem as one requiring teachers to unlearn and learn; and

2. There was little sensitivity to the plight of the teachers. They were being asked to learn procedures, vocabulary, and concepts that were not only new but likely to conflict with highly overlearned attitudes and ways of thinking. Many of the teachers were unable to voice their uncertainties and lack of understanding (pp. 41-42).

It has become apparent, from experience training teachers in new curricula, that training should build on strengths that teachers 
already have, and that attention should be paid to the specific development of necessary new skills and competencies (Joyce and Showers, 1980).

Concerns of teachers. Another important area that must be addressed if change is to be implemented in the classroom relates to the concerns of the teachers involved. These include the feelings, perceptions, motivations, and attitudes of individuals as they become aware of an innovation, and consider its use. These concerns continue throughout the use of the innovation.

Concerns about change are complex and varied. Personal ambivalence and resistance which often show up on a concerns profile mean different things, all of which need to be dealt with.

According to Miles and Passow (1957):

Ambivalence and resistance before and during early stages of training, far from being contra-indications for training, are probably more frequently a symptom that genuine involvement is taking place. In thinking about potential change, the individual has to have internal conversations dealing with the potential consequences that 1 ie ahead-gratifications such as confidence, adequacy, rewards from others, and discomforts such as time load, fears of failure, resentments of authority figures, strained relationsinips with peers ( $p p .344-345$ ).

Frances Fuller, during the 1960's, studied the concerns of student teachers as well as more experienced teachers. Through a series of in-depth interviews in counseling seminars, she found a developmental progression of these concerns (Fuller, 1969).

The first stage of concern was that of self. The teacher was absorbed with self-protection, self-adequacy, subject matter adequacy, 
finding a place in the power structure of the school, and figuring out the expectations of other teachers and supervisors. The second stage was that of task concerns. During this time, the emphasis was on the methodology and logistics of teaching. Questions such as "How do I do it?" predominated. Finally, concerns were with the impact of the teaching on the student. "Are the students learning?" "How does what I do affect their learning?"

Fuller concluded that those training teachers must move with the tide of concerns, not against it. A variety of questions, however, remained to be researched. Is the stage of concern a function of the individual or the situation, or both? If concerns are related to the characteristics of a person, what are these characteristics? Does an experienced teacher in a new situation go back to an earlier stage? Will he or she move through the earlier phase more rapidly than the inexperienced teacher?

In the early 1970's, Gene Hall and colleagues at the Research and Development Center for Teacher Education at the University of Texas at Austin found a similar progression from self to task to impact concerns in participants in regard to any particular innovation which was adopted (Ha11, 1979; Ha11, George, and Rutherford, 1977). To this group, "concern" represented a mentally aroused state, preoccupations, feelings and thoughts directed towards a particular issue. Different individual concerns about the same issue may vary considerably. When concerns are discussed, it is the person's perceptions which are being dealt with, rather than the reality of the situation. 
The type and intensity of concerns about an innovation will vary depending upon one's involvement with the innovation. Seven "Stages of Concern About the Innovation" have been identified (see Figure 2). Research has shown a developmental progression of individuals through these stages (Ha11, George, and Rutherford, 1977; Ha11, Wallace, and Dossett, 1973). More than one level of concern can be experienced concurrentiy, although usually certain types of concerns are more intense than others at different periods of time. This depends on an individual's knowledge of the innovation and extent of use of it. It can be seen from a study of figure 2 that the seven stages of concern show a progression similar to that of Fuller, moving from lack of concern, through self and task concerns to those of impact.

Consideration of concerns about innovations have important implications for teaching because of their developmental quality; i.e., the earlier concerns must be resolved or lowered in intensity before later concerns will emerge. Awareness and knowledge of the particular concerns of an individual can then lead to appropriate activities to lessen these concerns. For example, considerably more information may need to be provided about new ideas and approaches, and attention given to the feelings of inadequacy or insecurity of the teacher with the new ideas, before the actual management issues can be confronted.

Other factors need to be considered as we11. Perhaps the innovation is not a good one for this particular situation, for a particular teacher or school system. Perhaps the teacher does not have the educational background or intellectual ability to understand a new 
FIGURE 2

DEFINITIONS: STAGES OF CONCERN ABOUT THE INMOVATION*

6 REFOCUSING: The focus is on exploration of more universal benefits from the innovation, including the possibility of major changes or replacement with a more powerful al ternative. Individual has definite ideas about alternatives to the proposed or existing form of the innovation.

5 COLLABORATION: The focus is on coordination and cooperation with others regarding use of the innovation.

4 CONSEQUENCE: Attention focuses on impact of the innovation on students in his/her immediate sphere of influerce. The focus is on relevance of the innovation for students, evaluation of student outcomes, including performance and competencies, and changes needed to increase student outcomes.

3 MANAGEMENT: Attention is focused on the processes and tasks of using the innovation and the best use of information and resources. Issues related to efficiency, organizing, managing, scheduling, and time demands are utmost.

2 PERSONAL: Individual is uncertain about the demancs of the innovation, his/her inadequacy to meet those demands, and his/her role with the innovation. This includes analysis of his/her role in relation to the reward structure of the organization, decisionmaking and consideration of potential conflicts with existing structures or personal commitment. Financial or status implications of the program for seif and colleagues may also be reflected.

1 INFORMATIONAL: A general awareness of the innovation and interest in learning more detail about it is indicated. The person seems to be unworried about himself/herself in relation to the innovation. She/he is interested in substantive aspects of the innovation in a selfless manner such as general characteristics, effects, and requirements for use.

0 AWARENESS: Little concern about or involvement with the innovation is indicated.

*Original concept from G. E. Hall, R. C. Waliace, Jr., and W. A. Dossett. A developmental conceptualization of the adoption process within educational institutions. Austin: Research and Development Center for Teacher Education, The University of Texas, 1973. 
approach that is being advocated.

Lastly, in thinking about concerns, change towards the higher level concerns essentially comes from within the individual; it cannot be imposed from the outside, even though it can be facilitated. The interaction between the outside facilitator or trainer, the task, and the user is crucial, but in the final consideration, it is the individual who determines whether or not change will occur.

Administration and peer support for innovation. A variety of factors in the school and institutional environment affect the teacher's ability to change and grow. Rubin (1978) states:

The nature of the student population, the expectation of their parents, the aspirations of the school system, the customs of the particular faculty, and the school's physical resources all influence the ways in which the teacher must function. It follows, therefore, that these same environmental factors also affect both the competencies teachers need and the procedures for their development. Such differentiation, however, is not often reflected in the standard professional improvement program ( $p .7)$.

Evidence from a variety of sources indicates that support from the administration is necessary for successful innovative efforts on the part of a teacher (Bricke11, 1964; McLaughlin, 1976; Fulian, 1972; Goodlad, 1971, 1975). For individual teacher change, the principal must be supportive (Sarason, 1971 ; Orlich, 1973).

This support from the administration may occur in the form of shared decision-making about inservice projects in the schools, release time, funding, and resources. Release time to observe other classrooms where particular innovations are operating is a useful strategy for implementation (Smith, 1979). Teachers need to observe classrooms that 
work. This clarifies goals, roles, and methods, and makes new ideas credible. McLaughlin (i976) declares, "The teachers felt that seeing a similar program in operation for just a few hours was worth more than several days of consultants delivering talks on philosophy" (p. 345).

During the development and dissemination of the Physical Science Study Committee (PSSC) program, a new secondary physics course, a variety of new materials and methods were to be used by the teachers. They were frequently negative to the new materials and had no visible proof, even after attending training institutes, that the new materials worked under actual school situations. In areas where there was no opportunity to observe PSSC classrooms, expansion of use did not occur. Actually observing working classrooms was as influential in a teacher's decision to adopt the new materials as attending an institute to learn how to use them.

In addition to administrative support, the social forces in peer groups have a strong influence on changes in teacher behavior (Miles and Passow, 1957; Corey, 1957; Edwards, 1975; Coffey and Golden, 1957). Any diagnosis of needs for inservice is closely involved with individual small-group, and institutional readiness to change (Miles and Passow, 1957). Training in shared decision-making and in cooperative problem solving becomes a necessity if group norms are to be changed so that innovations can become permanent.

New science programs have not succeeded when not enough teachers per building have become involved. A minimum of two teachers per 
grade or subject area is desirable to provide support and mutual assistance when implementing something new (Mahan, 1972; O'Toole, 1974).

Change takes time. Time is an important factor in the success of an innovation (Goodlad, 1971, 1975; Ha11, 1979; Arbuck7e, 1977). Meadows (1978) found that the longer the training for secondary science teachers, the more influential the effects of the workshop.

Hall and Associates at the Research and Development Center at the University of Texas at Austin have developed the Concerns-Based Adoption Model (CBAM) in an attempt to ga in a greater understanding of the change process, including how to manage it more effectively and evaluate it (Ha11, 1979). Many educationa? innovations have resulted in no significant difference in teaching, and lack of understanding of the change process is very likely the reason.

According to this model, change is viewed as a process rather than an event. A process is something that happens over a period of time. "Change is not accomplished by the simple passing of a law, by a decision-maker making an announcement in the fall faculty meeting, sending a memo, or holding a two-day pre-school workshop" (Hal1, 1979, p. 3). Time is also necessary for the developmental growth involved in change, both in terms of an individual's personal relationship to an innovation as well as skill in using it. This means that continuing and ongoing support for a change is necessary.

In spite of general agreement on the above points, the question still arises whether changes have resulted from short-term workshops. 
Does the one-shot inservice workshop have no value? Educators planning inservice workshops need to know more about effects of the length of the workshop on participants' perception of change. This is economically as well as theoretically important, considering that one-shot workshops are continually being presented and attended.

The question of the usefulness of short-term workshops cannot be resolved in isolation of other factors concerning the content and format of the workshop. Although long-term programs with follow-up and continued leadership and support are most important for major changes, evidence can be cited to indicate that short-term inservice instruction can produce significant changes in teachers' attitudes and ciassroom practices. Several examples selected from the literature given below support this statement.

Harders (1972) studied the relationship between selected inservice activities and the supportive verbal behavior of thirty-eight secondary science teachers who volunteered for the project. He found that six hours of classroom instruction made a significant difference in the proportion of supportive verbal behaviors used. In another study by Bartholomew (1970), a half-day inservice session, incorporating the viewing of a videotaped teaching model, significantiy increased the investigative behaviors of twenty-seven experienced earth science teachers.

Carline (1970), using fourteen hours of role-play simulation and video-feedback to train twenty-three teachers in interaction analysis techniques, found significant positive changes in interaction 
patterns over the control group. The training of new behaviors was much easier than eliminating old behaviors. This relates to Kuhn's (1979b) observations in the cognitive realm that the main difficulty may not be the acquiring of new patterns, but the elimination of misconceptions and preconceptions.

Attitudes also can be altered as a result of short-term programs. Russell (1974) investigated the effect of a short two and onehalf hour session with fifty-nine secondary social studies teachers, a session designed to promote greater use of computer terminals. Positive changes in attitudes and use of the computer terminals were made by this voluntary, experimental group. Another half-day workshop, which included exposure to a film model constructed to illustrate the behavioral approach to counseling (Sorenson, 1971), resulted in significant changes in the viewer's conception of a counseling role for middle school and junior high teachers. In this case, however, the post-test was immediate, and no later follow-up occurred. Additional studies (Hulleman, 1973; Ashley and Butts, 1970) have shown positive changes in attitudes resulting from short-term sessions.

Although evidence does suggest that short-term workshops can lead to changes in attitudes and behaviors, many questions remain unanswered including the longevity of the effects.

Additional individual factors. There is no evidence that individual factors, such as grade level taught, previous teaching experience, age, or sex, correlate with teachers' use of innovations (White, Raum, and Butts, 1969; Angius, 1974). Principals placed a higher value than 
teachers on most existent inservice programs, and teachers' skepticism regarding the value of inservice programs increases with experience (Angius, 1974).

Adaptations of innovations. New programs and ideas must be adapted to the needs and particular situations of the users if they are to be successful (Sikorski, 1975; Hall and Loucks, 1978). Interviewing participants during pilot projects helps to determine which elements are successfully modified so that continual improvements in a model can be made.

Different research groups have conceptualized this adaptation process in a variety of ways. These different forms and patterns of innovations as adopted by different individuals at different locations are called "Innovation Configurations" by the Research and Development Center at the University of Texas at Austin (Hall and Loucks, 1978; Hall, Wallace, and Dossett, 1973). Some modifications result in minor improvements, while others are macro-mutations which bear little resemblance to the original idea. Research has shown that change facilitators and users do not necessarily agree on what are acceptable forms of the innovation. In addition, innovation alterations are difficult to assess since the essential components of an innovation are often not clearly defined.

Techniques to help teachers adapt ideas to their particular situations include attention during the development of the new ideas to the fact that they will be altered, as well as assistance in the use of the new ideas, helping in the adaptation to each individual 
situation. Because teachers have different styles and personalities, the main elements of a workshop, such as Science Teaching and the Development of Reasoning, will be adapted in a variety of ways. Otherwise, the ideas are unlikely to be adooted by many teachers.

Barrows and Klenke (1980) have carried the idea of innovation configurations several steps further. They have developed the "Use Profile" to document change over time. It has three dimensions: complexity of use (what is being done); scope (how often it is being done); and levels of use (how well it is being managed). Complexity of use is similar to the innovation configuration, the actual form the innovation is taking, quantitatively or qualitatively. A user implements an innovation at a certain complexity level for a certain amount of time, and at a certain level of use.

McLaughl in (1976) ascribes the failure of many new programs to the lack of a two-way process of "mutual adaptation." The implementation of an innovation is a variable, dynamic, organizational process, characterized in different situations by three different interactions:

Non-implementation is the breaking down or ignoring of an innovation.

Cooptation is adaptation of the project design with no change on the part of the institutional setting or participants. Either teachers, resistant to change, fit new ideas into old frameworks, or support and follow-up is limited.

Mutual adaptation characterizes successful implementation. Both the design of the project, the institutional setting and the participants are changed during the process. 
According to McLaughlin, mutual adaptation is most likely seen in classrooms of a receptive institution. Five factors are important for classroom innovation:

1. Ease of explanation and communication to others.

2. Possibility for trial on a limited basis.

3. Ease of use.

4. Congruence with existing values.

5. Superiority over practices that existed previously.

Additional factors conducive to mutual adaptation in classrooms are:

1. Production of materials by the local staff.

2. Ongoing staff training (concrete, inquiry-based training activities, visits to other schools, and how-to-do-it sessions).

3. Adaptive planning, including feedback networks.

In summary, mutual adaptation is a learning process during which the developmenta? needs of the users must be considered.

\section{The Positivist and Phenomenological Approaches to Evaluation}

To understand the particular research design chosen for this study, a discussion of two important research paradigms is necessary: the positivist model of scientific research and evaluation, and the phenomenological approach.

Positivism is based on the idea that methods developed in the natural sciences are applicable to the analysis of social events and processes. The closer to natural science the methods, the more 
accurate knowledge will be obtained. It assumes:

The unity of scientific method despite the diversity of subject matters, the ideal of explanation as consisting in the subsumption of individual cases under general laws, and the formal structure of mathematical physics as a metiodological ideal (Mishler, 1979, p. 3).

In the positivist tradition, the observer is ideally outside and independent of the observed and studied phenomenon (Carini, 1975; Patton, 1975). This paradigm has a quantitative emphasis whereby the observer sets up categories and characteristics to be studied through traditional methods of systematic evaluation. The components and outcomes of a phenomenon are analyzed, and reliability is strongly emphasized.

In the past, this positivist model has dominated the social and behavioral sciences and their application to the field of education. However, criticisms of this approach in educational research which deals with people and social systems are abundant. According to Butts and Raun (1970), statistical studies which have attempted to determine the impact of inservice education programs on the teaching behaviors of science teachers have not had conclusive outcomes. In addition, no clear-cut results have emerged from studies of teachers' characteristics and attitude change as predictors of successfut implementation of innovative curricula, when analyzed with psychometric instruments. Many of the variables cannot be controlled and many of the procedures and outcomes cannot be put into quantitative terms (Rubin, 1978; Lawrence, 1974). 
What the experiment tests is not whether the hypothesis is true but rather whether the experimenter is a sufficiently ingenious stage manager to produce in the laboratory conditions which demonstrate that an obviously true hypothes is is correct (McQuire, 1973, p. 44).

Mishler (1979) elaborates further on this theme, emphasizing that human action is dependent upon the context within which an individual functions. Therefore, research findings in education are context-dependent. Yet, traditional parametric research and its applications to educational research ignore the importance of context. We behave "as if context were the enemy of understanding, rather than the resource for understanding which it is in our everyday lives" (p. 2)

Scientists and educators want to prove the generality of hypotheses. As a result, methods of experimental design, measurement, and statistical analysis strip away context. Subjects are removed from natural social networks and normal roles and randomly assigned as if interchangeable. The search is for pure variables, for measures that will not be contaminated by other variables. But do these independent and pure variables give us any deeper understanding of human action?

In an alternative approach to evaluation, the phenomenological tradition, the viewer's perspective is not separated from the phenomenon being studied (Carini, 1975; Patton, 1975). Many truths, rather than a single truth, are possible as the methods, perspectives, or purposes of the study change. Since reality is knowable in a variety of ways, the investigator has a choice of descriptions depending on his/ her purposes as an investigator and the focus of the investigation. 
The researcher needs to look for appropriate and systematic methods to study contextually related, meaningful behavior.

This results in an emphasis on qualitative methods and validity, a holistic analysis of process as well as outcome. An attempt is made to understand the meaning of the phenomenon as a unity (Patton, 1975). The paradigm stresses:

1. The meaning of human behavior;

2. The context of social interaction;

3. An understanding of subjective states; and

4. A connection between subjective states and behavior.

This means an active, involved, personally insightful role for the researcher. As Patton (1975) summarizes:

The alternative evaluation paradigm makes the issue of validity central by getting close to the data, being sensitive to qualitative distinctions, attempting to develop empathy with program participants, and thereby approaching the data subjectively, and taking a holistic and process perspective on evaluation. The overriding issue is the meaning of the scientist's observations and data, particularly its meaning for participants themselves. The constant focus is on a valid representation of what is happening, not at the expense of reliable measurement, but without allowing reliability to determine the nature of the data.

To provide a holistic evaluation of the Science Teacher and the Development of Reasoning workshops, a phenomenological approach was used. This included qualitative methods, i.e., descriptive data, interviewing, and self-report, an evaluation which does not separate the innovation from the environment in which it functions. This methodology has the advantage that both expected and unexpected or additional consequences of the workshops can be included. 


\section{Teachers' Perceptions as a Source of Data}

To study the question of whether teachers' perceptions are a reliable source of accurate information about their use of ideas and practices from inservice workshops, a literature search was done of perception in relation to evaluation. Two points of view were evident in the literature:

1. Teachers must be the source of data in evaluating inservice workshops, and

2. Teachers' perceptions are not a reliable source of information. Classroom observations are more accurate.

In a review of classroom interaction studies, Powers (1977)

states that most systems for rating classrooms do not have enough contextual information. One cannot understand what is being rated unless the point of view, including the intentions and planned strategies of the teachers, is included. Observation instruments are not sufficiently developed to pick up inquiry and process types of activity. The frequency of verbal behaviors is primarily observed, and the importance of non-verbal behaviors omitted. The whole area of cognitive processes cannot be measured in terms of frequency.

Balzer (1969) concurs with this point of view, stating:

A study of the literature of teacher behavior reveals that most researchers have made numerous advance decisions concerning what to include and what to exclude in their observations. From a scientific point of view, this should be a matter of concern since an incomplete and misleading picture of classroom teacher behavior is the nearly inevitable consequence (p. 226). 
The main methodological approach to studying and analyzing interactions of teachers and students in classrooms is being critically reexamined (Mishler, 1979). Methods of "interaction analysis" (Flanders, 1970) use sets of predefined categories in which observers code instances of teacher and pupil behavior.

While results have grown to voluminous proportions, their contribution to understanding has been disproportionately sma11. . . In America, therefore, a decade of classroom research has not produced the revolution in educational understanding which its proponents expected (Delamount and Hamilton, 1976, p. 27).

After collecting interaction profiles on many teachers using Flanders' system, it was shown that to have a real understanding of classroom interactions information was needed about the contexts of behavior, the subject being taught, the classroom physical setting, the personality of the teacher, and student opinions and interpretations of student behavior. An anthropological approach that includes interviews and more unstructured observations was necessary.

Festinger (1953), in discussing interviewing as a source of data collecting, states:

Interviewing as a source of collecting data has both advantages and disadvantages. If the focus of the research is the attitudes and perceptions of individuals, then speaking with the individuals is an appropriate approach. If one is studying behavior in a controlled situation, then observational methods are valuable. They are not as useful in researching attitudes and perceptions, and are uriable to probe the past or determine future intentions.

The criteria of directness and economy, and the ability to collect data about beliefs, feelings, past experiences, and future intentions, have widened the range of application of the interview (p. 330). 
Loucks, Newlove, and Hall (1975) believe that the interview has several advantages over direct observation:

1. Interviews can get at past events, at events when the interviewer is alone, and at situations where outsiders would alter behavior;

2. Interviews can reveal behavior not occurring during times when observations are made;

3. Interviews can reveal relationships that cannot be observed;

4. Interviews are quick and efficient. (p. 3)

Evidence exists to show that different observers watching the same teacher teach or studying data concerning her will arrive at very different evaluations (Barr, 1961). Even evaluation experts start with different assumptions, use different approaches, and use different data gathering devices. An observer only sees moments in time. Teachers' perceptions, combined with observations, result in a better sense of the classroom setting. The evaluation of feelings and motives, particularly in terms of factors resisting change and/or factors that involve the problem-solving approach to learning, are advocated by a variety of researchers (Sjogren, 1970; Herrick, 1957; Powers, 1977 ; Coffey and Golden, 1957; Light, 1975).

Sjogren (1970) suggests that evaluation should move beyond specific content objectives, to processes, transactions, and antecedent conditions. He prefers the perception approach when the teaching environment has been changed as the result of an inservice experience. How is the environment perceived by the participants? Light (1975) also mentions the need for data based on the judgments and perceptions 
of those involved in programs being studied.

Meadows (1978) states that teachers' perceptions must be the source of data to determine the effectiveness of workshops. Observation of a teacher conducting a lesson or several disjointed lessonsegments by outside observers with or without video equipment is not appropriate for determining whether the inservice experience was the source of new knowledge or methods being displayed. A classroom lesson is not a simple discrete event. A lesson is frequently a diverse, continuous series of operations involving the teacher's whote repertoire from inception, lesson plannirg, objectives, activities, closure to final evaluation. The source and rationale for each step comes from the teacher.

What evidence do we have that a teacher's assessment or use of an innovation bears resemblance to what an outsider would observe? Limitations of the interview method include the bias resulting from the necessary involvement of the individual in the data being reported. The withholding and distorting of facts is difficult to control, particuiarly when the data is highly personal. The respondent may also be unable to provide certain information because of the nature of the questions asked. Memory bias is a third factor which must be considered.

Studies indicate that in quantitative assessments, such as number of dyadic interactions between pupils or IQ estimates, teachers perceptions are not accurate (Martin and Keller, 1974; Good and Brophy, 1973). In the realm of goals, purposes, ideas and tasks, their 
perceptions are more reliable.

A contrasting point of view concerning the validity of teachers' perceptions is stated by Goodlad (1971), describing a project directed by the University Elementary School, University of California at Los Angeles, whereby staff visited more than two hundred and fifty classrooms in more than one hundred schools and interviewed teachers and principals. Classroom observations revealed traditional teacherdominated classrooms with relatively little inductive reasoning encouraged.

An interesting finding came out of the interviews with teachers. In substantial contrast to our perceptions, they perceived their instruction to be marked by extensive use of inductive, inquiry approaches rather than deductive approaches to learning; attention to individual differences among students; a wide range of instructional materials; and a generally modern approach to education (p. 158).

It becomes clear that the perceptions of a teacher concerning what happens in his/her classroom and its relationship to inservice programs will be very different from that of an outside observer or student. The teacher is generally moving towards pre-planned gcals, and it may be difficult for others to be aware of the motivations and judgments guiding the teacher's decisions. This awareness supports a more thorough analysis of teacher motivation and viewpoints, goals and sources of decision-making. Knowledge of these factors will lead to a better understanding of how classroom practices and directions are determined. 


\section{Summary}

The first section of this chapter focused on issues related to the stage of formal operational thought, and provided an analysis of an application of the theory of equilibration to secondary science education, the learning cycle. It appears that formal operational thought is not a single, unified stage of cognitive development as originally thought. The learning processes characteristic of formal thought, however, may be valid goals to achieve, at least in certain areas of our thinking lives, and their achievement probably can be promoted by certain educational approaches more than others.

One of these approaches is a self-paced interactive workshop, Science Teaching and the Development of Reasoning, for secondary school science teachers, based on the theory of Jean Piaget. The goal of the workshops is for teachers to find out how their science teaching can be used to help their students improve their reasoning and conceptual understandings. Teachers also find out how they can interpret some of the reasoning patterns used by their students. The workshop combines group and individual activities that make use of films, puzzles, laboratory materials, discussions, and readings. Science texts and test questions, that are widely used in secondary science courses, are examined and analyzed in terms of the reasoning patterns required to understand them. The objectives of Science Teaching and the Development of Reasoning workshops are listed as follows: 
1. To assist teachers in distinguishing among various patterns of tnought used to solve simple problems in science.

2. To enable them to distinguish between concrete and formal reasoning patterns.

3. To assist them in describing and/or identifying responses that indicate concrete and formal reasoning patterns applied to Piagetian tasks.

4. To assist them in classifying science text passages in regard to their requirements for concrete and formal reasoning.

5. To give teachers an understanding of "selfregulation." To assist them in using the "learning cycle" approach to teaching for self-regulation.

6. To assist teachers in identifying and designing laboratory and field experiences that encourage self-regulation and promote the use of formal reasoning patterns.

7. To assist teachers in classifying science concepts on the basis of the patterns of reasoning needed to understand them.

3. To assist teachers in sequencing instruction so as to encourage self-regulation.

9. To assist teachers in recognizing, selecting, and designing test items that will be helpful in (1) evaluating student understanding and reasoning patterns and (2) encouraging self-regulation.

10. To assist teachers in selecting and utilizing teaching strategies that will encourage self-regulation on the part of their students.

11. To assist teachers in balancing course goals aimed at content with those aimed at improved reasoning.*

*Taken from Science Teaching and the Development of Reasonina, a Workshop by Robert Rarplus, et a). Lawrence Hall of Science, University of California, Berkeley, California (Copyright 1977 by The Regents of the University of California). 
The second section of the chapter presented a review of the literature in the areas of inservice programs and change theory. As new information about the process of innovation as applied to inservice programs was researched, certain factors emerged as being necessary for successful implementation of new programs. They included:

1. The importance of decision-making and choice in planning and implementing of inservice programs.

2. Support in the develupment of new skills necessary for innovation.

3. Awareness of and attention to the concerns of teachers regarding innovative ideas and practices.

4. Administrative and peer support for innovation.

5. The adaptation of innovative ideas.

These factors were used as the basis for an evaluation of the effects of Science Teaching and the Develogment of Reasoning workshops on the teaching behaviors of secondary science teachers in New England.

The final portion of this chapter included a literature search supporting the use of teachers' perceptions and viewpoints as a valid source of data for a study of the effect of a particular workshop approach. The instruments used for data collection to accompl ish the aims of this evaluation, questionnaires and interviews, rely primarily on the perceptions of the teachers who participated in the workshops. A description of this methodology will now be presented in Chapter III. 


\section{METHODOLOGY}

\section{Introduction}

This chapter describes the procedures used to accomplish the aims of this study. The instruments used for data collection will be discussed in turn, each description including the following, where appropriate:

-- Development of the Instrument

-- Population

-- Administrative Procedures

The second part of the chapter describes the use of the data to accomplish the purposes of the study. Each of the aims of the study is stated followed by a listing of the questions and materials which were used to address the issue, and a discussion as to how they were used.

\section{Instrumentation and Data Collection}

Information from the following sources was utilized for this study:

1. A twenty-nine item questionnaire developed and pre-tested by the researcher and sent to participants of Science Teaching and the Development of Reasoning workshops in New England. 
2. interviews with twenty secondary science teachers who indicated that they had used the ideas from these workshops in their classrooms and schools.

3. Materials prepared and submitted ty teachers who have attended the workshop. These are cur riculum materials which they feel illustrate the effects of these workshops on their teaching.

4. Telephone interviews with twenty secondary science teachers who did not respond to the questionnaire. This sample was randomly selected from participants of workshops in which the researcher had had no involvement with respect to organization or leadershio.

5. The "Stages of Concern" Questionnaire administered to tiventy-one junior high school teachers who attended a fourteen-hour reasoning workshop in Worcester, Massachusetts.

6. Evaluation of the workshops and dissemination project by the subcenter directors.

7. Workshop evaluations written by participants immediately following Science Teaching and the Development of Reasoning workshops.

A discussion of each of these instruments and materials used for data collection now follows.

Workshop evaluation questionnaire.

Deveiopment and pre-testing of the questionnaire. A twentynine item questionnaire was designed consisting of several sections (See Appendix B):

1. Demographic data about the respondents.

2. Questions employing a five-point Likert scale which identified:

a. Characteristics and philosophy of the workshop itself. 


\section{b. Factors in the school environment relevant to effective inservice pro- grams. \\ c. Applications of the ideas presented in the workshop.}

3. An open-ended question asking for specific examples of application of ideas from the workshop.

Content validity. The questionnaire was submitted to a panel of experts (three authors and consultants involved in the developing of the workshops), eight subcenter directors, four inservice specialists, and three educational research specialists. These authors, teachers, and researchers were requested to evaluate the instrument regarding its face validity, the form of the questions, length, and appearance. A second draft was then developed. Questions were rewritten, the questionnaire was shortened, and the form modified to facilitate data processing. It was again submitted to the panel of experts for approval.

The questionnaire was pre-tested with a population of twelve teachers who had participated in Science Teaching and the Development of Reasoning workshops, but who were not included in the current study. The questionnaire was further refined and reworded as a result of the pre-testing.

Reliability. The questionnaire was tested for reliability by using a test-retest procedure. A group of twenty, who responded initially to the questionnaire, were retested at the beginning of their interviews, approximately one month following their original filling out of the questionnaire, to assess the stability of the instrument 
over a short period of time. The instrument was scored by summing the responses to items eleven through twenty-eight and determining the Pearson Product Moment Correlation. A Pearson correlation coefficient of 0.8 was found. This is a significant correlation at the .001 level.

Questionnaire population. From over one thousand teachers who attended Science Teaching and the Development of Reasoning workshops in New England, two hundred and ten were selected for participation in this study. Those selected included all secondary science teachers who attended workshops which exceeded three hours in 1 ength, and whose addresses had been recorded. Questionnaires were sent to participants of workshops at fifteen locations. As can be observed from Table 1, one hundred and ten of the two hundred and ten questionnaires were returned.

Sixty of the one hundred and ten returned questionnaires included a response to the open-ended question asking for specific examples of applications of ideas from the workshop.

User interviews.

Development and pre-testing of the interview protocol. To gain a more complete understanding of the use and adaptation of the workshop ideas by participant teachers, interviews were conducted with twenty teachers.

Teachers responding to the workshop evaluation questionnaire, who were willing to be interviewed regarding their use of workshop materials and ideas, were requested to write their name, address, and 


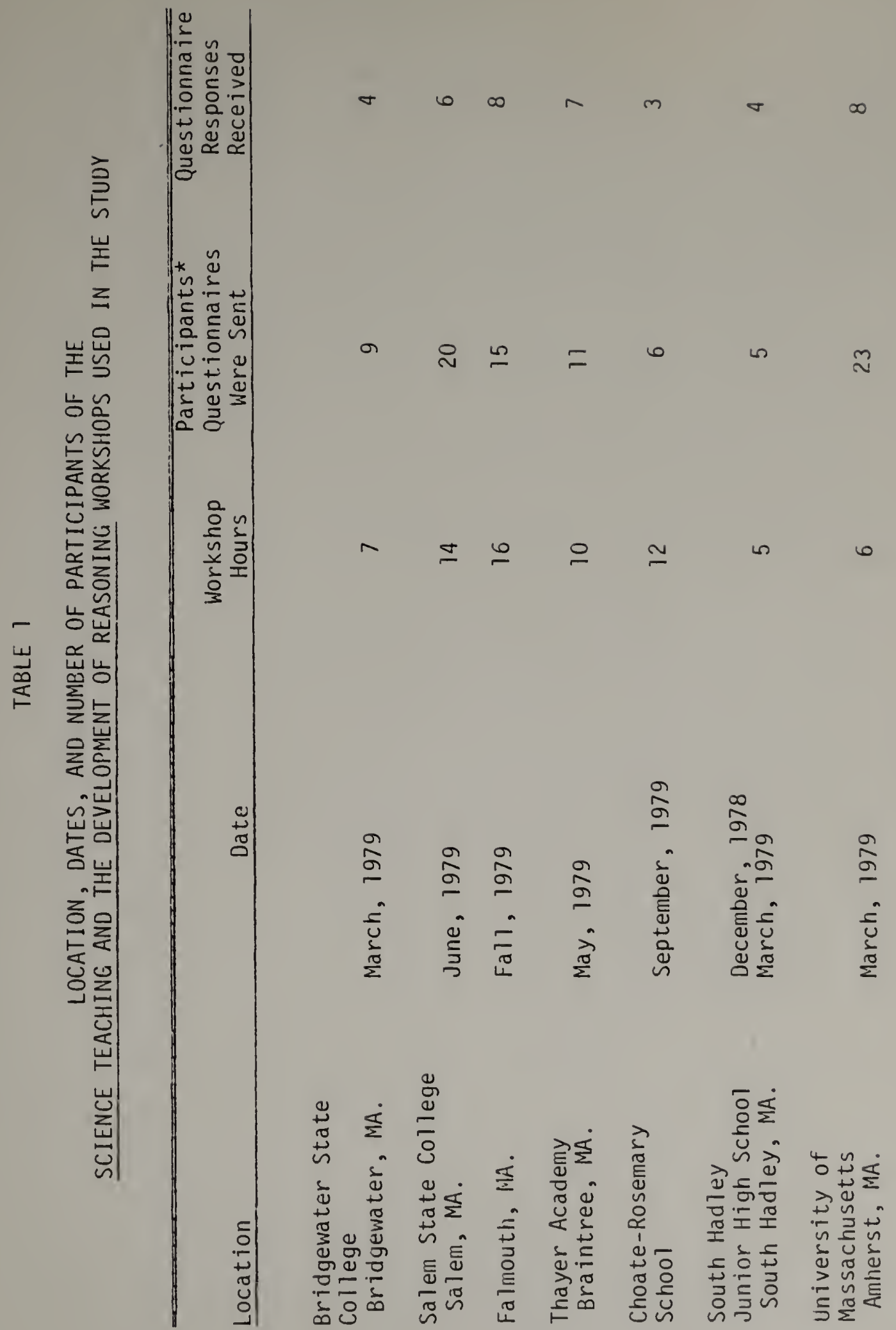




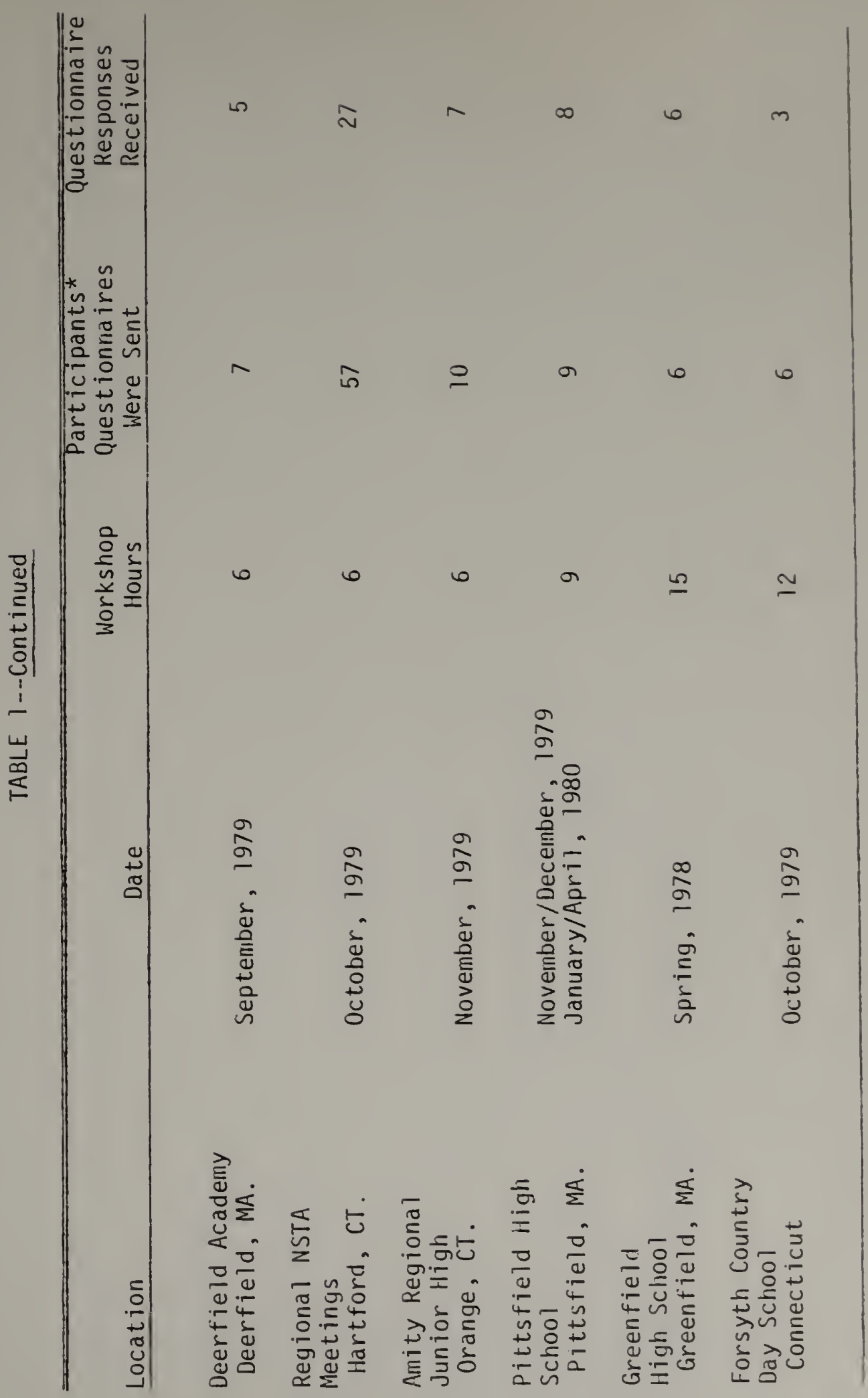




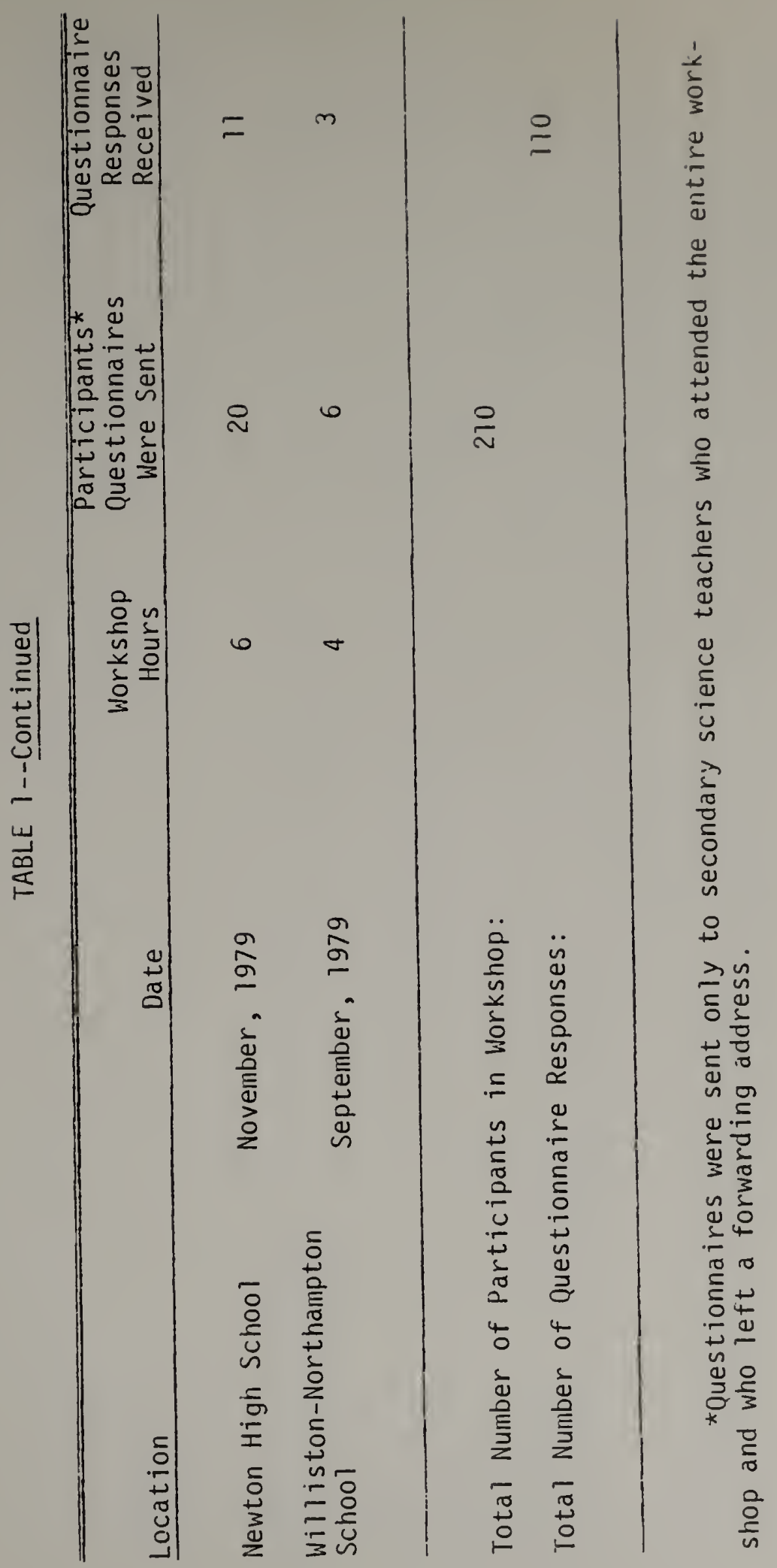


telephone number at the end of the questionnaire. Of the one hundred and ten returned questionnaires, thirty-one individuals indicated a willingness to be interviewed. Twenty of the thirty-one were selected at random to be interviewed.

A list of teachers affecting use of the workshop, as determined from the literature and summarized in Chapter II, was used as a guideline in designing the interview questions. The interview guide (See Appendix B) consisted of questions which focused the direction of the interview, but also allowed latitude for the interviewer. A highly structured interview was not utilized since responses to and uses of the workshop ideas were varied, and a good deal of usefut information would have been lost, without latitude provided by the interviewer.

In requesting information on how ideas from the workshop were used, the interviewer was careful not to mention specifics. For example, the following question was asked:

"Have you been able to use the workshop ideas in your teachings?" "In what specific ways?"

rather than:

"How did you use the workshop ideas in the laboratory?"

or:

"Did you use the workshep ideas in the iaboratory?"

This sort of questioning was an attempt to avoid suggestion on the part of the interviewer.

The interview questions were pre-tested on several teachers and department heads to determine whether the wording was clear and suited 
to the understanding of the audience, as well as to check the amount of time necessary to administer the interview. As a result, the order of the questions was modified to improve continuity. The interviews ranged from twenty to sixty minutes, depending on the time available, the amount of information collected, and the responsiveness of the teachers.

Interviewing procedures. Standard interview procedure was used in conducting the interviews. The interviewer was carefu? to put the respondents at ease by assuring them of the non-judgmental perspective of the researcher, the anonymity of responses, and her interest in their perspectives and perceptions. The statement was made that this information would be helpfui in determining whether workshops of this nature were useful, whether they should continue to be developed and funded, and what changes should be made if they were. Interviewees were willing to share ideas about the workshops, the uses they had made of them, and factors that either helped or hindered implementation.

Interviews were arranged by telephone and took place at each teachers'school, either during free periods or after school. Permission was obtained for the taping of all interviews.

Materials submitted by teachers. The interviewed teachers were requested to have available curriculum materials which they felt illustrated the effects of the workshops on their teaching. This was a useful additional source of data to supplement and corroborate the teachers' own perceptions as well as a basis for observing adaptation of the ideas of the workshop. 
Teachers, who had developed inaterials, were eager to share them. Some were received at the time of the interview; others were sent during the two months following the interviews.

Telephone interviews with non-responders. Twenty randomily sampled nonrespondents to the questionnaire were interviewed by telephone to determine their attitude towards the workshop. This was done to provide a basis of comparison with the teachers who responded to the aliestionnaire. This sample was selected from participants of workshops in which the researcher had had no involvement with respect to organization or leadership. This assured greater accuracy of response. The same interview guide as in the previously described interviews was used.

The Stages of Concern Questionnaire (SoCQ). The Stages of Concern Questionnaire was developed by the Texas Research and Development Center of Teacher Education at the University of Texas, Austin (Hall, George, and Rutherford, 1977), to assess the seven Stages of Concern about an innovation (See Figure 2). The SoCQ is a Likert-type instrument with a seven-point scale which allows respondents to respond to thirty-five statements of concern by indicating how closely each statement describes a concern that they feel at that particular time. Each Stage of Concern has five statements or items (See Appendix B).

The SoCQ has resulted from an extended tiwo and one-haif year procedure of item writing, Q sorting by a panel of judges, completion of a one hundred and ninety-five item prototype measure by three 
hundred and sixteen individuals and factor analysis. Seven factors corresponding to the seven Stages of Concern resulted from a VARIMAX rotation. Those items which loaded highest on each factor vere selected for the final instrument.

Test-retest reliability correlations of the SoC Questionnaire ranged from .65 to .86 on the seven Stages of Concern scores (Ha1?, George, and Rutherford, 1977, p. 11). Validity studies involving intercorrelation matrices, judgments of concerns based on interview data, and confirmation of expected group differences and changes over time have shown that the SoC Questionnaire measures Stages of Concern as they have been defined (George, 1977).

Data from the SoC Questionnaire are scored using a percentile table. An SoC profile is developed which shows the intensity of concern expressed by an individual on each Stage of Concern. A group profile can also be developed that describes the average intensity of concerns of individuals within the group being studied for each Stage of Concern.

Population (SOC Questionnaire). The group to whom the SOC Questionnaire was administered consisted of twenty-one junior high school teachers who attended a three session, fourteen-hcur workshop in Worcester, Massachusetts, during March 1980. The goal of the workshop was to assist the teachers to become aware of the reasoning levels of their students and to take these reasoning levels into consideration when designing curriculum. The "learning cycle" (exploration, concept introduction, and concept application) was experienced as one approach 
which allows students to move at their own developmental levels. Teachers were given the opportunity to design learning cycles appropriate to their own courses, cycles which they would then try out in their classrooms.

The SoC Questionnaire was administered to this group at the conclusion of the fourteen-hour workshop. Both individual and group profiles were developed.

Workshop evaluations by subcenter directors and workshop participants.

The subcenter directors of the project were requested to respond to an evaluation following the Directors' Conference, November 6-8, 1978, as well as at the project's termination. Evaluations were also filled out by participants immediately following workshops.

These evaluations were taken into consideration in improving subsequent workshops. They will be used in this study to determine the strengths and weaknesses of the workshops as perceived by the participants.

\section{Organization and Use of the Data}

The following section is organized according to the aims of the study as stated in Chapter I and researched in the literature in Chapter II. Each of the aims will now be restated followed by a list of collected data which are relevant to that aim. 
A. To determine whether teachers who participated in Science Teaching and the Development of Reasoning workshops in 1978 through 1979 felt that they had utilized the ideas of the workshops in changing their teaching style and methods.

1. Workshop Evaluation Questionnaire (Frequency Distributions)

Item 11: As a result of this vorkshop, I have become more aware of the reasoning processes of my students.

Item 18: I felt I could riot incorporate the ideas of the workshop into my teaching.

Item 20: I feel I should plan or teach some of my classes differently as a result of the workshop.

Item 23: I feel that some change in my teaching has occurred as a result of participating in this workshop.

Item 28: To what extent have you applied the ideas of the workshop in the following areas?

a. Laboratory Design

b. Use of Textbook

c. Introducing New Topics

d. Tests

e. Presentation of Concepts

f. Other (Explain)

2. User Interview Questionnaire

Question 2: Are you currently using the ideas and methods from the workshop?

Question 22: Can you summarize for me where you see yourself right now in relation to the use of the ideas of the workshop?

3. Telephone Interviews with Non-Responders

The same questions as listed under \#2 above. 
B. To determine the nature and extent of changes made which are consistent with the intent and philosophy of the workshop (Adaptation of (nnovation).

i. Workshop Evaluation Questionnaire

Item 29: If you have applied the ideas of the workshop in any of the above areas, please describe one or more examples.

2. User Interview Questionnaire

Question 3: Please describe ways you have used the ideas and methods from the workshop.

Question 5: Did you find that variations of the ideas of the workshop or going beyond the ideas of the workshop worked for you?

Question 6: In what ways do you feel you have adapted the workshop ideas to your own use and style?

3. Telephone Interviews with Non-Responders

4. Materials Prepared and Submitted by Teachers Which Illustrate the Effects of the Workshop on Their Teaching

C. To identify what factors teachers perceived either facilitated or hindered their ability to make changes.

Teacher Decision-Making and Choice:

1. Workshop Evaluation Questionnaire

Item 14: I was involyed in the decision to have the Science Teaching and the Development of Reasoning workshop at my school.

Item 15: The teachers generally have input into making decisions about inservice programs at my school.

Frequency distributions were determined for Items 14 and 15. 
Item 10: A T-test was done comparing voluntary and mandatory participation in the workshops with regard to application of the ideas of the workshop in the classrcom (Items 23 and 28).

2. User Interview Questionnaire

Question 18: Did you attend the workshop voluntarily?

Did that factor have any effect on your use of the workshop ideas?

Questicn 20: What have been your prior experiences with inservice workshops in your school?

Are you involved in the decisions about them?

Is participation required?

Characteristics of the Workshop as Perceived by Participants:

1. Evaluations of Participants Immediately Following Workshops

2. Workshop Evaluation Questionraire (Frequency Distributions)

Item 12: Most of secondary school science is appropriate for the developmental level of the students taught.

Item 13: The "learning cycle," as described in the workshop (exploration, concept introduction, and concept application), can be an effective way to teach secondary school science.

Item 16: The workshop addressed my individual concerns as a teacher.

Item 17: I had the opportunity to participate actively during the workshop.

Item 19: The workshop provided the opportunity to work and discuss with other participants. 
Item 21: The ideas of the workshop did not fit with what I already believed about teaching and learning.

Item 22: After the workshop, I agreed with the approach to teaching and learning presented in the workshop.

3. User Interview Questionnaire

Question 1: What is your overall reaction to the workshop as you reflect back on it at this time? Did you feel any differently immediately after you attended it?

Questions 9 and 10: What do you see as the strengths and weakness of the workshop?

Question 12: What are the most important points which you got out of the workshop?

Question 15: If the workshop were to be given again, do you have any suggestions for changes or additions?

4. Telephone Interviews with Non-Responders

Administrative and Peer Support During the Development of New Skills Necessary for Innovation:

1. Workshop Evaluation Questionnaire (Frequency Distributions)

Item 24: The morale in my school is high.

Item 25: My administration does not support changes I make in the direction of increased emphasis on reasoning development.

Item 26: I need more planning time during school hours if I am going to make any innovations in my science teaching.

Item 27: The issue of job security prevents me from being as innovative as I would like. 
A T-test was done comparing the responses of teachers who took the workshop with their whole department and independently with regard to application of the ideas of the workshop in the classroom (Items 23 and 28).

2. User Interview Questionnaire

Question 7: Have you talked with others and shared information regarding the workshop ideas?

Question 8: Have you worked with others on matters related to the workshop?

Question 16: What factors in your school situation helped you to use the ideas of the workshop?

Question 17: What prevents you from making more changes?

Question 21: What degree of trust and administrative support is there when you try out new ideas?

3. Telephone Interviews with Non-Responders

\section{Concerns of Teachers:}

1. Stages of Concern Questionnaire (Individual and Group Profiles)

2. User Interview Questionnaire

Question 13: What are your major concerns about the workshop and its ideas at the present time?

Question 22: Can you summarize where you see yourself right now in relation to the use of the ideas of the workshop?

3. Interviews with Non-Responders

4. Evaluation of the Workshops and Dissemination Project by the Subcenter Directors

5. Workshop Evaluations Written by Participants Immediately Following Workshops 


\section{Additional Factors:}

To determine what additional factors may be related to the application of workshop ideas in the classrooms, the first eight items of the workshop evaluation questionnaire (See Table 2):

1. Total Number of Workshop Hours

2. Number of Months since Attending the Workshop

3. Present Grade or Teaching Level

4. Total Number of Years Teaching

5. Subject Areas Taught

6. Highest Degree Earned

7. Sex

8. Size of Classes Taught

were cross-tabulated with Items 23 and 28 which indicate the extent of use of workshop ideas.

A cross-tabulation analysis with the chi-square test of statistical significance as a measure of association was done. The variables indicating use of the ideas of the workshop used in the cross-tabulation analys is were:

1. The response to Statement 23 of the questionnaire.

Statement 23: "I feel that some charge in my teaching has occurred as a result of participating in this workshop."

Both the categories "Strongly Agree" and "Agree" were grouped together under the category "Agree". Both the categories "Strongly Disagree" and "Disagree" were grouped together to simplify the analysis.

2. The responses to Question 28.

Question 28: "To what extent have you applied the ideas of the workshop in the following areas? 


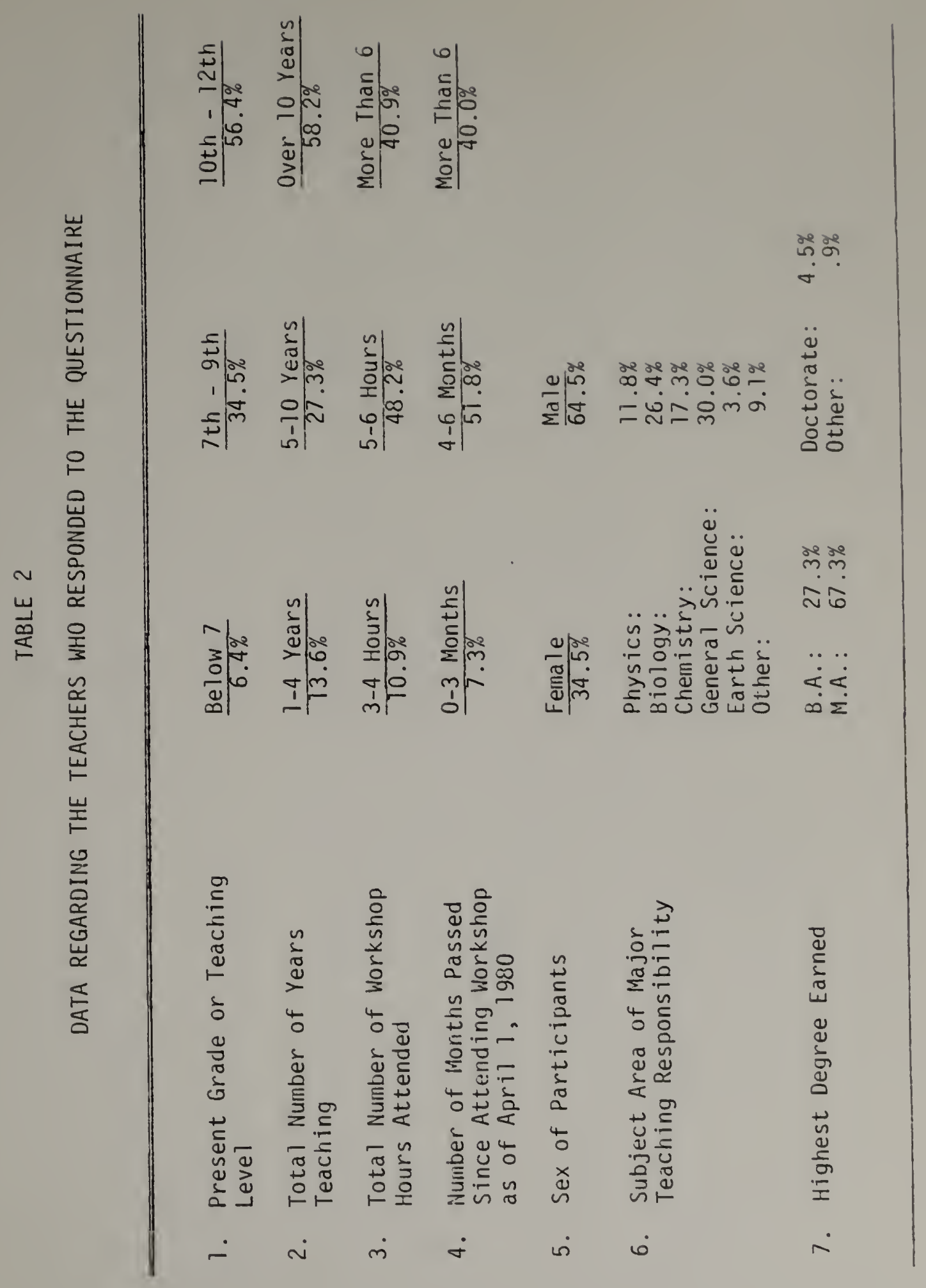




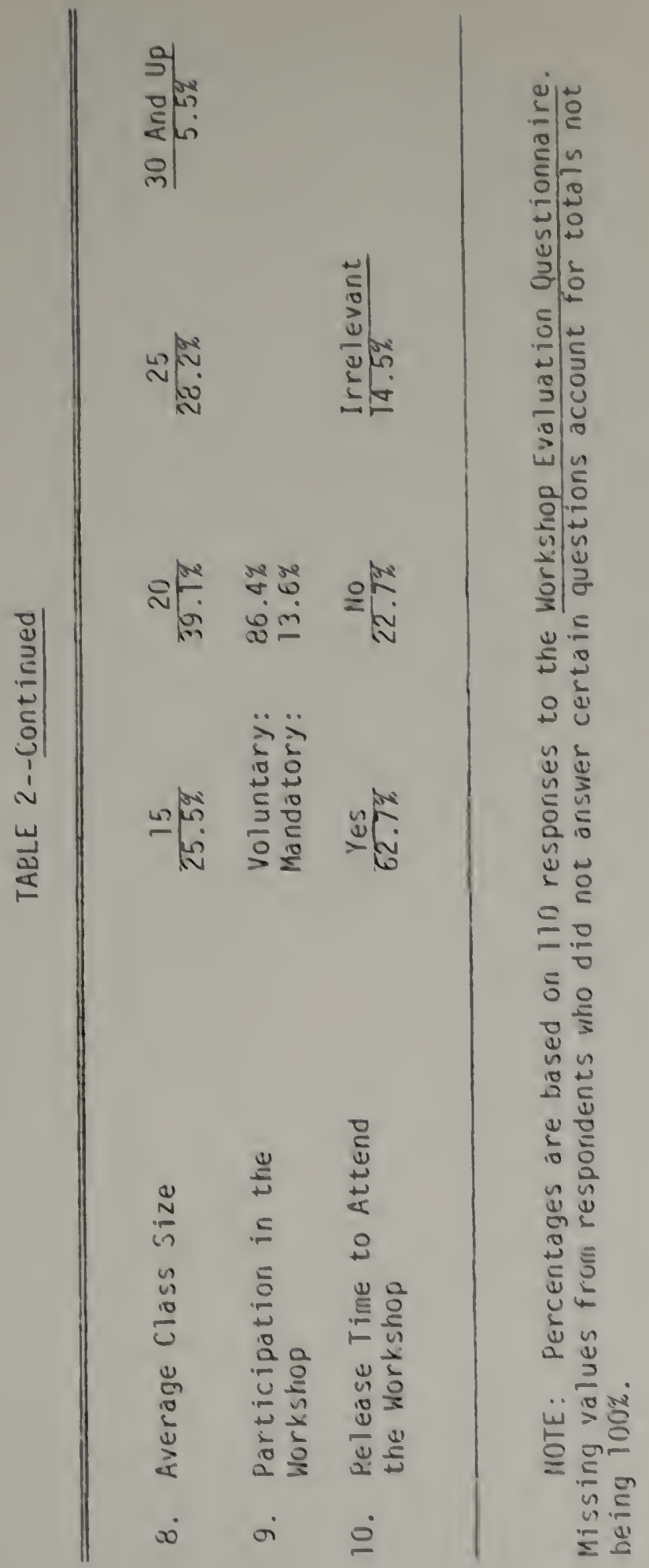


a. Laboratory Design

b. Use of Textbook

c. Introducing New Topics

d. Tests

e. Presentation of Concepts

Extent of use of each of these areas (ranging from "Not At All" to "A Great Deal") was cross-tabulated with the eight factors listed above. 


\author{
CHAPTER IV \\ DESCRIPTION AND ANALYSIS OF OATA
}

\title{
Introduction
}

This study was designed to determine whether teachers who participated in Science Teaching and the Cevelopment of Reasoning workshops during 1978 through 1979 felt that they had used the ideas of the workshop in changing their teaching style and methods; to determine the nature and extent of changes made; and to identify and describe factors which the teachers perceived as either facilitating or hindering their ability to make changes.

The description and analysis of this chapter utilized daca from the Workshop Evaluation Questionnaire and interviews with twenty secondary science teachers who responded to the questionnaire indicating that they had used the ideas from the workshop in their classrooms. Additional data included teacher prepared materials, results from the Stages of Concern Questionnaire, evaluations written immediately following workshops, and telephone interviews with twenty non-responders to the questionnaire.

These data will now be presented and analyzed with respect to the stated purposes of the study. 


\section{Reported Utilization of Workshop ideas}

The frequency distributions of the responses to items on the 'Norkshop Evaluation Questionnaire which report changed attitudes, teaching style, and methods are shown in Table 3 . Of the one hundred and ten who responded to the questionnaire, eighty-nine percent indicated that they had become more aware of the reasoning processes of their students, and seventy-nine percent felt that they should plan or teach some of their classes differently as a result of the workshop. Seventyfive percent felt that they could incorporate the ideas of the workshop into their teaching, whereas seventy-three percent indicated that some change in their teaching had occurred as a result of participating in the workshop. Table 4 indicates the extent to which the responding teachers felt they had applied the ideas of the workshop in the areas of laboratory design, textbook use, introduction of new topics, presentation of concepts, and testing. The greatest amount of change was reported in the introduction of new topics and the presentation of concepts and the least in the use of the textbook.

of the twenty "users" who were interviewed, ail were positive about the workshop, but they divided into three groups with regard to their leve? of use of the workshop ideas. Four were aiready familiar with the information and orientation from reading or from previous workshops and reported using the ideas in their classes. They attended the workshop to ga in further information and ideas for application. 


\section{TABLE 3}

EFFECTS OF SCIENCE TEACHING AND THE DEVELOPMENT OF REASONING WORKSHOPS

As a result of the workshop, teachers became more aware of the reasoning processes of their students.

$89.7 \%$

$6.4 \%$

Teachers felt they could incorporate the ideas of the workshop into their teaching.

The teachers felt they should plan or teach some of their classes differently as a result of the workshop.

$79.1 \% \quad 12.7 \%$

The teachers felt that some change in their teaching had occurred as a result of participating in the workshop.

$73.6 \% \quad 14.5 \%$

$11.9 \%$

NOTE: Percentages are based on 110 responses to the Workshop Evaluation Questionnaire. A grouping of data was made for clarification. See Appendix B (Täble 15). 
TABLE 4

APPLICATION OF THE IDEAS OF SCIENCE TEACHING AND THE DEVELOPMENT OF REASONING WORKSHOPS IN LABORATORY DESIGN, USE OF TEXTBOOKS, INTRODUCING NEW TOPICS, PRESENTING CONCEPTS, AND TESTING

\begin{tabular}{lccc}
\hline \hline & $\begin{array}{c}\text { Not At All to } \\
\text { Very Little }\end{array}$ & $\begin{array}{c}\text { Moderately to } \\
\text { Considerably }\end{array}$ & $\begin{array}{c}\text { Undecided or } \\
\text { Not Applicable* }\end{array}$ \\
\hline & & & \\
$\begin{array}{l}\text { Laboratory } \\
\text { Design }\end{array}$ & $37.2 \%$ & $49.1 \%$ & $13.7 \%$ \\
$\begin{array}{l}\text { Use of } \\
\text { Textbook }\end{array}$ & $42.8 \%$ & $44.5 \%$ & $12.7 \%$ \\
$\begin{array}{l}\text { Tests } \\
\text { Introducing }\end{array}$ & $30.0 \%$ & $60.9 \%$ & $9.1 \%$ \\
New Topics & $20.0 \%$ & $72.6 \%$ & $7.4 \%$ \\
$\begin{array}{l}\text { Presentation } \\
\text { of Concepts }\end{array}$ & $13.7 \%$ & $80.0 \%$ & $6.3 \%$ \\
& & & \\
\hline
\end{tabular}

NOTE: Percentages are based on 110 responses to the Workshop Evaluation Questionnaire. A grouping of data was made for clarification. See Appendix B (Table 15).

* Some teachers do not include laboratories in their courses; others do not use a text. 
Half of the interviewees reported having made distinct changes since attending the workshop. Examples of these changes will be presented in this chapter. The third group of six feit that their awareness of the reasoning processes of students had been raised, but that they had not made specific changes. A similar change in awareness was expressed by eighty-nine percent on the questionnaire and by all of those interviewed, who were not oreviously familiar with the workshop. One seventh and eighth grade science teacher expressed this change as follows:

I look at students more carefully now, at what their capabilities are. I am aware of the possibility that students can't handle something not because they don't work hard enough, but rather because they are not ready for the material. It takes a change in mind set, to realize that there are some concepts in science traditionally taught in junior high which shouldn't be taught there. It takes some adjustment to take some concepts that you've been teaching for years and feel are an integral part of science, and say to yourself, "I should really substitute something else."

As well as a new view of student capabilities, this heightened awareness included the reasoning requirements of textbooks and laboratory manuals.

In summary, approximately ninety percent of the teachers responding to the Workshop Evaluation Questionnaire reported looking at their students and their course content with a new level of awareness. Many of these (see Table 4) have been able to translate this awareness into action. The next section of the chapter will present the nature and extent of changes which have been made, followed by a discussion of factors which facilitate these changes. 


\section{Interview Analysis}

Tables 5 and 6 show the number of teachers interviewed who indicated that they had used the ideas of the workshop to make changes in their teaching in the areas of concept presentation, laboratory design, and procedure, use of textbooks, and evaluation. The greatest number of changes were reported in methods of presenting topics and introducing concepts, with the least number of changes in use of textbooks. These results were similar to those from the Workshop Evaluation Questionnaire with regard to relative frequency of changes in the different aspects of science teaching.

Analysis of interview transcripts and curriculum materials provided by teachers reveals varying interpretations on the part of the teachers with regard to the meaning of the terms "concrete," "formal," and "exploration," three important concepts upon which the workshop approach being evaluated is based.

Although the terms "formal" and "concrete" were used freely by all of the teachers interviewed, two explicitly stated that they were not sure at times which concepts in their courses were formal and which concrete. In the words of one:

I went to the seminar that Karplus gave and was amazed that he thought that a problem that I had used on a chemistry exam was as difficult as it was. I conciuded that I was being much more formal than I thought I was.

Other teacher comments which illustrate a confusion between formal and concrete operational thinking are quoted below: 


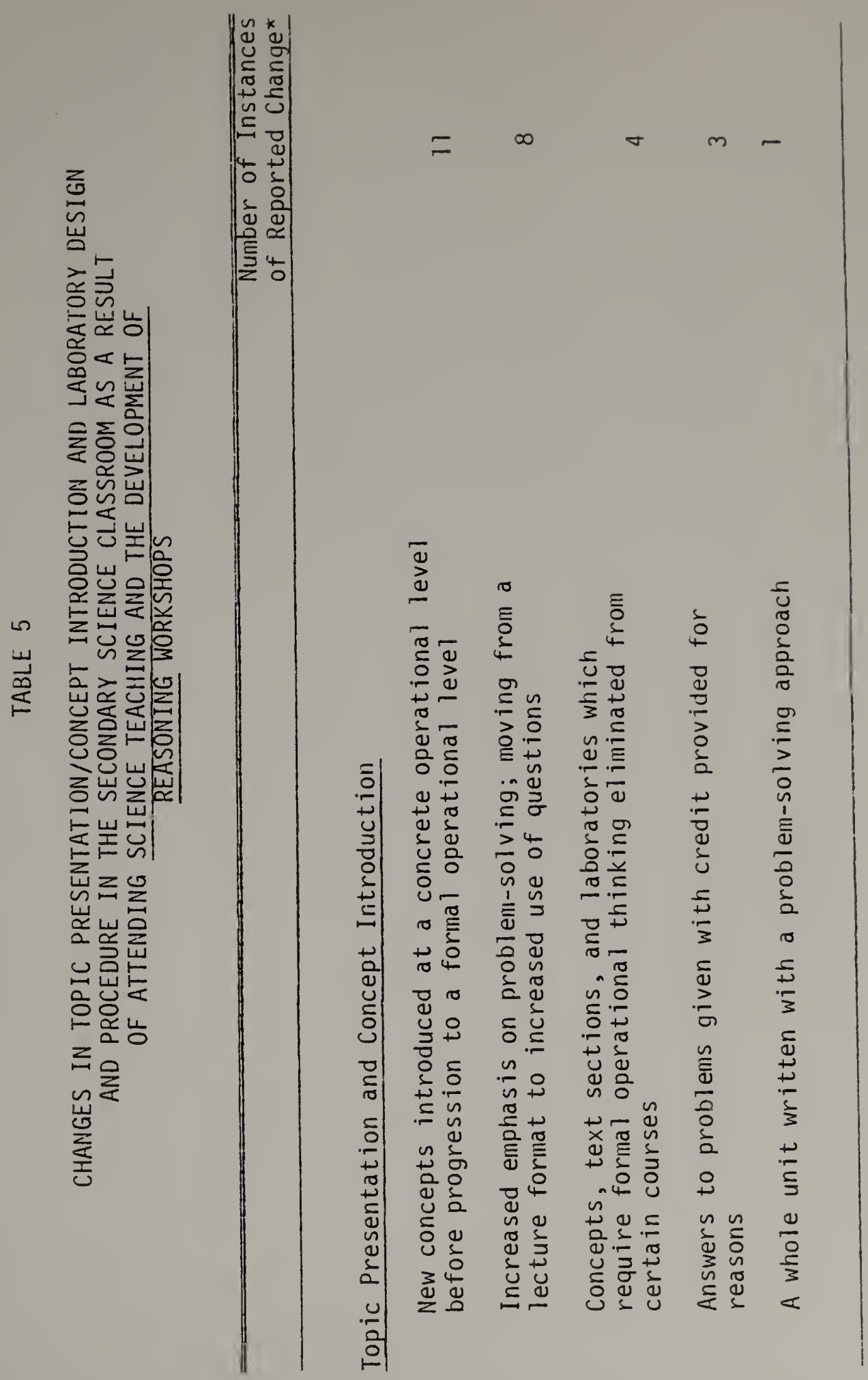




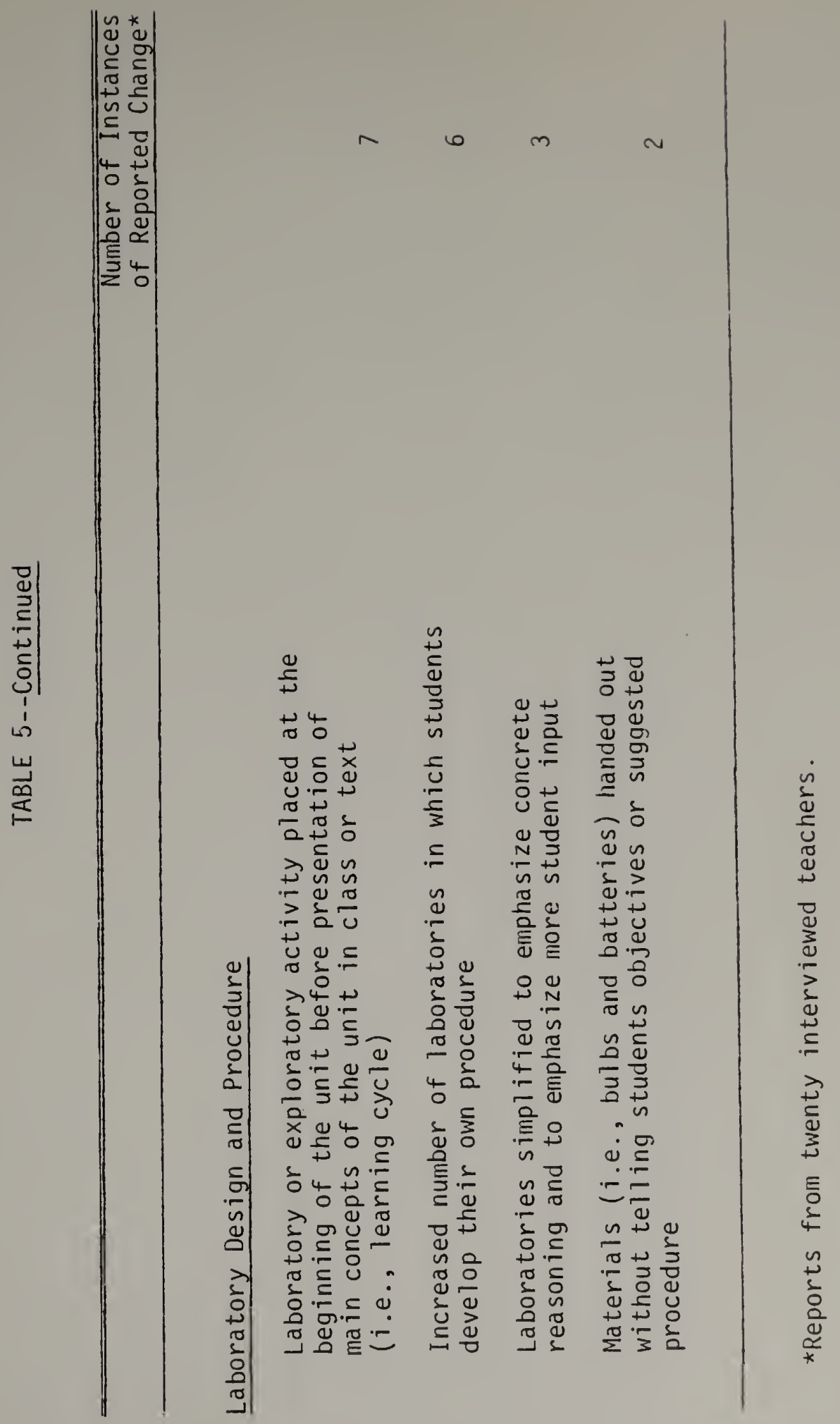



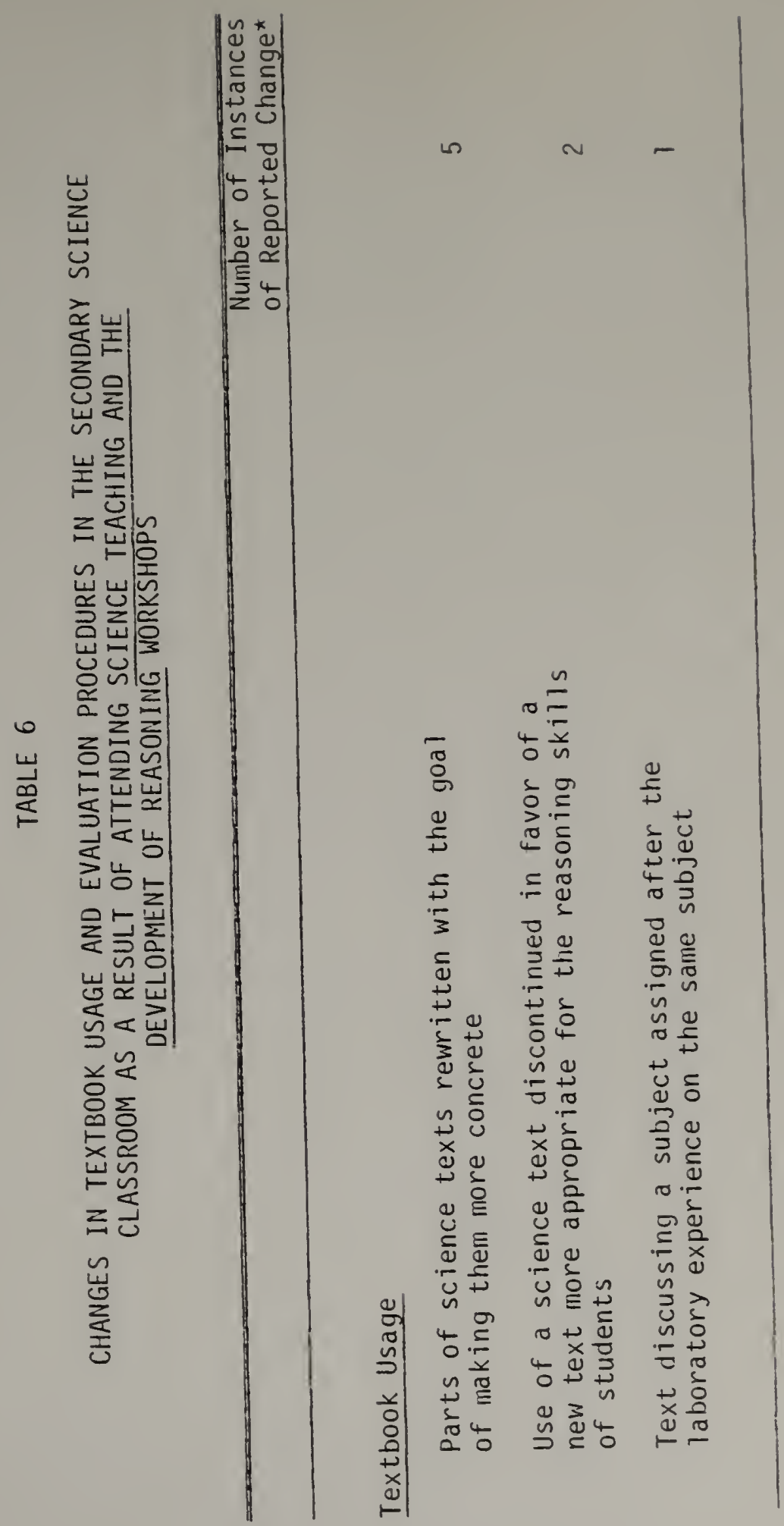


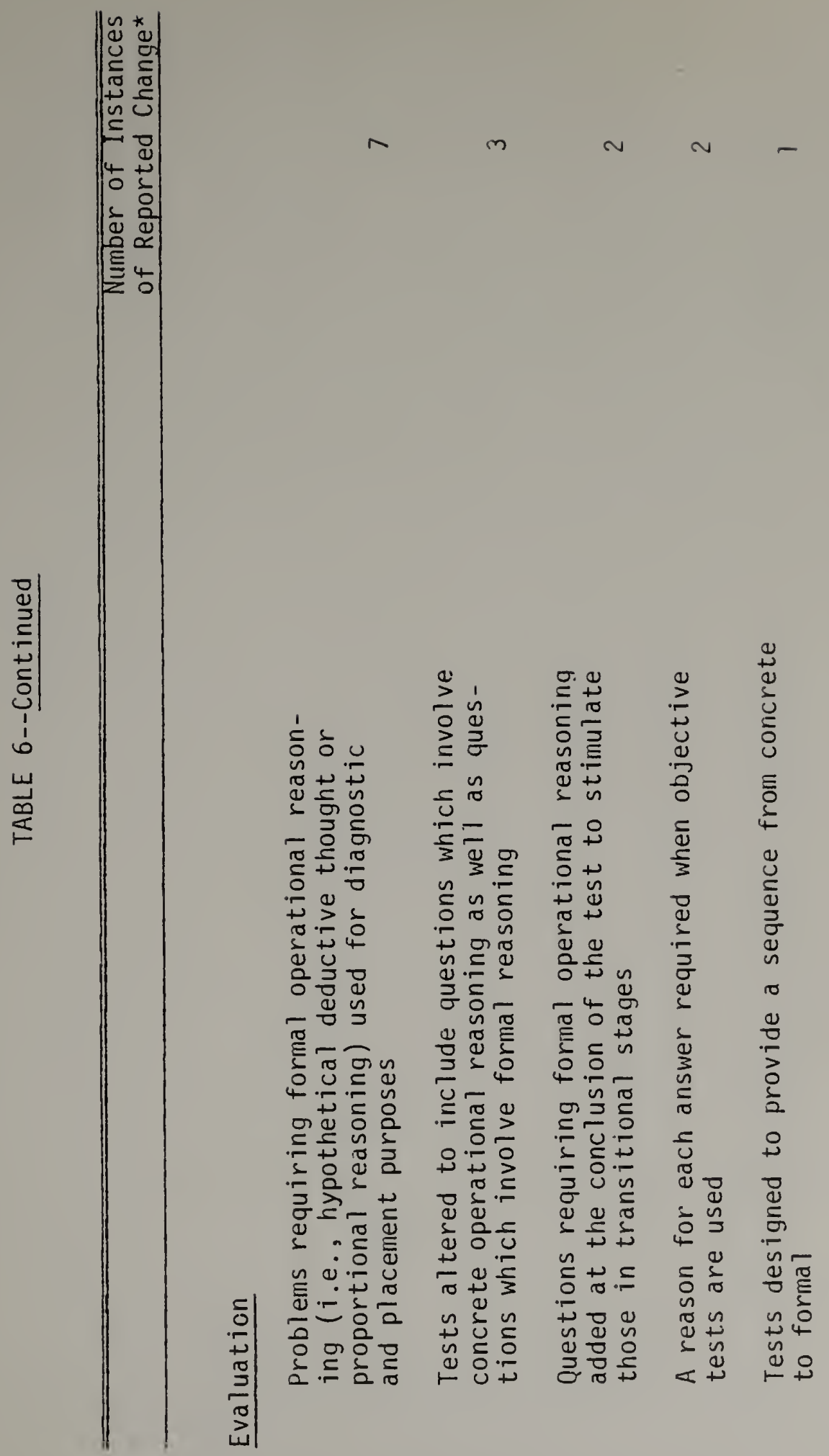


Chemistry is the perfect model for the development of reasoning. For one thing, it is concrete.

I didn't know how to introduce areas that used a threedimensional imagination. I tried by personifying chemistry. "These molecules have an attraction to each other. They form a bond." It made them view electronic chemistry on a more concrete level. They liked it better.

A common misconception, as observed in the abcve quote, was that using "concrete" methods of presentation, such as diagrams, demonstrations, models, historical and everyday examples, and discovery type experiments make a concept which requires formal operational thought to understand, more concrete. A confusion exists between effective teaching methods and those which promote cognitive development. Concrete models and analogies may be effective ways to illustrate formal concepts, but there is no evidence to indicate that concrete operational thinkers will move to formal operational thought with respect to a certain concept as a result of exposure to these models.

The following quote describes the use of a "concrete experience" such as presenting data to introduce new topics:

Every time I start a new topic, I start with some kind of concrete experience: I either do an experiment or give them some data, have them look at the data very carefully and see what conclusions they draw. If they draw improper conclusions, that's OK. After a while, if they are not drawing the right ones, I will present them with another possibility and eventually we get to the ideas we are trying to arrive at.

This teacher does not seem to realize that presenting data to be analyzed often requires formal operational thinking. In addition, al though the teacher professes to encourage thinking, there is a strong emphasis on reaching the predetermined "right answer." In this case, "we get to 
the idea we are trying to arrive at" appears to mean "I present the important ideas."

Four of the twenty teachers interviewed mentioned el iminating the teaching of concepts which require formal operational thinking in their classes. This suggests that many continue to teach formal concepts to students who are not developmentally prepared to understand them, as illustrated by the following attempt to teach multiple proportions to middle school students:

We're dealing right now with the "fasteners and rings" experiment, an introduction to the law of multiple proportions. i don't dare call it that, but the kids really have a hard time because they can't do it. There are ratios involved. I make sample data sheets for them. A lot leave here not knowing what was done to them in that particular experience.

The rationale expressed by this teacher for presenting proportions to eighth graders is that even though the students are presently confused as a result of this experience, they will understand proportions better when they get to chemistry.

One of the teachers interviewed had written a new unit for his advanced biology course in which the emphasis was on defining problems, formulating hypotheses, and designing experiments to solve the problems.

This first unit of the year was defined as a study of problems in experimentation, uncertainty, measurement, data organization, data analysis and reporting of results. According to the teacher:

Whenever possible, concrete material is presented before abstract, definitions are not presented of each activity, and students are expected to master concepts prior to naming the concept. 
Analysis of the unit by this researcher revealed procedures clearly outlined by the teacher, including graphs already made for reporting data. In spite of stated emphasis on moving from concrete to formal in the material, little evidence of this was observed.

The interviews revealed that al though most of the twenty interviewed showed concern atout the problem, only three or four could provide evidence that they understood the difference between concrete and formal, and had used this understanding to make changes. One of the few whose interview and curriculum materials indicated that she understood the difference observed:

With some groups of students, I hardly get into the formal at all any more. It is almost as though they have a safety valve where as soon as I start getting abstract, their heads start going down on their desks, and the doodles appear on the notebooks. When I get back down into the concrete again, give them things, bring in cow eyes, and have something they can see and touch and feel, they perk up.

This teacher stated that she had stopped using anything beyond a simple monohybrid ratio in teaching genetics in her non-college oriented biology classes.

The concept of "the learning cycle," the idea of placing a laboratory activity or "exploratory" activity before presentation of the main concepts of the unit, had reportedly been used by seven of the twenty teachers interviewed. There was no agreement, however, on what the term "exploration" meant. Examples described and/or sent by workshop participants showed a range from structured laboratory exercises and demonstrations to a totally unstructured experimentation with materials. 
Statements from two teachers indicated a tendency toward laboratories that directly conflict with the intent and philosophy of the workshop:

It is important to reinforce college-style teaching. I want to use less observational labs and more quantitative, measurement labs.

and,

My laboratory design is now more tightly linked to class discussion and lecture material.

Four other interviewees described "exploraticn" as allowing students time to experiment with the material before the "right answer" is presented. For example:

I allowed the students a certain time period to come up with their own responses, and the majority of them did come out with something very close to the actual response.

You can let them play with things for a while and after they have wasted some time, lead them down the right path.

My idea of the learning cycle is some kind of experiment, the rethinking of $i t$, getting to the right idea.

One teacher considered the following laboratory constructing

pulleys, an exploration:

The problem is to construct several pulley systems to raise a cylinder. You will design each system on paper and predict the force required to raise the cylinder. Then you will build each system and measure the force. In addition, you will measure the distance you must pull to raise the cylinder $10 \mathrm{~cm}$. Your first pulley system should consist of a single pulley. The second system will contain two pulleys. The third system will contain more than two pulleys (use your imagination). Record your diagrams, predictions, and measurements below.

Close scrutiny of these laboratory directions reveals a definite structure with little room for innovation or originality. The teacher 
stated, however, that the students were confused by the lack of direction, and that he will give more specific directions in the future.

An attempt to make a laboratory experience on mitosis more exploratory is described below in the words of the teacher:

In previous years, students were asked to learn the stages of mitosis. These were presented in the text, and outlined and labelled on the board. Then they looked under the microscope at examples of the different stages which they identified and labelled.

To achieve a greater understanding of the process of mitosis, I tried a new approach this year. I began by having the students examine a large group of slides of Whitefish embryos undergoing mitosis. The word mitosis was not mentioned nor discussed before this experience. They were asked to pick six different looking cells, draw them, and put them aside. They then repeated the process with onion root tip slides. They then observed a fiim of mitosis without sound and saw the process occurring with no labelling. They then went back to each of the six cells they had drawn and put them in some sort of sequence similar to the film they had seen. They were then asked to explain what they did and why they did it. They were then asked to arrange models in stages and describe the process.

The word, mitosis, was only mentioned after the exploration, and the usual terminology of the different stages was completely omitted, being considered unnecessary if the process was understood.

This teacher reported that the students' understanding of mitosis following this experience was superior to that of previous years. They became less confused by the terminology used to describe the process. Three other teachers aiso mentioned that certain aspects of laboratories such as terminology have become simplified as the laboratories become more exploratory.

All of the teachers interviewed expressed difficulty with the concept of a completely open exploration, the "here are the materials; 
see what you can discover" approach. One probiem is the amount of time necessary to implement such an approach. Another is classroom management, control, and safety.

In summary, it was evident from interviews and teacher-prepared materials that although the majority of the teachers who responded to the questionnaire were aware of and attempting to apply the ideas of the workshop, different interpretations remained with regard to concrete and formal operational thought, and effective ways to approach science concepts, topic introduction, the reading of textbooks, and evaluation. In spite of a variety of interpretations of the meaning of "exploration," more than twenty specific examples of laboratories and field experiences were described as "exploratory" by the questioned and interviewed teachers, all of which showed a tendency to move away from teacher direction towards increased activity and initiative on the part of the student (see Appendix C).

\section{Factors Affecting Teacher Change}

A series of factors which are known to affect teachers' ability to make changes in their teaching were discussed in cinapter II. These include :

-- Teacher decision-making and choice

-- Characteristics of a workshop as perceived by participants

-- Administrative and peer support

-- Concerns of teachers

-- Additional factors 
In response to open-ended questions posed during the twenty user interviews, numerous factors were mentioned by the teachers which they felt limited their ability to apply the ideas of the workshop in their classrooms. These are listed in Table 7. Further discussion of these factors will be included under the five headings above.

Teacher decision-making and choice.

T-test. The literature, as described in Chapter II, suggests that teacher choice has an important relationship to implementation of ideas from inservice programs. To determine whether teachers who voluntarily attended the Science Teaching and the Development of Reasoning workshops used the information and ideas of the workshop more than those who were required to attend, a T-test was done comparing the mean responses of these two groups with regard to their use of the workshop ideas. The particular responses tested were those of Question 28 of the questionnaire regarding implementation of the workshop ideas in the following areas:
a. Laboratory Design
b. Use of Textbook
c. Introduction of New Topics
d. Tests
e. Presentation of Concepts

Because workshop leaders were aware of the importance of voluntary participation, they encouraged the science department heads of the schools where workshops were being given to make them optional. As a 
TABLE 7

FACTORS MENTIONED BY TEACHERS DURING THE TWENTY USER

INTERVIEWS WHICH LIMITED THEIR ABILITY TO APPLY

THE IDEAS OF THE WORKSHOP IN THEIR CLASSROOMS

\begin{tabular}{ll}
\hline \hline Factors & $\begin{array}{c}\text { Number of Teachers who } \\
\text { Menticned It }\end{array}$ \\
\hline $\begin{array}{l}\text { Lack of knowledge, including applica- } \\
\text { tion in specific subject areas }\end{array}$ & 15 \\
Isolation from other interested teachers & 14 \\
Lack of preparation time & 12 \\
Necessity of covering content & 5 \\
Administrative lack of support & 2 \\
Parent expectations & 2 \\
Text used is differently oriented & 2 \\
Refusal to sacrifice content for & 2 \\
reasoning emphasis & 1 \\
No way to test the learning that has & 1 \\
taken place & 1 \\
Heterogenous groups in classes & 1 \\
Physical facilities & 1 \\
Class size & 1 \\
Lack of supervision & \\
Inertia & \\
&
\end{tabular}

*These factors were mentioned by teachers spontaneousiy during the interview. They were not articulated specifically by the interviewer. 
result, only fifteen of the one hundred and ten respondents to the questionnaire did not attend the workshop voluntarily.

No significant difference at the .05 level was found in responses of teachers who took the workshop voluntarily and those who attended because it was mandatory. These results were contrary to expectation and were not in agreenent with previous studies. This could well be due to the small size of the sample (one hundred and ten) and the uneven number of cases in each category; i.e., Voluntary (ninetyfive) and Mandatory (fifteen).

Interview and questionnaire analysis. Forty-four of the one hundred and ten respondents attended workshops at their own school, and approximately one half of these were involved in the decision to have the workshop. Table 8 shows that $63 \%$ of ail the respondents indicated that they generally have input into decisions made about inservice programs at their schools. All of the interviewed teachers who have inservice programs at their schools stated that their input was welcome regarding ideas for workshops. Participation is required at activities held during school hours, but generally there is a choice among several. For all of those who had been a participant at a workshop at their own school, this was the first workshop they had attended specifically addressing secondary science teachers.

Seven science department heads who were interviewed reported that the majority of their science teachers do not wish to attend inservice programs at $a 11$ and do not take advantage of the opportunity to suggest programs to their department heads for curriculum days at 
TABLE 8

TEACHER DECISION-MAKING AND CHOICE

\begin{tabular}{lccc}
\hline & Yes & No & $\begin{array}{c}\text { Not } \\
\text { Applicable* }\end{array}$ \\
\hline $\begin{array}{l}\text { I was involved in the decision } \\
\text { to have the Science Teaching and } \\
\text { the Development of Reasoning }\end{array}$ & & & \\
workshop at my school. & $21.8 \%$ & $31.8 \%$ & $46.4 \%$ \\
$\begin{array}{l}\text { Teachers generally have input } \\
\text { into making decisions about } \\
\text { inservice programs at my } \\
\text { school. }\end{array}$ & & & \\
\end{tabular}

NOTE: Percentages are based on 110 responses to the Workshop Evaluation Questionnaire. A grouping of data was made for clarification. See Appendix B for complete table.

*A large number of teachers attended the workshop at conferences or locations other than their own school. (See Table 2.) 
their schools. The large attendance at workshops at conferences indicates that interested teachers look outside their schools for programs which interest them.

Characteristics of the workshop. From the responses recorded in Table 9 , it is clear that a large percentage of the responding teachers agreed with the theoretical basis of the workshop and feit that the content was reievant to their teaching. Since most of the teachers attended the workshops voluntarily due to interest in the subject of the workshop, a high level of basic agreement with the ideas was expected. Individual written evaluations by participants immediately following workshops also indicated that the ideas discussed in the course of the workshop were considered relevant by the majority of participants. A sample of the range of ideas from the workshop considered most important to participants is presented below:

-- Some materials in science classes are inappropriate for some students.

-- There are ways to identify the types of reasoning a student uses.

-- Students progress from concrete operational through a transitional stage to formal operational in their thinking.

-- Students are at different levels in the same grades.

-- Looking at student thought processes is relevant to teaching.

-- Self-regulation is a way of learning.

-- Self-regulation involves a level of frustration. 
STATEMENTS RELATED TO THE CONTENT AND THEORETICAL BASIS

OF THE SCIENCE TEACHING AND THE DEVELOPMENT OF REASONING WORKSHOP

\begin{tabular}{|c|c|c|c|}
\hline & Agree & Disagree & Undecided \\
\hline $\begin{array}{l}\text { Most of secondary school } \\
\text { science teaching is appro- } \\
\text { priate for the developmental } \\
\text { level of the students taught. }\end{array}$ & $36.4 \%$ & $50.0 \%$ & $13.6 \%$ \\
\hline $\begin{array}{l}\text { The "learning cycle," as } \\
\text { described in the workshop } \\
\text { (exploration, concept intro- } \\
\text { duction, and concept applica- } \\
\text { tion), can be an effective } \\
\text { way to teach science. }\end{array}$ & $88.2 \%$ & $4.5 \%$ & $7.3 \%$ \\
\hline $\begin{array}{l}\text { The workshop addressed the ir } \\
\text { individual concerns as a } \\
\text { teacher. }\end{array}$ & $79.1 \%$ & $14.5 \%$ & $6.4 \%$ \\
\hline $\begin{array}{l}\text { The ideas of the workshop fit } \\
\text { with their previous beliefs } \\
\text { about teaching and learning. }\end{array}$ & $84.6 \%$ & $10.9 \%$ & $4.5 \%$ \\
\hline $\begin{array}{l}\text { After the workshop, they } \\
\text { agreed with the approach to } \\
\text { teaching and learning } \\
\text { presented in the workshop. }\end{array}$ & $81.0 \%$ & $4.5 \%$ & $14.5 \%$ \\
\hline
\end{tabular}

NOTE: Percentages are based on 110 responses to the Workshop Evaluation Questionnaire. A grouping of data was made for clarification. See Appendix B for complete table. 
-- The learning cycle, i.e., an exploratory approach, is an alternative to the lecturediscussion method.

-- Introduction of a concept through laboratory activities before discussing it is cften appropriate.

-- The emphasis on hands-on activities has a theoretical base. Teachers need to get down to the thinking level of the students and build from there.

Since the workshop focused on how individuals learn, it was crucial to the planners that the workshop experience itself modeled the learning theory upon which it was based. There were strong indications from the responses of participants that this did indeed occur, as indicated in Table 10.

Specific comments about other aspects of workshop presentations were obtained from evaluations immediately following the workshops, from comments on the questionnaire, and during the interviews. These are divided into:

\section{Strengths}

-- A good balance of practical and theoretical.

-- Hands-on activities rather than lecture.

-- Introduction of concepts through activities before discussion occurred.

-- Excellent order of presentation and variety of activities.

-- High involvement during the workshop.

-- Exercises done with partners.

-- Workshop organization consistent with the ideas being presented. 
TABLE 10

STATEMENTS DESCRIBING THE MANNER IN WHICH THE WORKSHOP WAS CONDUCTED

Agree isagree

$97.3 \%$

$0.9 \%$

$1.8 \%$

The workshop provided the opportunity to work and discuss with cther participants.
$96.3 \%$

$2.8 \%$

$0.9 \%$

NOTE: Percentages are based on 110 responses to the Workshop Evaluation Questionnaire. A grouping of data was made for clarification. See Appendix B (Table 15). 
-- Testing of own reasoning abilities ano finding out that people attack problems such as proportional reasoning in totally different ways.

\section{Weaknesses}

-- More time needed to digest the material. (This was particularly mentioned by those in workshops of six hours or less.)

-- More time needed for reading and reflection before coming to conclusions.

-- More help needed in setting up a curriculum on this model.

-- When teachers participating in the workshop were not reasoning formally themselves, a problem arose. They didn't understand and became frustrated. For these people, the workshop, largely dealing with formal concepts, emphasized their weaknesses rather than their strengths.

In summary, the large majority of teachers attending Science Teaching and the Development of Reasoning workshops and responding to the Workshop Evaluation Questionnaire were in agreement with its philosophical and learning base. The conducting of the workshop was also consistent with and modeled the ideas experienced. The most significant weakness repeatedly mentioned by teachers was the length of the workshop. Lack of time for participants to understand thoroughly and assimilate the ideas, as well as develop curriculum materials based on these ideas, resulted in teacher concerns which could not be resolved without follow-up. These concerns are discussed in a later section of this chapter. 


\section{Administrative and Peer Support}

Administrative support was considered necessary by all inter-

viewed teachers for implementation of ideas from the workshop. In the words of one teacher:

Having emotional support and being in an environment where risk-taking is okay is important. I feel I could be the biggest risk-taker in the world, but unless there is a clear and direct message from my superiors that they want it that way, you can forget about it.

Lack of administrative support, however, was not considered by these teachers to be a problem as can be seen in Table 11 . Of the responders to the questionnaire, less than $10 \%$ indicated that their administration does not support changes they make in the direction of increased emphasis on reasoning development. However, in spite of statements of support of both the workshops and ideas represented by them from the administration, in only one case was this support translated into the necessary time to revise curriculum. It is difficult to revise a curriculum which has been taught for many years because of the time and energy necessary to overcome the inertia which maintains the patterns of the past.

Perceived administrative pressure to "cover the material" tends to counteract any innovation that takes more than the time allotted for that topic. This was perceived as a particular problem in college preparatory courses in which the college board examinations determine the material to be taught. Over one-half of the teachers interviewed complained of a rigid curriculum which does not allow for much "exploration." As expressed by a private school biology teacher: 
TABLE 11

ISSUES RELATED TO ADMINISTRATIVE SUPPORT

\section{Yes}

No

Undecided

The teachers felt that their administration supports changes they make in the direction of increased emphasis on reasoning development.

$69.1 \% \quad 8.2 \% \quad 22.7 \%$

More planning time during school hours is needed for innovation in their science teaching.

$65.5 \% \quad 22.7 \% \quad 11.8 \%$

The teachers felt that the issue of job security prevents them from being as innovative as they would like. $10.9 \% \quad 72.7 \% \quad 16.4 \%$

The morale in my school is high.

$41.8 \% \quad 40.0 \% \quad 18.2 \%$

NOTE: Percentages are based on 110 responses to the Workshop Evaluation Questionnaire. A grouping of data was made for clarification. See Appendix B (Table 15). 
We all have to teach the same thing at the same time. And we also have to prepare the kids to take the achievement tests in biology. Although I hate to teach for an exam, it's not fair to them not to prepare them.

We see our kids for three single periods and one double period per week, and cover a chapter a week of about twenty to thirty pages. We don't have any time to explore a given topic. We really have to get down to the nuts and bolts in the quickest possible way.

I have an intern from Antioch who wanted to do a game he had made up to illustrate how a nerve impulse travels along a neuron, but it took fourteen minutes to illustrate how a nerve impulse travels when you've got to cover the entire nervous system in three days. You just can't.

Not only does this quote show the lack of support by the administration for teacher individuality in methods and objectives, but also the frustration of this teacher regarding her inability to use the time available within the given schedule in ways which she feels are profitable. It also shows a lack of understanding that there may be ways to promote reasoning development within rigid time schedules without sacrificing content.

Two teachers noted that it is difficult for parents to accept the "development of reasoning" as a major goal, since it is not measured by the traditional grading system. Parents then say to the teacher who is trying this approach, "You say he is learning, but how do I know?" Teachers could benefit from simulated parent conferences showing a teacher explaining the child's grades in terms of reasoning. The teachers also expressed a need for administrative support which reached into other more undefined areas, a good atmosphere which provides reinforcement and feedback for innovation. Only $42 \%$ of the 
teachers responding stated that the morale in their school was high.

This was expressed in a variety of ways as illustrated by the following quotes:

Especially when you spend six hours coming up with something you think is really great. It bombs, and you're not sure why it bombed. Perhaps because it was two days before vacation, not because the lab was not good. With no reward or reinforcement for creativity, you get kind of tired of putting out the effort. Emotionally, unless you have a back-up of support, it is very hard.

Teachers need to be in a stabie situation where they're not worried about jobs, where the administration, the town, and the school committee are education oriented. Then that framework provides a nice, warm cocoon to grow, develop, and try to change. Currently, we begin to feel that nobody gives a darn what I do anyway, so why shouid I knock myself out. Let's face it. Any of these approaches is more emotionally consuming, more physically demanding than handing out a book, telling kids to answer questions number 1 to 10 , and then giving them a test.

Although administrative support was considered to be of prime importance, desire for the support of colleagues was mentioned by fourteen of the twenty interviewed teachers (see Table 7). Continuing innovative efforts on one's own was considered to be very difficult. Two examples will now illustrate the demoralizing effects of lack of colleague support, with a third ending on a more positive note. Not within the realm of this study, but important to consider when considering these examples, is the skill of developing colleague support for new ideas.

One biology teacher felt the need to work with others like herself who have difficulty recognizing formal abstractions in their courses. She found that newly developed laboratories must be run several times to determine their strengths and weaknesses. With 
several teachers working together, this process could be shortened. Because of the lack of this mutual interest at her own school, conventions take on an increasing importance for her. They have become an opportunity to share ideas and receive feedback. When she returns, she has now impetus to introduce, modify and add to what she is already doing.

Another teacher stated that lack of support in her department makes modification of curriculum extremely difficult. The laboratory manual used is written by two members of the department and is sold to the students in September, resulting in considerable pressure to use it. This teacher has the difficult problem of learning how to focus on reasoning development within a very structured situation.

Finally, on the more positive side is a physics teacher who reports a favorable teaching situation with a high level of trust and support from his department chairman and superintendent, who actively encourages the new approaches he is attempting. This has resulted in double laboratory periods for more extended exploratory-type iaboratories. Colleagues have been supportive to the extent of requesting him to present his ideas at a department faculty meeting.

I-test results. Earlier, we hypothesized that individuals from science departments that took the workshop together as a group would apply the ideas to a greater extent than teachers who took the workshop individually. The latter return to their school, frequently the only members of their department familiar and enthusiastic about the ideas. Therefore, a T-test was done comparing the mean responses 
of those teachers who took the workshop with the science department at their school and those who attended individually, with regard to their responses to Question 28 on the questionnaire:

To what extent have you applied the ideas of the workshop in the following areas?
a. Laboratory Design
b. Use of Textbook
c. Introducing New Topics
d. Tests
e. Presentation of Concepts

Of the five areas, "Laboratory Design" was the only one to show a significant difference in the means of the two groups at the .05 level. Teachers taking the workshop with their department felt that they had changed their laboratory design and procedures to a greater degree (see Table 12).

The fact that a significant difference did not appear in other areas of the curriculum may reflect the fact that the situations in which whole departments took workshops together were often not ideal. In some cases, attendance at the workshop was mandatory and the attitudes of those forced to attend a workshop against their will and interest was not ideal for implementation. In addition, teachers who attended workshops independently were frequently highly motivated, traveling long distances at their own expense. These factors may have resulted in no significant difference between the two groups with regard to implementation of the ideas.

The exception with regard to changes in laboratory design may reflect the fact that these changes are the most complex to implement. 


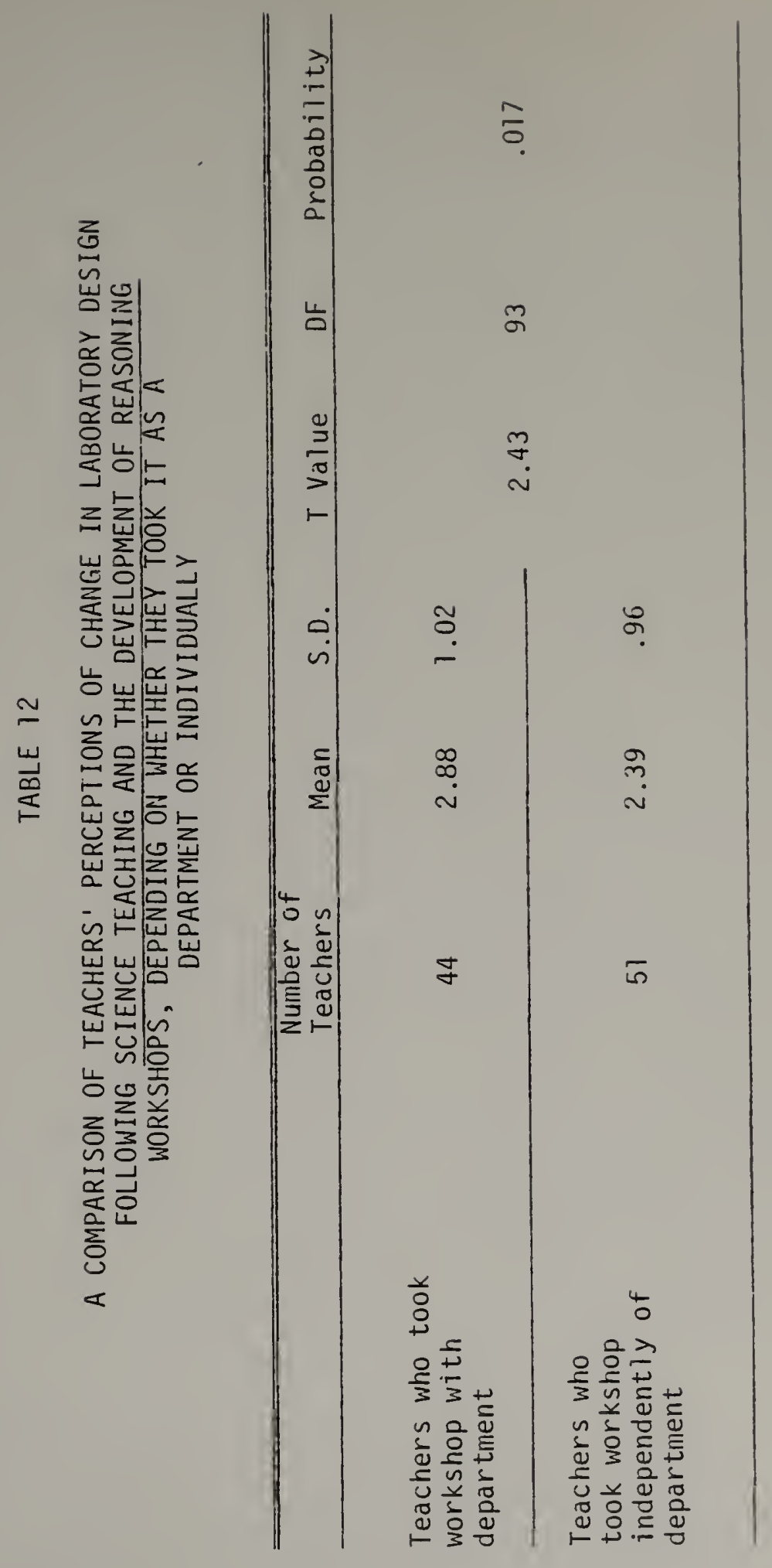


Less structured laboratories may need more departmental support and frequently result from discussion with colleagues, perhaps more so than altering tests and ways of presenting new concepts, etc. It is certainly easier to change laboratories in a department that supports the change and is familiar with the philosophy behind the change.

To summarize, the results support the hypothesis that administrative and peer support is necessary to implement ideas from inservice workshops. Changes in the classroom occur to the extent that administrative support is translated into time, both in class preparation, in scheduling, and in curriculum demands. Administrative and peer support result in improved morale which provides the atmosphere for innovation. Teachers quoted in this section described the support problems involved in changing their teaching style and course material in the direction of increased emphasis on reasoning.

Concerns of teachers. A discussion of the relevancy of the concerns of teachers to the implementation of innovations in the classroom was discussed in Chapter II. In Chapter III, the development and validation of the Stages of Concern Questionnaire were described. The population to which this questionnaire was administered consisted of twenty-one teachers who had just completed a fourteen-hour development of reasoning workshop.

Interpretation of the high score for both individual and group data was based directiy on the Stages of Concern About the Innovation definitions which were presented in Figure 2. The stage scores were 
related to the stage definitions with the relative intensity of concern being indicated by the percentile score. The higher the score, the more intense the concerns at that stage.

Table 13 is a listing of the Individual Stage of Concern Percentile scores for the curriculum innovation, the Learning Cycle Approach. At the bottom of the table, the individual data were aggregated by developing a profile that presents the mean scores for each stage of the individuals in the workshop. Table 14 is a tally of the number of individuals that are high on each stage. This gives a picture of the range of peak stage scores within a group.

These group averages indicate that the highest scores were at Stages 0, 1, and 2. Those with their highest staue of concern at Stage 0 showed an awareness of and concern for the innovation. A high Stage 1 score indicated an interest in having more descriptive information about the innovation. Those individuals were concerned about what the innovation was and what their use of the innovation would entail.

High Stage 2 scores indicated personal concerns, the "self" concerns described by Fuller (1969). These may reflect feelings of inadequacy, uncertainty about roles, rewards, decision-making, and personal conmitment. These personal concerns, when high, tend to block out more substantive concerns about the innovation. 


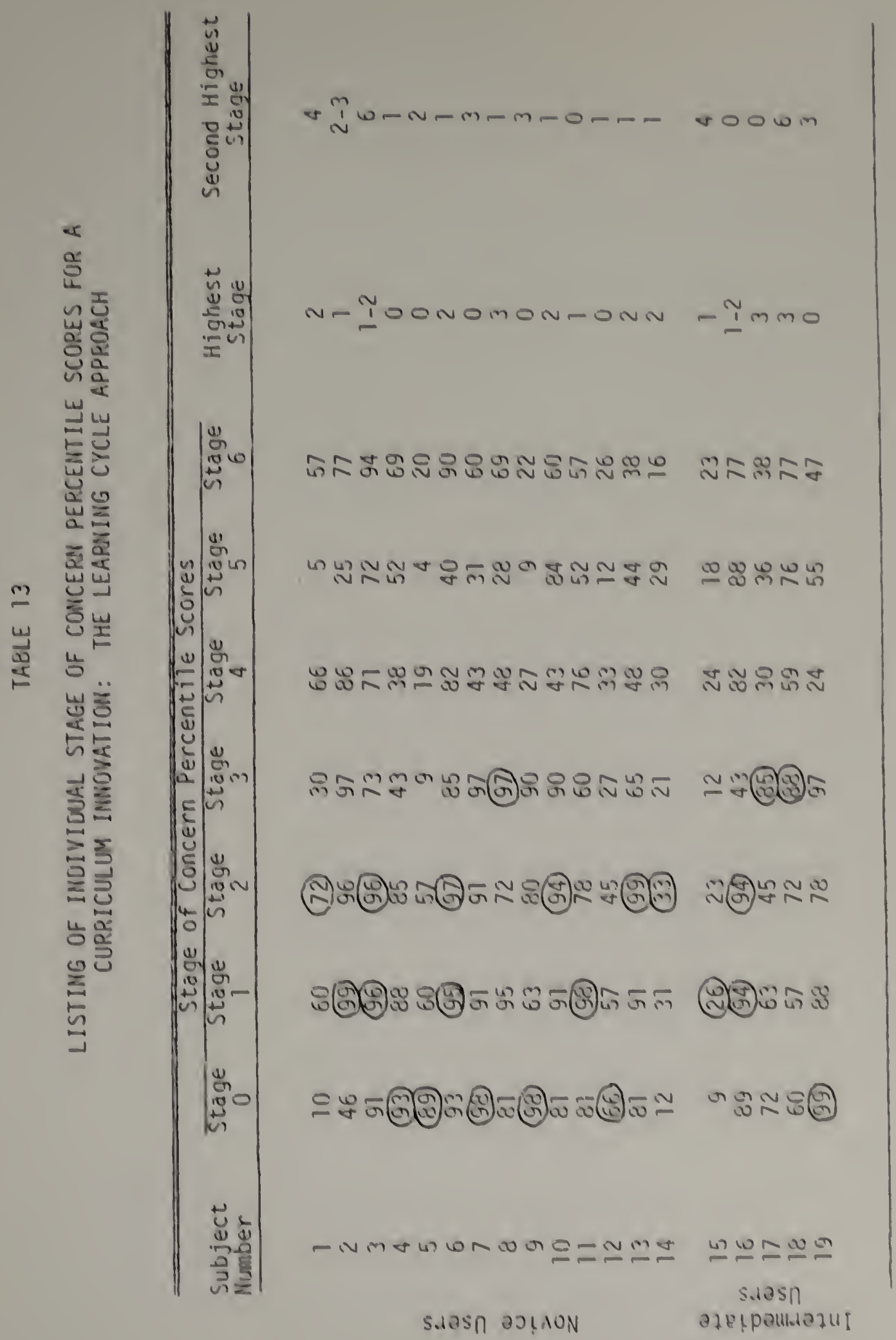




\section{Administrative and Peer Support}

Administrative support was considered necessary by all inter. viewed teachers for implementation of ideas from the workshop. In the words of one teacher:

Having emotional support and being in an environment where risk-taking is okay is important. I fee I I could be the biggest risk-taker in the world, but unless there is a clear and direct message from my superiors that they want it that way, you can forget about it.

Lack of administrative support, however, was not considered by these teachers to be a problem as can be seen in Table 11. Of the responders to the questionnaire, less than $10 \%$ indicated that their administration does not support changes they make in the direction of increased emphasis on reasoning development. However, in spite of statements of support of both the workshops and ideas represented by them from the administration, in only one case was this support translated into the necessary time to revise curriculum. It is difficult to revise a curriculum which has been taught for many years because of the time and energy necessary to overcome the inertia which maintains the patterns of the past.

Perceived administrative pressure to "cover the material" tends to counteract any innovation that takes more than the time allotted for that topic. This was perceived as a particular problem in college preparatory courses in which the college board examinations determine the material to be taught. Over one-half of the teachers interviewed complained of a rigid curriculum which does not allow for much "exploration." As expressed by a private school biology teacher: 
The teachers felt that their administration supports changes they make in the direction of increased emphasis on reasoning development. $69.1 \% \quad 8.2 \% \quad 22.7 \%$

More planning time during school hours is needed for innovation in their science teaching.

$65.5 \% \quad 22.7 \% \quad 11.8 \%$

The teachers felt that the issue of job security prevents them from being as innovative as they would like.

$10.9 \% \quad 72.7 \% \quad 16.4 \%$

The morale in my school is high.

$41.8 \% \quad 40.0 \%$

$18.2 \%$

NOTE: Percentages are based on 110 responses to the Workshop Evaluation Questionnaire. A grouping of data was made for clarification. See Appendix B (Table 15). 
We all have to teach the same thing at the same time. And we also have to prepare the kids to take the achievement tests in biology. Although I hate to teach for an exam, it's not fair to them not to prepare. them.

We see our kids for three single periods and one double period per week, and cover a chapter a week of about twenty to thirty pages. We don't have any time to explore a given topic. We really have to get down to the nuts and boits in the quickest possible way.

I have an intern from Antioch who wanted to do a game he had made up to iliustrate how a nerve impulse travels along a neuron, but it took fourteen minutes to illustrate how a nerve impulse travels when you've got to cover the entire nervous system in three days. You just can't.

Not only does this quote show the lack of support by the administration for teacher individuality in methods and objectives, but also the frustration of this teacher regarding her inability to use the time available within the given schedule in ways which she feels are proitable. It also shows a lack of understanding that there may be ways to promote reasoning development within rigid time schedules without sacrificing content.

Two teachers noted that it is difficult for parents to accept the "development of reasoning" as a major goal, since it is not measured by the traditional grading system. Parents then say to the teacher who is trying this approach, "You say he is learning, but how do I know?" Teachers could benefit from simulated parent conferences showing a teacher explaining the child's grades in terms of reasoning.

The teachers also expressed a need for administrative support which reached into other more undefined areas, a good atmosphere which provides reinforcement and feedback for innovation. Only $42 \%$ of the 
teachers responding stated that the morale in their school was high.

This was expressed in a variety of ways as illustrated by the following quotes:

Especially when you spend six hours coming up with something you think is really great. It bombs, and you're not sure why it bombed. Perhaps because it was tivo days before vacarion, not because the lab was not good. With no reward or reinforcement for creativity, you get kind of tired of putting out the effort. Emotionally, unless you have a back-up of support, it is very hard.

Teachers need to be in a stable situation where they're not worried about jobs, where the administration, the town, and the school committee are education oriented. Then that framework provides a nice, warm cocoon to grow, develop, and try to change. Currently, we begin to feel that nobody gives a darn what I do anyway, so why should I knock myself out. Let's face it. Any of these approaches is more emotionally consuming, more physically demanding than handing out a book, telling kids to answer questions number 1 to 10 , and then giving them a test.

Although administrative support was considered to be of prime importance, desire for the support of colleagues was mentioned by fourteen of the twenty interviewed teachers (see Table 7). Continuing innovative efforts on one's own was considered to be very difficult. Two examples will now illustrate the demoralizing effects of lack of colleague support, with a third ending on a more positive note. Not within the realm of this study, but important to consider when considering these examples, is the skill of developing colleague support for new ideas.

One biology teacher felt the need to work with others like herself who have difficulty recognizing formal abstractions in their courses. She found that newly developed laboratories must be run several times to determine their strengths and weaknesses. With 
several teachers working together, this process could be shortened. Because of the lack of this mutual interest at her own school, conventions take on an increasing importance for ner. They have become an opportunity to share ideas and receive feedback. When she returns, she has now impetus to introduce, modify and add to what she is already doing.

Another teacher stated that lack of support in her department makes modification of curriculum extremely difficult. The laboratory manual used is written by two members of the department and is sold to the students in September, resulting in considerable pressure to use it. This teacher has the difficult problem of learning how to focus on reasoning development within a very structured situation.

Finally, on the more positive side is a physics teacher who reports a favorable teaching situation with a high level of trust and support from his department chairman and superintendent, who actively encourages the new approaches he is attempting. This has resulted in double laboratory periods for more extended exploratory-type laboratories. Colleagues have been supportive to the extent of requesting him to present his ideas at a department faculty meeting.

T-test results. Earlier, we hypothesized that individuals from science departments that took the workshop together as a group would apply the ideas to a greater extent than teachers who took the workshop individually. The latter return to their school, frequently the only members of their department familiar and enthusiastic about the ideas. Therefore, a T-test was done comparing the mean responses 
of those teachers who took the workshop with the science department at their school and those who attended individually, with regard to their responses to Question 28 on the questionnaire:

To what extent have you applied the ideas of the workshop in the following areas?
a. Laboratory Design
b. Use of Textbook
c. Introducing New Topics
d. Tests
e. Presentation of Concepts

Of the five areas, "Laboratory Design" was the only one to show a significant difference in the means of the two groups at the .05 level. Teachers taking the workshop with their department felt that they had changed their laboratory design and procedures to a greater degree (see Table 12).

The fact that a significant difference did not appear in other areas of the curriculum may reflect the fact that the situations in which whole departments took workshops together were often not ideal. In some cases, attendance at the workshop was mandatory and the attitudes of those forced to attend a workshop against their will and interest was not ideal for implementation. In addition, teachers who attended workshops independently were frequently highly motivated, traveling long distances at their own expense. These factors may have resulted in no significant difference between the two groups with regard to implementation of the ideas.

The exception with regard to changes in laboratory design may reflect the fact that these changes are the most complex to implement. 


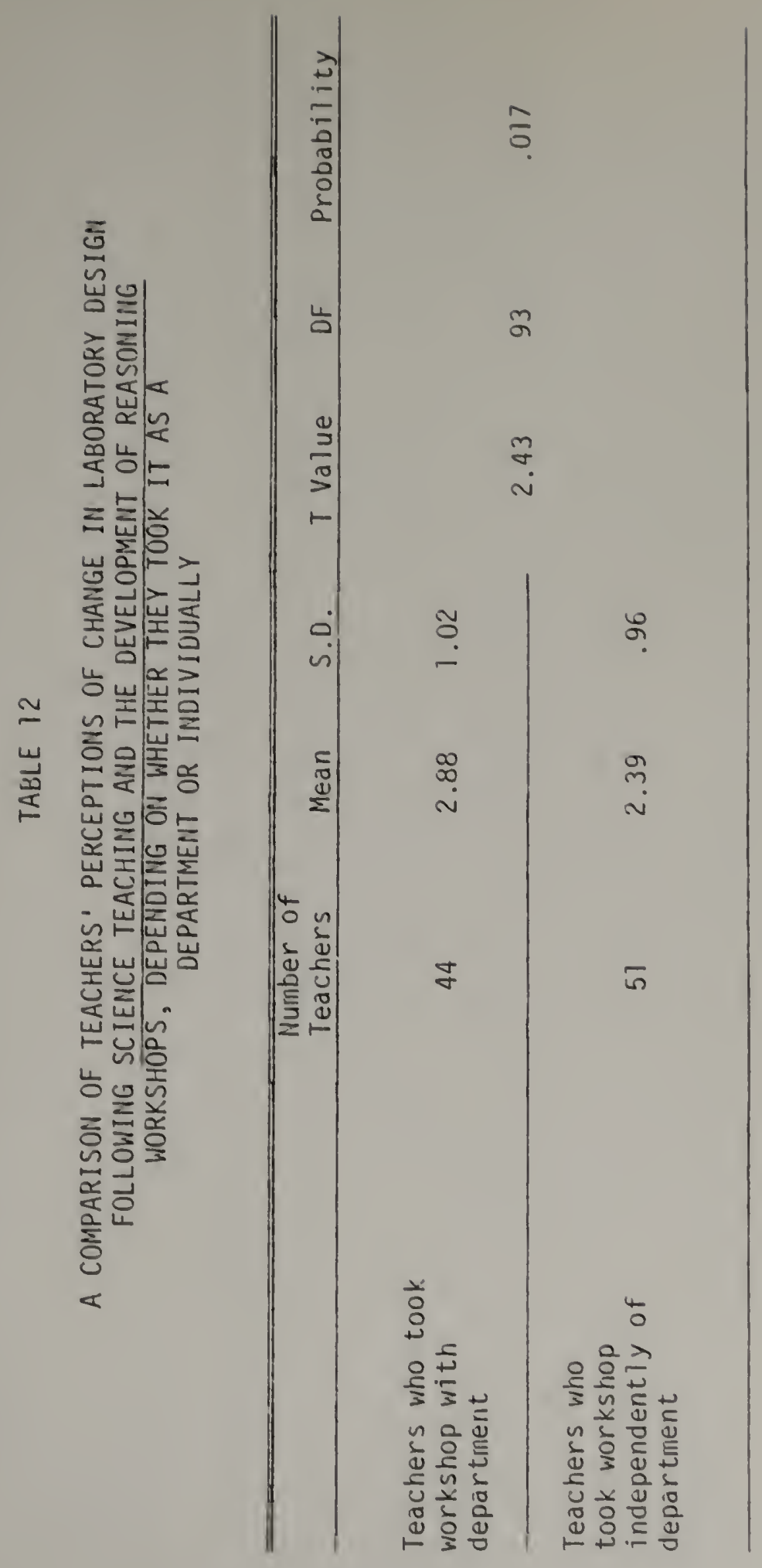


Less structured laboratories may need more departmental support and frequently result from discussion with colleagues, perhaps more so than altering tests and ways of presenting new concepts, etc. It is certainly easier to change laboratories in a department that supports the change and is familiar with the philosophy behind the change.

To summarize, the results support the hypothesis that administrative and peer support is necessary to implement ideas from inservice workshops. Changes in the classroom occur to the extent that administrative support is translated into time, both in class preparation, in scheduling, and in curriculum demands. Administrative and peer support result in improved morale which provides the atmosphere for innovation. Teachers quoted in this section described the support problems involved in changing their teaching style and course material in the direction of increased emphasis on reasoning.

Concerns of teachers. A discussion of the relevancy of the concerns of teachers to the implementation of innovations in the classroom was discussed in Chapter II. In Chapter III, the development and validation of the Stages of Concern Questionnaire were described. The population to which this questionnaire was administered consisted of twenty-one teachers who had just completed a fourteen-hour development of reasoning workshop.

Interpretation of the high score for both individual and group data was based directly on the Stages of Concern About the Innovation definitions which were presented in Figure 2. The stage scores were 
related to the stage definitions with the relative intensity of concern being indicated by the percentile score. The higher the score, the more intense the concerns at that stage.

Tabie 13 is a listing of the Individual Stage of Concern Percentile Scores for the curriculum innovation, the Learning Cycie Approach. At the bottom of the table, the individual data were aggregated by developing a profile that presents the mean scores for each stage of the individuals in the workshop. Table 14 is a tally of the number of individuals that are high on each stage. This gives a picture of the range of peak stage scores within a group.

These group averages indicate that the highest scores were at Stages 0,1 , and 2 . Those with their highest stage of concern at Stage 0 showed an awareness of and concern for the innovation. A high Stage 1 score indicated an interest in having more descriptive information about the innovation. Those individuals were concerned about what the innovation was and what their use of the innovation would entail.

High Stage 2 scores indicated personal concerns, the "self" concerns described by fuller (1969). These may reflect feelings of inadequacy, uncertainty about roles, rewards, decision-making, and personal commitment. These personal concerns, when high, tend to block out more substantive concerns about the innovation. 


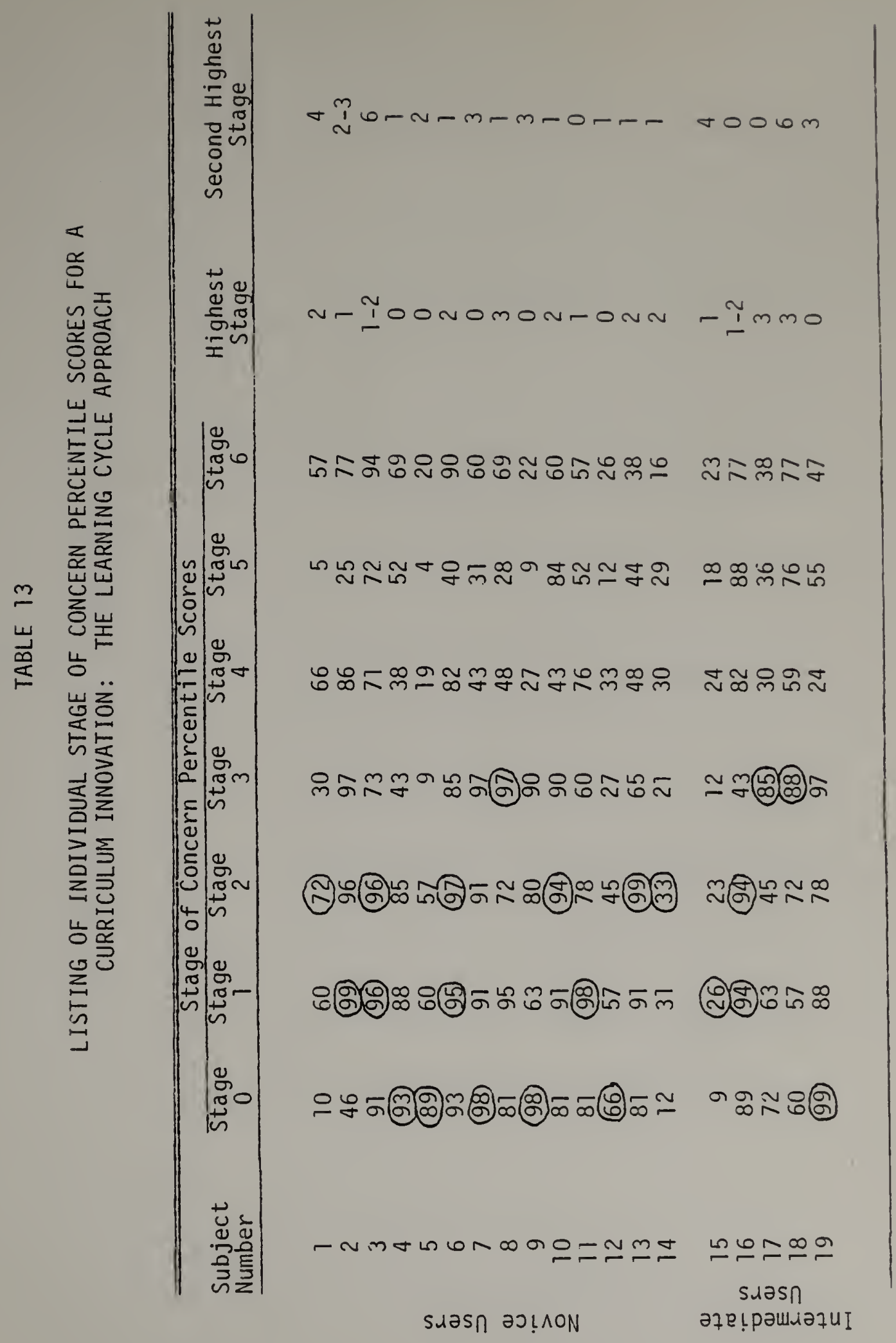




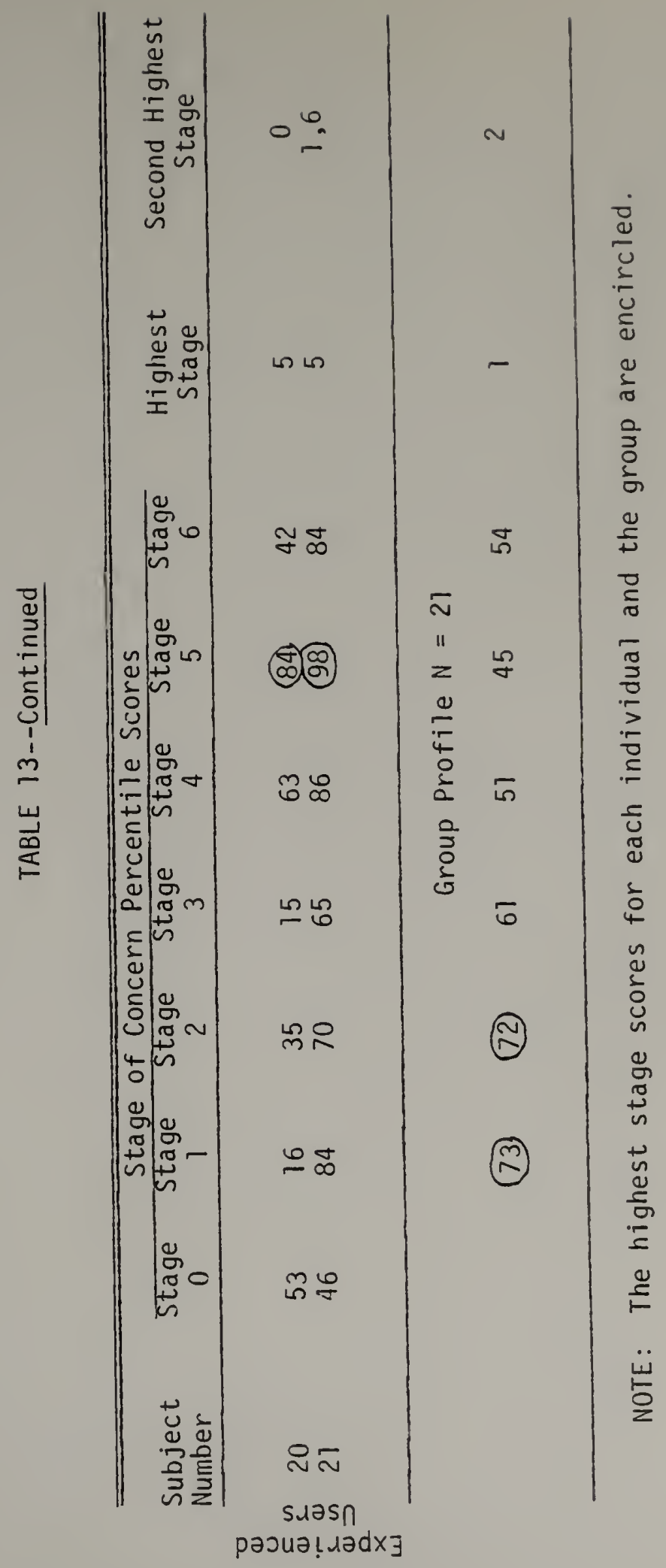




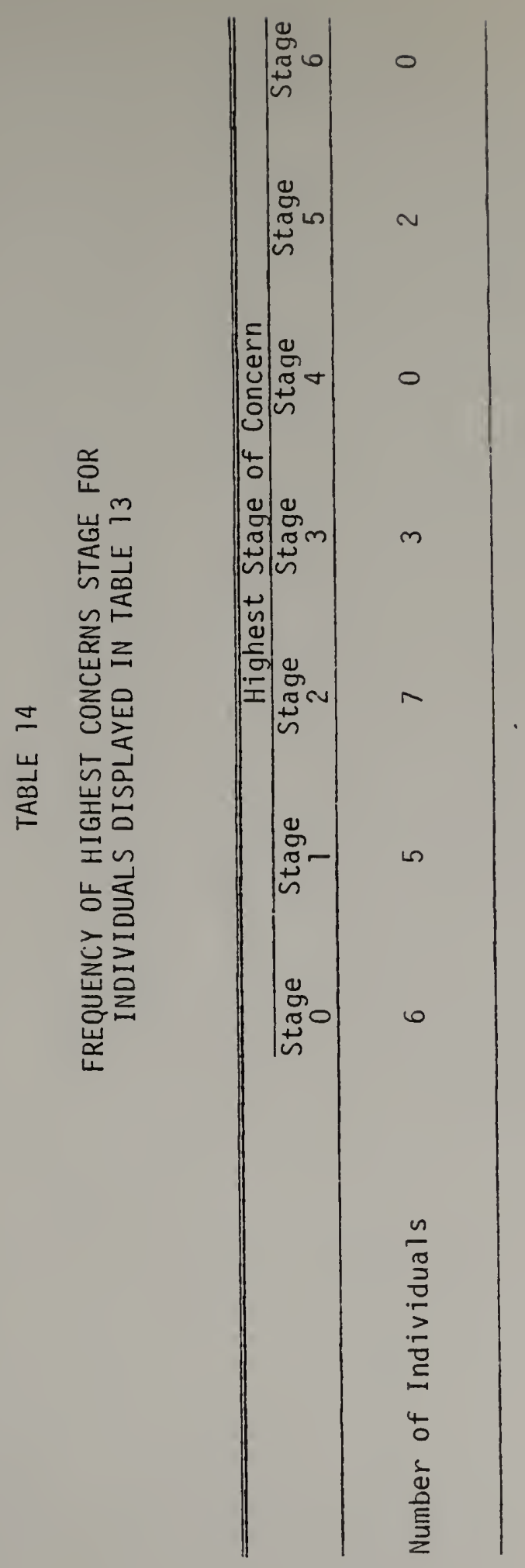


To ga in further understanding of the individual and group concerns, the group was divided, based on self-report, into non-users and users. Profiles of each of these groups were developed (see Figure 3).

The non-users $(N=14)$ showed high informational and personal concerns about the innovative ideas. At this point, they were not intensely concerned about the innovation's consequences for students (low Stages 4 and 5). The tailing-up of Stage 6 generally means that the individual has other ideas that she/he sees as having more merit than the proposed innovation. This is a warning of potential or existing resistance to the innovation.

The users $(N=7)$ continued to show informational and personal concerns with management concerns also taking an important role. Since they were now using the "Learning Cycle" approach, they were becoming concerned with organization, scheduling, and time problems, the practical concerns of implementing the innovation. Collaboration and cooperation concerns (Stage 5) moved up relative to the others. Refocusing concerns were down, indicating that these users were not looking for alternatives or major changes in the innovation.

This observed progression from non-users to experienced users was to be expected. It was a movement from preoccupation with gaining more information about the new ideas, and with personal insecurities 
FIGURE 3

CONCERNS PROFILES FOR NON-USERS AND USERS

IN THE WORCESTER WORKSHOP

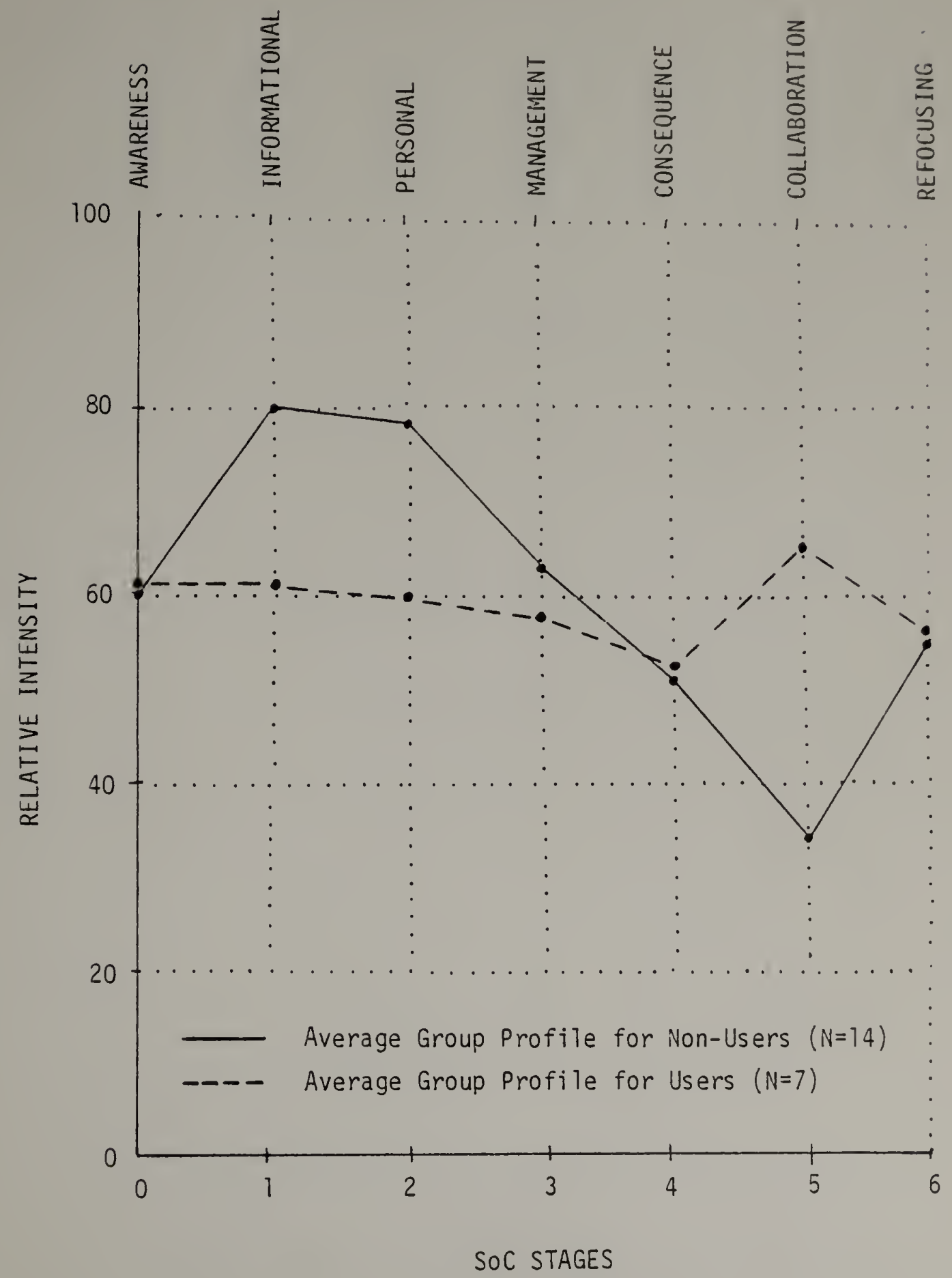


giving rise to some resistance to the innovation, to resolution of some of the primary management issues in the classroom, finally reaching an emphasis on student change and collaboration with others to effect these changes. The non-users were not using the ideas from the workshop because their informational and personal concerns were not resolved. Beginning and intermediate users also needed help and support in resolving their management concerns.

The concerns reflected on the Stages of Concern Questionnaire by those who had just completed a workshop corroborated those expressed on evaluations by participants immediately following other workshops presented throughout New England. The most frequently stated needs were as follows:

-- More time to understand and develop skills in this new approach.

-- More time to develop laboratories using the Learning Cycle model.

-- More materials for specific subject areas.

-- Suggestions for questions for quizzes. What type of questions should be used?

-- More time for application.

These comments reflect a desire for more knowledge and personal concerns about how the new approach will work. Again, these concerns are to be expected from those who have not had the opportunity to try out the new ideas. Similar informational concerns were expressed in a variety of ways by nine of the teachers who were interviewed. Several illustrations follow: 
I'm still trying to find ways to incorporate what I have learned, and I find it very difficult. I try to use more thought-provoking questions that will test reasoning ability, not just total recall, but I find it very hard and need to get more information.

Can you help kids towards higher reasoning capabilities, or do you just have to wait until they get there?

What kind of analogies or physical objects can I use so that they can see what's happening?

We need more specifics on how to do things in each subject area?

How do you test the iearning that has taken place?

Personal concerns were expressed by six of those interviewed:

Theoretically, the idea of the learning cycle and having kids generate their own procedure is fine, but I don't have the confidence to try it. I would have to do it on my own, and I would have to be successful, when I have never had a chance to see anyone el se do it successfully.

But because most of those interviewed were users to various extents, management concerns predominated, as illustrated in the following quotes:

Even with just nine kids, there is not enough time to delve into the issues that come up.

The students are heterogenousiy mixed. How do you challenge the weak kids to go beyond "I've done what you expected; why do I need to do more?" It is difficult to control the safety, to control the class, and to make the most of mistakes made by the students.

My main frustration is that I don't have time to sit down and figure out how I want to use the information, how to make changes in our structure to be able to use it.

I tried self-pacing because there was a range from concrete to formal. Total self-pacing didn't work at all. I ran into logistical problems with groups of different sizes, etc. 
With substitute teachers, discipline could not be maintained using these approaches.

Stage 5 concerns, focusing on the impact of exploratory approaches on students, were expressed by teachers who had worked more extensively with these ideas. They are discussed in the following section, Impact on the Innovation of the Students.

Additional factors. The cross-tabulation analysis described in Chapter III showed no significant evidence at a .05 level to indicate that teachers' perceptions of change in classroom teaching or application of the ideas of the workshop in the areas of laboratory design, use of the textbook, introduction of new topics, tests, or presentation of concepts were related to:

1. Length of the workshop attended;

2. Number of months since attending the workshop;

3. Present grade or teachirig level;

4. Total number of years teaching;

5. Subject areas taught;

6. Highest degree earned;

7. Sex of the participant;

8. Size of classes taught.

Impact of Innovations on the Students

Several questions on the User Interview Questionnaire probed teachers' perceptions of the impact of the new classroom techniques on 
students. There is no objective way to evaluate at this point how students are changing as a result of increased emphasis on reasoning development and more exploratory approaches as a means of implementing this. We only have teacher and student perceptions about the changes, and this study explored the former.

When stronger emphasis was placed on concrete reasoning in the classroom, teachers found their students less frustrated and more attentive in class. When laboratories become more individualized and unstructured, a variety of responses ensued. A high school physics teacher initially found considerable resistance to the laboratories which he had rewritten in a learning cycle format. Periodically, when he reverted to one of his previous "cook-book" types of laboratories, students expressed relief to see a laboratory sheet that they just "had to fill in." But they eventually reached the point where they were expected "thinking types" of laboratories every week. Each class included those who enjoyed the challenge while others found it extremely difficult. The most positive feedback was received from the gifted groups. Teachers found it difficult to simplify the activities enough so that the less able student could succeed without feeling that the activity was ridiculous.

Ambivalence was also evident when a chemistry teacher described the impact on her students resulting from changes in laboratory format and text usage. On the one hand, the students felt more at ease in class and developed more confidence. She found with heterogenously grouped classes the individualized laboratories gave her more time to 
help those in difficulty. On the other hand, the issues of control and safety were difficult to resolve.

Strong initial resistance to a new approach was noticed by

several teachers, as shown in the following quote:

Once the kids were aware of why I was doing this, they were more with me. At first they would say, "I can't do that. This is the only way I can get you to start thinking at this other leve1. Let's give it a try." At first it was very negative. Certain people tried, and when they solved a problem, they said, "I can see now. Hey, I can understand that."

Another junior high teacher describes student reactions to having laboratories with no definite conclusions:

At first they came to me full of anxiety, but less of what is happening now. They are talking to each other more in the lunchrooms, around the school. Those who don't have any idea about the conclusion will talk to others. Other students will be able to help them. They seem to be using me less as a source person.

Finally, the question of student confidence and trust needs to be mentioned. The struggle from states of distrust of unstructured situations to comfort with open-ended approaches is often long and requires patience on the part of the teacher. One junior high teacher states it well:

The learning cycle approach oniy works when kids feel comfortable enough to make mistakes. My students started out with an attitude of distrust, feeling that they would be penalized for making a mistake. They wouldn't try. Then they resisted by suggesting that if I were a good teacher I would help them more. I responded to this by indicating to them that I am not responsible for their learning. I will try to create an environment in which they can learn, but I will sleep at night whether they learn or not. By May, some of them said something like, "This answer may not be right, but." I felt at that point that I had made about as much progress as I was going to. If they take that attitude into the Biology class, the same thing is cultivated. . . . But many of them don't realize what I am trying to do. 
Conclusions about the impact of the described innovations on students cannot yet be made. Teachers report, however, that students at the concrete operational level with regard to certain concepts or topics respond positively to discussion and laboratories adjusted to that level. Although some students apparently thrive on exploratory, open-ended experiences, teachers report that the majority have an initial resistance to less structured types of approaches. This is very often due to the fact that the previous experiences of both teacher and student have been structured. If the majority of teachers in this study feel that these approaches at the least constitute good teaching and possibly encourage the development of reasoning, what is necessary for both teachers and students to become comfortable with this approach?

\section{Telephone Interviews With Non-Reponders}

Telephone interviews were conducted with a random sample of twenty of the ninety teachers who had not returned the questionnaire. The intent of these interviews was to determine:

1. Attitudes towards the workshop;

2. Understanding and recall of ideas of the workshop;

3. Use of ideas from the workshop.

Four of the twenty interviewed stated that they had retained good comprehension of the workshop content and purpose and that they were using the resulting ideas. The specific changes they had made 
have been incorporated into previous sections of this chapter. These included a workshop for twenty-three teachers conducted by one of the participants at his own school.

Nine additional teachers from this interviewed group were positive about the workshops but stated that they needed either more time or follow-up workshops to assist in assimilation of the material. They stated that their awareness had increased regarding the importance of reasoning in the classroom, but they had done little to change the ir curriculum. Recall of workshop ideas among this group was considerably less than among the previous four. Five from this group mentioned that they did not return the questionnaire because they could not remember the workshop well enough. Two indicated that they were planning to take follow-up courses the following semester.

The final group of seven, including two who did not return for the second part of the workshop, stated that they did not find the workshop useful. The following are comments from this group:

I already knew all about it; there was nothing new.

It was over-intellectualizing something that was obvious.

I didn't use it because there wasn't enough there.

It was a total waste of time. I didn't go back the second day.

The negativity towards the workshop expressed by this group explains their lack of interest in returning the questionnaire. Extrapolating these data, of the ninety individuals who did not respond to the questionnaire, approximately one-fifth found the workshop useful 
in the sense that they made changes, one-half felt positive about their learnings, but had not made changes; and approximately one-third found the workshop of no use.

\section{Summary}

Approximately ninety percent of the secondary science teachers who responded to the Workshop Evaluation Questionnaire indicated that they had become more aware of the reasoning process of their students as a result of participating in Science Teaching and the Development of Reasoning workshops. A considerably smaller percent reported that they had applied the ideas of the workshop in laboratory design (49\%), use of the textbook (44\%), introducing new topics (73\%), presenting concepts $(80 \%)$, and testing $(60 \%)$. Three-fourths of the teachers interviewed reported sharing ideas from the workshop with professional coll eagues.

Interviews with twenty teachers who had stated that they had used the ideas of the workshop confirmed that they were having difficulty translating their new awareness into classroom changes.

Confusion regarding the use of the terms "concrete operational reasoning," "formal operational reasoning," and "exploration" was noted and analyzed. In spite of lack of clarity regarding these concepts, interviews revealed trends towards seeking more "concrete" methods of presenting science concepts, and towards increased activity and initiative on the part of students in class and laboratory. 
The primary factors which the teachers felt limited their ability to use the ideas from the workshop were:

-- Insufficient time during and following the workshop to understand and assimilate the ideas.

-- Insufficient knowledge about the reasoning requirements of curriculum they are teaching, including application in specific subject areas.

-- Insufficient time in schools for preparation and revision of curriculum.

-- Isolation from professional colleagues who have similar interests.

Chapter $V$ will now present the conclusions of this study, discuss the significance and implications of the findings, and suggest areas for future study. 


\section{CHAPTER V}

\section{SUMMARY}

\section{Introduction}

This study has evaluated an inservice workshop approach for secondary science teachers. The purpose of the study was three-fold:

1. To determine whether teachers who participated in Science Teaching and the Development of Reasoning workshops in New England in 7978 and 1979 thought that they had utilized the ideas of the workshop in modifying their teaching style and methods.

2. To determine the nature and extent of changes made that were consistent with the intent and philosophy of the workshop.

3. To identify what factors the teachers perceived either facilitated or hindered their ability to make changes.

Chapter I presented the background of the project which provided development of reasoning workshops for secondary science teachers in New England and the rationale for evaluating the effects of this workshop approach. It is important to identify the changes that occur as a result of workshops provided by those outside the school system, so that individuals and schools can assess whether money and time spent in this way are accomplishing the desired goals.

Chapter II reviewed the 1 iterature, providing a rationale for this particular workshop approach. It was concluded that science Teaching and the Development of Reasoning workshops were appropriate for 
this study because they follow many of the guidelines suggested by current researchers and practitioners of inservice development, and because they provide an application of Jean Piaget's constructivist theory of cognitive development.

Chapter III presented the methodology by which this evaluation was conducted. Information was collected from questionnaires, interviews, teacher-prepared materials, and evaluations immediately following workshops. A compilation of the results of the study was completed in Chapter IV from which certain conclusions can be made. A discussion of the implications of this research, including recommendations for future study, follow these conclusions.

\section{Conclusions}

Research Question A: To determine whether teachers who participated in Science Teaching and the Development of Reasoning workshops in New England in 1978 and 1979 thought that they had utilized the ideas of the workshop in changing their teaching style and methods. A large majority of responding teachers felt that their attitudes towards students and the content of their courses changed as a result of attending the workshop. Eighty-nine percent reported an increased awareness of the reasoning processes of their students, and approximately $75 \%$ felt that some change in their teaching had occurred. The perception of change in order from greatest to least occurred in presentation of new topics and concepts, testing procedures, laboratory design, and use of texts. 
These teachers have stated that a single or several workshops can be effective in changing their awareness and increasing their knowledge about a topic. They also feel that innovation in classroom techniques and strategies can result from a single workshop experience.

Research Question B: To determine the nature and extent of chanaes made which were consistent with the intent and philosophy of the workshop. The changes reported by teachers responding to the questionnaire, by those who were interviewed and by those who provided materials they had developed, showed wide variation in adaptations of the workshop ideas. These changes fall into three categories: attitudinal changes, curriculum changes, and sharing of the workshop ideas.

Attitudinal changes. Since nearly $90 \%$ of the responding teachers reported an increased awareness of the reasoning processes of their students and $79 \%$ felt that they should teach their courses differently as a result of the workshop, a first step towards change, a change in attitude was evident.

Interviews revealed that these teachers knew that their teaching was too formally oriented, and were looking for ways to adapt it to the reasoning abilities of their students. They were also examining the reasoning requirements of textbooks more critically.

Curriculum changes. The extent of curriculum change reported by the teachers varied widely. At one end of the spectrum were teachers who were experimenting with new ways of presenting topics in the classroom and who had revised one or two laboratories to make them more 
open-ended. Of the teachers who had done more extensive development and revision of the curriculum, one developed a whoie unit, another a series of laboratories following the models experienced in the workshop. Tables 5 and 6 show the types of curriculum changes that have been made and the number of instances of reported change.

The most interesting conclusion to be made from these results is that some curriculum changes have been reported by these teachers as a result of attendance at a single workshop. Whether these chanaes will increase in extent or whether there will be a reversion to previous ways of teaching will depend on the factors influencing innovation presented later in this chapter.

A multiplier effect. A number of interviewed teachers had internalized the ideas from the workshop to the extent that they had shared these ideas with professional colleagues. Fifteen of the twenty met with other faculty members at their school in meetings or on a oneto-one basis. Two organized workshops at their school for other faculty and five presented workshops or courses at other schools, meetings, or conferences. Three examples will iilustrate the variety of these meetings.

A junior high science teacher presented a reasoning workshop to the elementary teachers in his district. Another teacher started a study group with members of his department as well as science teachers from nearby schools to draw up a proposal for a project which would promote the development of reasoning in their schools. The third example is that of a high school teacher who, as a result of the workshop, 
became involved with the "basic competencies" which the State of Vermont had drawn up for their public school system. He came to the workshop out of curiosity because he found the basic competencies, including reasoning competencies, very confusing. What he found out was that some of the skills which Vermont was caliing reasoning competencies were probabiy not reasoning competencies at all. He is now serving on a committee to study and clarify these competencies.

This sharing of information from the workshops has resulted in a multiplier effect. After many of the workshops which were given at professional meetings and in university settings, teachers returned to their schools and organized their own faculty workshops. (See Appendix A.) As a result, over one thousand teachers in New England have become exposed to the ideas in the Science Teaching and the Deve? opment of Reasoning workshops.

This means that a number of teachers are recognizing that reasoning development as a goal of science teaching is valid and important. This is also evident from the fact that a follow-up workshop at the Annual Conference of the American Association of Biology Teachers in Boston, Massachusetts, in October 1980, for those who had previously attended Science Teaching and the Development of Reasoning workshops was well attended. In addition, support in the form of letters for a new project helping teachers with curriculum development based on the workshops has been encouraging.

In addition to these positive results, analysis of the interviews and curriculum materials already developed revealed a considerable 
variation in interpretation of the concrete and formal operational reasoning, as well as the concept of exploration. This researcher suspects that this lack of clarity is partly due to confusion on the part of theorists and educators who are attempting to apply Piagetian theory to classroom settings and partly due to the fact that one or several workshops do not provide enough time and experience for understanding these complex concepts.

Research Question C: To determine what factors teachers perceived as either facilitating or hinderina their ability to make changes.

Teacher decision-making and choice. Conclusions about the effect of teacher decision-making and choice on the use of ideas from Science Teaching and the Development of Reasoning workshops could not be drawn because approximately $90 \%$ of the workshop participants attended the workshop voluntarily.

Interviews, however, revealed that schools with funding for inservice programs welcome the suggestions of science teachers. Schools which held development of reasoning workshops did so upon recommendation of department heads and teachers who had heard about or attended the workshop elsewhere. Because inservice programs do not exist at many schools, interested teachers depend on workshops at conferences to continue their professional training.

Characteristics of the workshop as perceived by participants.

A large majority of the teachers responding to the questionnaire agreed with the content and theoretical basis of the workshop. They felt that 
the development of reasoning was an important goal for teachers and students. At least half of the teachers thought that their current science curriculum was not appropriate for the developmental level of the students they are teaching.

Over $90 \%$ of the teachers responding thought that the workshop modeled the learning theory it espoused, i.e., the introduction of concepts through activities rather than lecture and opportunity to work and discuss with other participants. The main criticism was the lack of time during the workshop to assimilate the concepts being presented. Lack of time appeared to be the single most important factor limiting implementation of the ideas from the workshop in the classroom.

Administrative and peer support. Administrative and peer support were considered necessary by teachers who were implementing ideas from the workshop. Although administrators verbally supported their teachers in the approaches suggested by the workshop, this support was rarely translated into the time to prepare and alter curriculum. When a curriculum emphasizes reasoning and includes exploratory, processoriented approaches, teachers need support in deaing with both parents and students, who are accustomed to seeing grades based objectively on fact-oriented evaluations. Education is needed on all levels to recognize the value of reasoning as a goal.

The support of colleagues for innovative approaches was also considered important. A solo effort in new directions was found to be difficult to maintain, particularly with parental and student resistance. 
Concerns of teachers. Teachers who participated in science Teaching and the Development of Reasoning workshops, who were interested and aware of this approach to learning, but who have not made innovations based on the ideas from the workshop, have high personal and informational concerns, as measured by the Stages of Concern Questionnaire. They felt the need for more knowledge about the ideas of the workshop before they would feel secure enough to try out the ideas. Beginning users of the workshop ideas continued to express personal and informational concerns, but were also struggling with classroom management issues.

\section{Recommendations Regarding Future Science Teaching and the Development of Reasonina Workshops}

Research described in Chapter II supported the hypothesis that change is more likely to occur when teachers choose to be involved in the initiation and development of their own inservice programs. Ideally, Science Teaching and the Development of Reasoning workshops should be teacher initiated and attendance should be voluntary. More teacher input into the format and ideas of the workshop enhances its effectiveness. Requesting teachers to bring in the texts they are using, laboratory directions and tests they have given, and using these as the basis of analysis in addition to or instead of those provided by the workshop has been successful in increasing relevancy and teacher involvement.

The lack of time during most workshops to assimilate the complex ideas of the workshop needs to be addressed. It must be made clear to 
administrators and teachers who request workshops, that a few hours provide only an introduction and superficial familiarity with potential appications of Piagetian theory. Opportunity for follow-up sessions needs to be made available to interested teachers. This is happening in the New England area with the develcpment of a proposal enabling forty secondary science teachers who have responded enthusiastically to this evaluation to continue to meet periodically to share and evaiuate curriculum they have developed based on this model. This will also supply the colleague support considered necessary by all the teachers who were interviewed.

Finally, workshop leaders need to be aware of and knowledgeable about the Concerns Based Adoption Model developed by Gene Hall and Colleagues (Hal1, 1979). If they are alert to the concerns expressed throughout the process of adopting innovations through inservice programs, these then can be specifically addressed.

\section{Implications and Suggestions for Future Research}

The implications from this study are both theoretical and practical. Suggestions for future research, therefore, will involve the time and energy of both learning theorists and educational practitioners. These suggestions are:

1. Studies to clarify the characteristics of formal operational thought with respect to the different subject matter areas of science. 
2. A realistic, research-based plan which will increase the impact of inservice programs promoting the development of reasoning.

3. A long-term documentation of the concerns of teachers and uses by teachers of the innovations promoted in Number 2 above.

4. A comparison of courses designed with reasoning as a goal with traditionally taught courses with respect to impact on students.

Each of these possibilities will now be more fully described.

1. Studies to clarify the characteristics of formal operational

thought with respect to the different subject matter areas of science.

In the Science Teaching and the Development of Reasoning workshops, both the educational objectives, i.e., to achieve or move in the direction of formal operational thought, and the educational methods (physical experience, social interactions, and equilibration) are derived from the theories of Jean Piaget. Some of the difficulties in applying this theory to education arise from the lack of clarity of the theory as well as the fact that it has been applied to education by those other than Piaget, by individuals who interpret it in different ways.

Curriculum cannot be based on developmental stages until the competencies of these stages are more fuliy defined in a 17 contexts. "Ecosystem" or "evolution" may be formal operational concepts. But what indicates the use of formal operational reasoning in relation to these concepts, and in what context would it be used? What is needed are examples of concrete and formal reasoning strategies as they are 
observed during the students' activities. Deanna Kuhn (1979) states that unless we have descriptions of how students' reason, we will not understand the competencies which should be produced, their nature or their significance. How will we know when we observe particular thought processes of the students in activities we design? The key is to observe students carefully when they are working on a problem. It will be a challenging task to figure out how formal operational reasoning shows up in each conceptual domain of the curriculum. According to Kuhn, this is a task which the developmental researchers and educators must accomplish together. She summarizes:

The need, then, is for a more comprehensive set of general definitions of formal reasoning strategies, that is, definitions applicable across the entire range of content domains, and an articulation of how these formal operational reasoning strategies manifest themselves in each of these domains. Accomplishing this objective, of course, entails defining these strategies in exactiy the sorts of everyday thinking context important to educators. Clearly, then, this is a point at which the tasks of the educational and developmental researchers intersect. (Kuhn, 1979, p. 347)

2. A realistic, research-based plan which will increase the impact of inservice programs promoting the development of reasoning. Once this clarification has been achieved, then inservice programs that have impact on the teachers and students involved need to be developed.

This study has shown that a single workshop on the development of reasoning can result in at least half of the participating teachers realizing the importance of reasoning development and beginning to focus on it. Some knowledge of the concepts was also achieved. But few developed the skills to transfer the concepts and suggested 
approaches to the classroom. Joyce and Showers (1980) describe five components which contribute to the impact of an inservice training program:

a. Presentation of theory or description of a skill or strategy;

b. Modeling or demonstration of skills;

c. Practice in simulated and classroom settings;

d. Structured and open-ended feedback;

e. Coaching for application (hands-on, in-classroom assistance with the transfer of skills and strategies to the ciassroom). (p. 380)

Programs need to be developed which incorporate various combinations of these elements. They can then be evaluated to determine which combination of training elements has the most impact.

\section{A long-term documentation of the concerns of teachers and uses by} teachers of the innovations promoted in Number 2 above. Those studying the change process in school systems conclude that three years is the minimum time necessary for an innovation to become incorporated into a system (Hall, 1979). During and following the above suggested training program to develop experimental courses, the Stages of Concern Questionnaire (Hall, George, and Rutherford, 1977) and the Level of Use Interviews (Loucks, Newlove, and Ha11, 1975) could be administered to document the concerns of teachers and their level of use of the innovation throughout the development process. 
4. A comparison of courses designed with reasoning as a goal with traditionally taught courses with respect to impact on students. As more teachers become familiar with developmental theory and begin to apply it, the question arises as to how much this theory should be involved in making decisions about educational policy and practice. This is a crucial question because of the current tension between developmentally based and traditional or back-to-basics curricula.

Therefore, inquiry-oriented, laboratory-centered courses using the Learning Cycle model, which have the goal of increasing students' understanding of concepts by making instruction appropriate to their developmental level as well as promoting formal operational thought relevant to the domain of the course (Feldman, 1980) need to be compared with traditionally taught high school science courses. These experimental and control courses, taught by the same teacher and containing randomly selected students, should be compared with respect to:
a. Increased ability of students to use formal thought;
b. Subject matter content learned;
c. Attitudes of students towards the course.

A final consideration relates to observations that teachers and learners all have different belief systems, personalities, teaching and learning styles. No single approach is optimal for all. The ideas from the workshop have generated many adaptations influenced by the classroom style of teachers and the needs and interests of students. 
Harvey (1970) found that both teachers and students can be grouped in terms of their need for structure, attitude towards transition, authority, open-mindedness, probiem-solving orientation, and ability to behave creatively. The majority, according to Harvey's research, enjoy traditional roles, authoritarian approaches, and resist innovation. Students with a high need for structure and guidance react negatively towards teachers strong in the qualities of abstract thinking, open-mindedness, with a strong problem-solving orientation, and complained that the latter did not give them freedom. The opposite was true for children low in need of structure and high in independence.

Freedom, then, subjectively is providing an environment which meets each individual's need at a particular time. For some, this means providing external structure, for others, allowing individual decision-making.

To take this 1 ine of argument a step further, ways need to be found for teachers, particularly those in secondary science, who are interested in following more exploratory, non-structured methods in their classrooms to be provided with students who will most benefit from this approach.

Because of these different attitudes and personality styles, there is no way to package innovation successfuily. It is a process of mutual adaptation through which each user progresses according to ability and inclination. Likewise, "learning cycles" and other approaches may have to be reinvented by each teacher attempting to 
promote reasoning in the classroom. Then, when the right combination of teacher and student occurs is the exciting dynamic of change and growth possible.

In summary, Conant (1964) observes that knowledge accumulates to the extent that empirical-inductive inquiry combines with the theoretical-deductive:

Educational practices provide the data, the subject-matter which form the problems of inquiry. They are the sole source of the ultimate problems to be investigated. These educational practices are also the final test of value of all researches. (pp. 26-27)

As what is in the structure of the mind only becomes real as it interacts with the physical environment, so theory such as that of Jean Piaget can only be understood and clarified as it bounces against practice and reality of our learning environments. This study is an attempt to evaluate a program so designed. It is one step along a continuing path. 
BIBLIOGRAPHY

Angius, D. The appropriateness of selected inservice education practices as perceived by secondary school educators. Dissertation Abstracts, 1974, 35, 917A.

Arbuckle, M. A. A Study of Factors Facilitating Continued Implementation of Educational Change. Doctoral dissertation, University of Massachusetts, 1977.

Ashley, J. P., and Butts, D. P. A study of the impact of an inservice education program on teaching behavior. In D. Butts (Ed.), Research and Curriculum Development in Science Education. Science Education Center, The University of Texas at Austin, 1970 .

Bady, J. B. Methodological issues in formal operations research: what does it mean to be forma1? Science Education, 1978, 62, 233239.

Balzer, L. Non-verbal and verbal behaviors of biology teachers. American Biology Teacher, 1969, 31, 226-229.

Barr, A. S. Teacher effectiveness and its correlates. Journal of Experimental Education, 1961, 30(1), 134-156.

Barrows, L. K., and Klenke, W. H. Documenting Change: Procedures, Problems and Possibilities. Wisconsin Research and Development Center for Individualized Schooling, University of WisconsinMadison. Presented at the Annual Meeting of the American Educational Research Association, Boston, Massachusetts, Apri1 1980.

Bartholomew, R. B. Determining the effect of instructional models on the investigative teaching behavior of experienced earth science teachers. Proceedings from the 43rd Annual Convention, National Association for Research in Science Teaching, 1970, 78-79.

Berman, P., and McLaughl in, M. W. Federal Programs Supporting Educational Change: A Mode of Educational Change, Vol 1. Santa Monica, California: Rand Corporation, R-1589/1, 1974.

Blume, R. Humanizing teacher education. Phi Delta Kappan, 1971, 42, $411-415$. 
Brickell, H. M. State organization for educational change: a case study and a proposal. In M. Matthew (Ed.), Innovations in Education. New York: Teachers College Press, 1964.

Bunker, R. M. Beyond iriservice--toward staff renewal. Journal of Teacher Education, 1977, 28, 31-34.

Butts, D. P., and Raun, C. E. A study of teacher change. In D. Butts (Ed.), Research and Curriculum Development in Science Education. Science Education Center, The University of Texas at Austin, 1970, 142-150.

Carini, P. F. Observation and Description: An Alternative Methodology for the Investigation of Human Phenomena. North Dakota Study Group on Evaluation Monograph. Grand Forks: University of North Oakota Press, 1975.

Carline, J. L. In-service training re-examined. Journal of Research and Development in Education, 1970, 4, $103-715$.

Chiappetta, E. L. A review of Piagetian studies relevant to science instruction at the secondary and college level. Science Education, $1976, \underline{60}(2), 253-262$.

Christopher, J. K. Teacher Perceptions of Factors in the School Environment Which Influence Innovative Science Teaching. Doctoral dissertation, Columbia University Teachers College, 1978.

Coffey, H. S., and Golden, W. P., Jr. Psychology of change within an institution. In N. B. Henry (Ed.), In-Service Education for Teachers, Supervisors, and Administrators. The Fifty-Sixth Yearbook of the National Society for the Study of Education, Part I. Chicago: The University of Chicago Press, 1957, 70-77; 83-102.

Combs, A. W.; Avila, D.; and Purkey, W. Helping Relationships: Basic Concepts for the Helping Professions. Boston: Allyn and Bacon, Inc., 1971.

Conant, J. B. Two Modes of Thought. New York: Simon and Schuster, 1964.

Corey, S. M. Introduction. In N. B. Henry (Ed.), In-Service Education for Teachers, Supervisors, and Administrators. The Fifty-Sixth Yearbook of the National Society for the Study of Education, Part I. Chicago: The University of Chicago Press, 1957.

Dasen, P. Cross-cultural Piagetian research: a summary. Journal of Cross-Cultural Psychology, 1972, 3 , 23-39. 
Delamont, S., and Hamilton, D. Classroom research: a critique and a new approach. In M. Stubbs and S. Delamont (Eds.), Exploration in Classroom Observation. London: Wiley, 1976.

Dulit, E. Adolescent thinking a la Piaget: the formal stage. Journal of Youth and Adolescence, 1972, 1, 281-301.

Edwards, P. K. D. Teachers' perceptions of present practices, process needs, alternative delivery systems, and priority of inservice education. Dissertation Abstracts, 1975, 36, 3581A.

Elkind, D. Quantity conceptions in junior and senior high school students. Child Development, 1961, 32, 551 . $i-2$.

Feldman, H. D. Stage and transition in cognitive-developmental research: getting to the next level. The Genetic Epistemologist, $1980, \underline{9}(1), 1-6$.

Festinger, L., and Katz, D. Research Method in the Behavioral. Sciences. New York: Holt, Rinehart and Winston, 1953.

Flanders, N. A. Analyzing Teacher Behavior. Reading, Massachusetts: Add ison-Westey, 1970 .

Flaveil, J. H. The Developmental Psychology of Jean Piaget. New York: D. Van Nostrand, 1963.

Fullan, M. Overview of the innovative process and the users. Interchange, $1972, \underline{3}(2-3), 1-46$.

Fuller, F. F. Concerns of teachers: a developmental conceptualization. American Educational Research Journal, $1969, \underline{6}(2), 207-226$.

Furth, H. G. Piaget and Knowledge: Theoretical Foundations. Englewood Cliffs, New Jersey: Prentiss-Ha11, 1969.

Gallagher, J. Knowing How a Child Knows: Phase Three of Piaget and the Learning Process. Paper presented at the Eighth Annual Symposium of the Jean Piaget Society, Philadelphia, May 1978.

Good, T. L., and Brophy, J. E. Looking in Classrooms. New York: Harper and Row, 1973.

Goodlad, J. I. Educational change: a strategy for study and action. Journa 1 of Secondary Education, 1971, 46, 157-166.

- The Dynamics of Educational Change: Toward Responsive Schools. New York: McGraw-HilT, 1975. 
Goodstein, M., and Howe, A. C. The use of concrete methods in secundary chemistry instruction. Journal of Research in Science Teaching, 1978, 15, 361-36\%.

Ha11, G. E. Using the Individual and the Innovation as the Frame of Reference for Research on Change. Procedures for Adopting Educational Innovations Project, Research and Development Center for Teacher Education, The University of Texas at Austin. Paper presented at the Annual Meeting of the Australia Association for Research in Education, Melbourne, November 1979.

Ha11, G. E.; George, A. A.; and Rutherford, W. L. Measuring Stages of Concern About the Innovation: A Manual for Use of the SOC Questionnaire. The Research and Development Center for Teacher Education, The University of Texas at Austin, 1977, ERIC No. ED 147342 .

Ha11, G. E., and Loucks, S. F. Innovation Configurations: Analyzing the Adaptations of Innovations. Austin: Research and Development Center for Teacher Education, The University of Texas, 1978.

Hall, G. E.; Wallace, R. C., Jr.; and Dossett, W. A. A Developmental Conceptualization of the Adoption Process Within Educational Institutions. Austin: Research and Development Center for Teacher Education, The University of Texas, 1973.

Harder, J. H. The relationship between selected in-service activities and supportive behavior by teachers. Dissertation Abstracts, $1972,32,6266 \mathrm{~A}$.

Harvey, 0. J. Beliefs and behavior: some implications for education. The Science Teacher, $1970,37,10-14$.

Hawkins, W. D. Some Factors Which Contribute to Successful Educational Innovation. Doctoral dissertation, University of Southern California, 1968.

Heathers, G. Overview of innovations in organization for learning. Interchange, $1972, \underline{3}(2-3)$.

Herrick, V. E. The evaluation of change in programs of in-service education. In N. B. Henry (Ed.), In-Service Education for Teachers, Supervisors, and Administrators. The Fifty-Sixth Yearbook of the National Society for the Study of Education. Chicago: The University of Chicago Press, 1957, 311-338.

Hruska, M., and Bunker, M. Inservice Education: One Approach; A Technical Paper. Hampshire Educational Collaborative, Hadley, Massachusetts, 1978. 
Hulleman, H. W. Effects of in-service training on elementary teachers pertaining to science achievement and attitudes toward

environmental science. Dissertation Abstracts, 1973, 33, 4007 A.

Inhelder, B., and Piaget, J. The Growth of Logical Thinking from Childhood to Adolescence. New York: Basic Books, 1958.

Inhelder, B.; Sinclair, H.; and Bovet, M. Learning and the Development of Cognition. Cambridge: Harvard Jniversity Press, 1974.

Joyce, B. Alternative Models of Elementary Education. Toronto: Xerox College Publishing, 1969.

Joyce, B., and Showers, B. Improving inservice training: the messages of research. Educational Leadership, 1980, 2, 379-385.

Kagan, M. H., and Tamir, F. Participation in and views concerring inservice training among high school and mathematics teachers in Israel--a survey. School Science and Mathematics, 1977, 77, $31-46$.

Karplus, R. Science teaching and the development of reasoning. Journal of Research in Science Teaching, 1977, 14, 169-175.

- Teaching for the development of reasoning. In AETS Yearbook, A. Lawson (Ed.), The Psychology of Teaching for Thinking and Creativity. Columbus, Ohio: ERIC-SMEAC, 1979.

Karplus, R., and Karplus, E. Proportional reasoning and control of variables in seven countries. Advancing Education Through Science-Oriented Programs. Report ID-25, Lawrence Hall of Science, Berkeley, California, 1975.

Karplus, R.; Lawson, A. E.; Wollman, W. T.; Appel, M.; Bernoff, R.; Howe, A.; Rusch, J. J.; and Sullivan, R. Science Teaching and the Development of Reasoning. Lawrence HalT of Science, University of California, 1977.

Kaufman, B. A., and Konicek, R. D. The Applicability of Piaget to Contemporary Curriculum Reform. Paper presented at the Annual Meeting of the National Association for Research in Science Teaching (47th), Chicago, Illinois, April 1974, ERIC, ED 091196.

Keasey, C. T. The Nature of Formal Operations in Preadolescence, Adolescence, and Middle Age. Unpublished doctoral dissertation, University of California, Berkeley, 1970.

Kuhn, D. The significance of Piaget's formal operations stage in education. Journal of Education, 1979a, 167, 34-50. 
The application of Piaget's theory of cognitive development to education. Harvard Educational Review, 1979b, 49, 340-359.

Kuhn, D., and Angelev, J. An experimental study of the development of formal operational development. Child Development, 1976, 47, $697-706$.

Kuhn, D., and Ho, V. The role of self-directed activity in the development of logical reasoning. Yearbook of the Jean Piaget Society. New York: Plenum, 1978.

Lawrence, G. Patterns of Effective Inservice Education. Tallahassee, Florida: Florida Educational Research and Development Program, 1974.

Lawson, A. E. Relationships Between Concrete and Formal Operational Science Subject Matter and the Intellectual Level of the Learner. Unpublished doctoral dissertation, University of Oklahoma, Norman, Oklahoma, 1973.

Lawson, A. E.; Blake, A.; and Nordland, F. Training effects and generalization of the ability to control variables in high school biology students. Science Education, 1975, 59(3), 387-396.

Lawson, A. E.; Karplus, R.; and Adi, H. The development of propositional logic and formal operational schemata during adolescence. AESOP. Lawrence Hall of Science, University of Cal ifornia, Berkeley, California, 1978.

Lawson, A. E., and Renner, J.W. A quantitative analys is of responses to Piagetian tasks and its implications for education. Science Education, 1974, 58(4), 454-459.

Lawson, A. E., and Wollman, W. T. Encouraging the transition from concrete to formal cognitive functioning: an experiment. AESOP. Lawrence Hall of Science, University of Cal ifornia, 1975.

Lewin, K. Field theory and learning. In The Psychology of Learning. Forty-First Yearbook of the National Society for the Study of Education, Part II. Chicago: The University of Chicago Press, $1942,227$.

Light, J. D. A model for the formative evaluation of teacher in-service education programs. Dissertation Abstracts, 1975, 36, $1217 \mathrm{~A}$.

Linn, M. C. Scientific reasoning: influence on task performance and response categorization. Science Education, 1977, 61, 357363. 
Loucks, S.; Newlove, B.; and Hall, G. Measuring Levels of Use of the Innovation: A Manual for Trainers, Interviewers, and Raters. Research and Development Center for Teacher Education, University of Texas, 1975.

Lovell, K. A follow-up study of Inhelder and Piaget's The Growth of Logical Thinking. British Journal of Psychology, 1961, 52,

Mahan, H. Frank observations on innovation in elementary schools. Interchange, 1972, $3(2-3), 144-160$.

Marek, E., and Renner, J. Intellectual development, IQ, achievement, and teaching methodology. The American Biology Teacher, 1979, 41, $145-150$.

Martin, R., and Keller, A. Teacher Awareness of Classrocm Dyadic Interactions. Paper presented at the Annual Meeting of the American Research Association, Chicago, I11 inois, April 1974, ERIC, ED 090243.

Maslow, A. Toward a Psychology of Being. New York: Van Nostrand Reinhold, 1962 .

McKague, T. Strategies for improving continuing education for teachers. In Proceedings of the 1975 Conference on Teacher Education, Vancouver, 8. C. (Canada), 5-7 May 1975. ERIC, ED 126084 , May $1976,64-72$.

Mckinnon, J. W., and Renner, 3. W. Are colleges concerned with intellectual development? American Journal of Physics, 1971 , 39, $1047-1052$.

McLaughlin, M. Implementation as mutual adaptation: change in classroom organization. Teachers College Record, 1976, 77(3), 339-351.

McQuire, W. J. The yin and yang of progress in social psychology. Journal of Personality and Social Psychology, 1973, 26, $446-456$.

Meadows, T. C. The Effect of Selected Variables on Elementary Teachers ' Ratings of Science In-Service Workshops. Doctoral dissertation, The University of Texas at Austin, 1978.

Miles, M. B., and Passow, A. H. Training in the skills needed for in-service education programs. In N. B. Henry (Ed.), Inservice Education for Teachers, Supervisors, and Administrators. The Fifty-Sixth Yearbook of the National Society for the Study of Education, Part I. Chicago: The University of Chicago Press, 1957. 
Mishler, E. G. Meaning in context: is there any other kind? Harvard Educational Review, 1979, 49, 1.

Niemark, E. D. Model for a thinking machine: an information processing framework for the study of cognitive development. Merrill-Palmer Quarterly, 1970, 16, 345-368.

Newlove, B. W., and Hal1, G. E. A Manual for Assessing Open-Ended Statements of Concern About an Innovation. The University of Texas, Austin, Texas, 1976.

Orlich, D.; May F.; and Harder, S. Change agents and instructional innovation. The Elementary School Journal, 1973, 73, 390-398.

O'Toole, R. E. Implementing new science programs. Science and Children, $1974, \underline{12}, 24-25$.

Parker, J. C. Guidelines for in-service education. In N. B. Henry (Ed.), In-Service Education for Teachers, Supervisors, and Administrators. The Fifty-Sixth Yearbook of the National Society for the Study of Education, Part I. Chicago: The University of Chicago Press, 1957.

Patton, M. Q. Alternative Evaluation Research Paradiam. North Dakota Study Group on Evaluation, University of North Dakota, Grand Forks, North Dakota, 1975.

Piaget, J. Cognitive development in children: development and learning. Journal of Research in Science Teaching, 1964, 2, 176-186.

- Intellectual evolution from adolescence to adulthood. Human Development, $1972, \underline{15}, 1-12$.

Powers, C. A critical review of science education interaction studies. Studies in Science Education, 1977, 4, 1-30.

Raven, R. Programming Piaget's logical operations for science inquiry and concept attainment. Journal of Research in Science Teaching, $1974,11,251-261$.

Riegel, K. Dialectic operations, the final period of cognitive development. Human Development, 1973, 16, 346-370.

Rogers, C. Freedom to Learn. Columbus, Ohio: Charles E. Merrill Publishing Company, 1969.

Rubin, L. J. The In-Service Education of Teachers: Trends, Processes, and Prescriptions. Boston: Allyn ard Bacon, 1978. 
Russel1, R. A. A study of the effect of a short in-service program on the participants' attitudes towards and use of computer based simulations. Dissertation Abstracts, 1974, 35, 7776A.

Sarason, S. B. The Culture of the School and the Problem of Change. Boston: Allyn and Bacon, Inc., 1971.

Scanlon, R. G. Building Relationships for the Dissemination of Innovations. Presented at Cedar Communications Group Workshop, Denver, CoTorado, August 1973, Research for Better Schools (ERIC, ED 108302 ).

Schultz, K., and Lombard, A. The Develorment of Reasoning Ability in

Science Students: A Goal for Secondary Science Teachers. National Science Foundation Grant Final Technical Report, SE $78-11901,1978$.

Sikorski, L. A.; Turnbu11, B. J.; Thorn, L. I.; and Bell, S. R. A Study of the Current Status of the Implementation of Science and Mathematics Materials at the Pre-College Level in the National Sciences, Social sciences, and Mathematics. San Francisco, California: Far West Laboratory for Educational Research and Development, April 1975.

Sinnott, J. Everyday thinking and Piagetian operativity in adults. Human Development, 1975,8 , 430-443.

Sjogren, D. D. Measurement techniques in evaluation. Review of Educational Research, 1970, 40(2), $301-320$.

Smith, P. J. View From My Classroom. Paper delivered at the Fifth Biennial Conference on Chemical Education in Dublin, Ireland, 1979.

Sorenson, D. L. Developing teacher understanding of behavioral counseling through film models and discussion techniques. Dissertation Abstracts, 1971, 32, 3041A.

Stafford, D. G., and Renner, J. SCIS helps the first grader to the logic in problem solving. School Science and Mathematics, 1970, 70, 159 .

Towler, J. 0., and Wheatley. Conservation concepts in college students: a replication and critique. Journal of Genetic Psychology, $1971,118,263$.

Walter, R. A.; Hendrix, J. R.; and Mertens, T. R. Sequenced instruction in genetics and Piagetian cognitive development. The American Biology Teacher, 1980, 42, 104-108. 
White, M. A.; Raun, C. E.; and Butts, D. P. A study of contrasting patterns of inservice education. Science Education, 1969, 53, $13-19$.

Wollman, W. T., and Lawson, A. E. The influence of instruction on proportional reasoning in seventh graders. Journal of Research in Science Teaching, 1978, 15, 227-233.

Youniss, J. Operation and everyday thinking. Human Development, 1974 , 17, 386-391. 
APPENDIX A

SCIENCE TEACHING AND THE DEVELOPMENT OF REASONING WORKSHOPS PRESENTED IN NEW ENGLAND

PARTICIPANTS AT THE REASONING CONFERENCE NOVEMBER $6-8,1978$

SCHEDULE OF ACTIVITIES AT CONFERENCE 


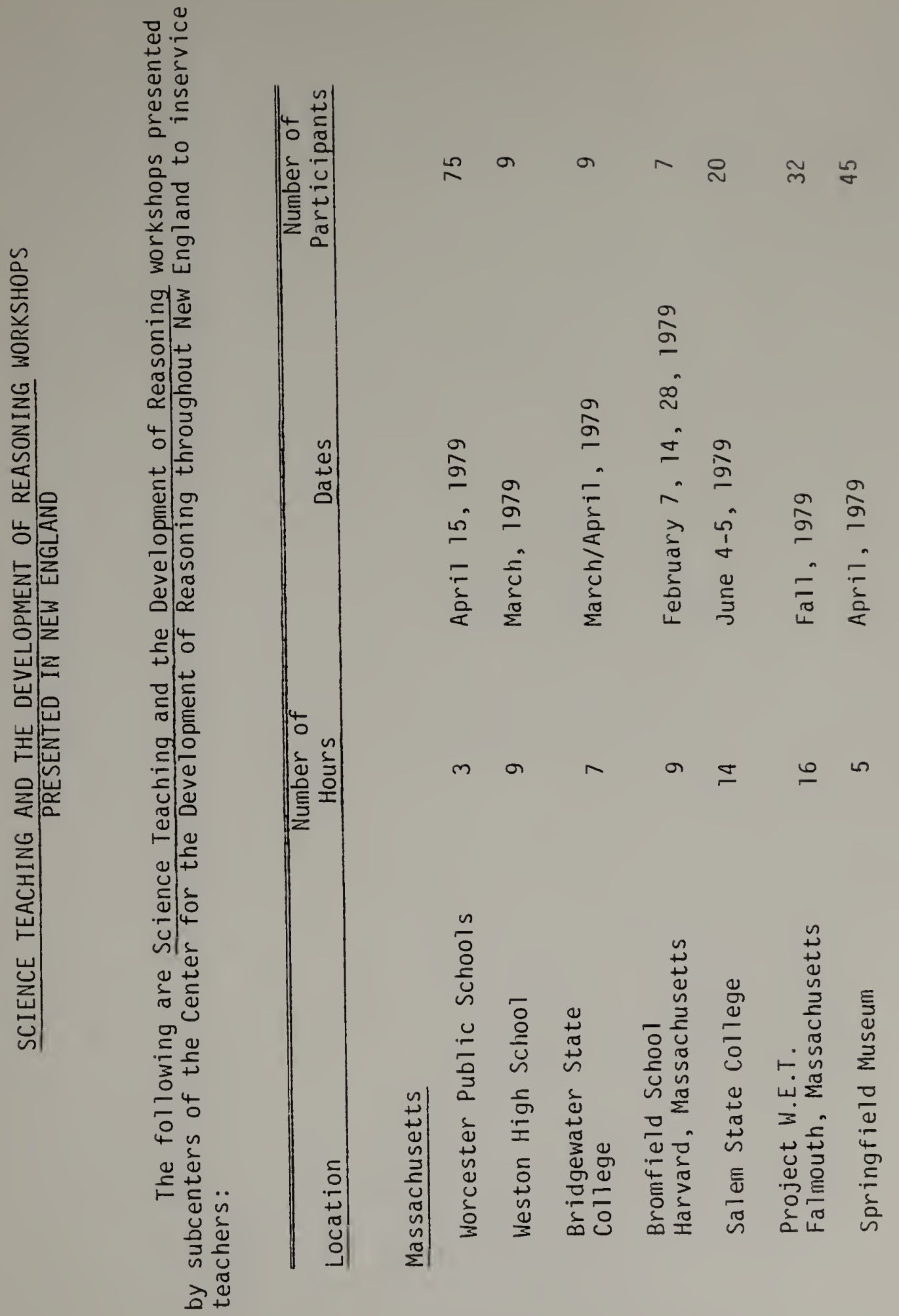




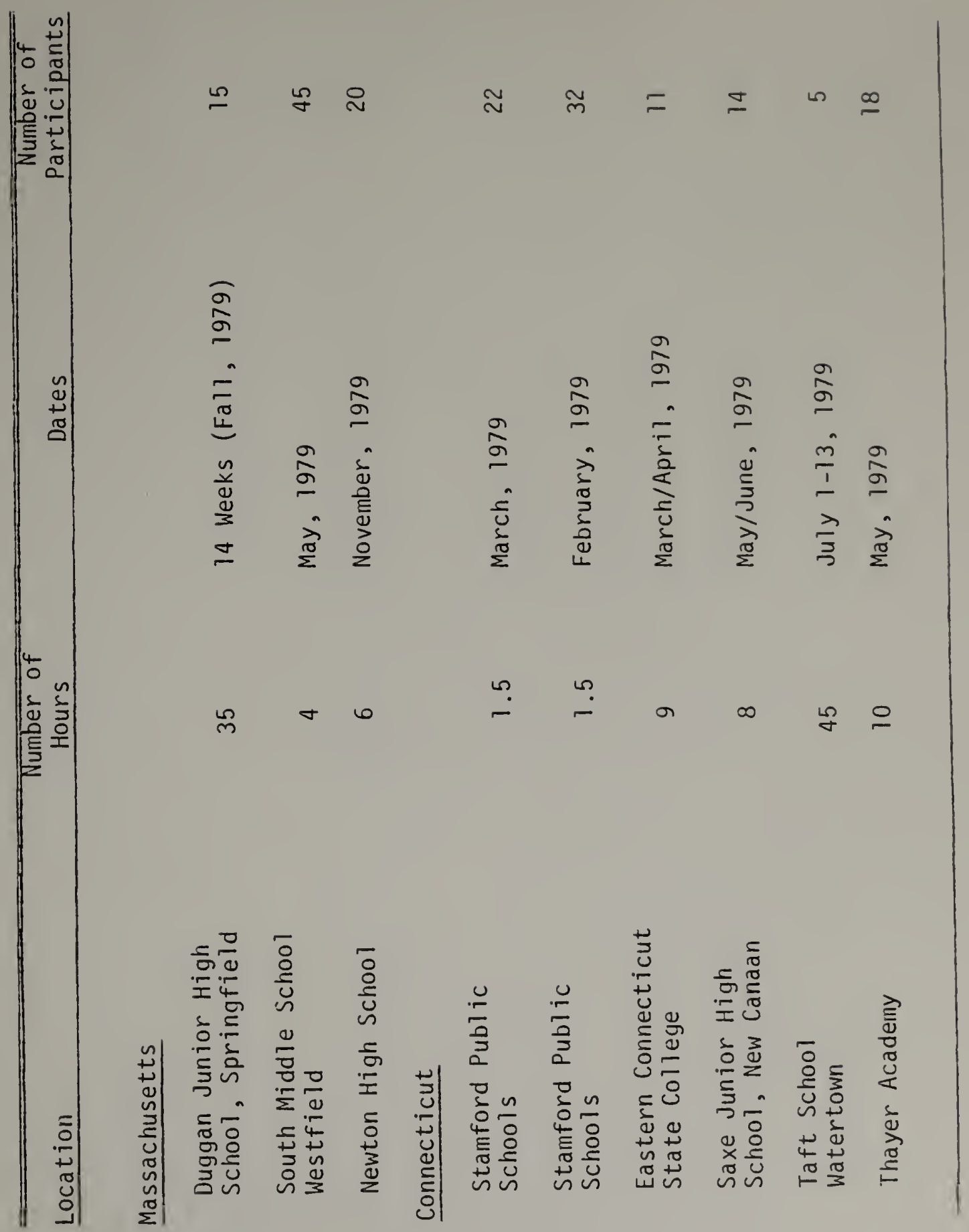




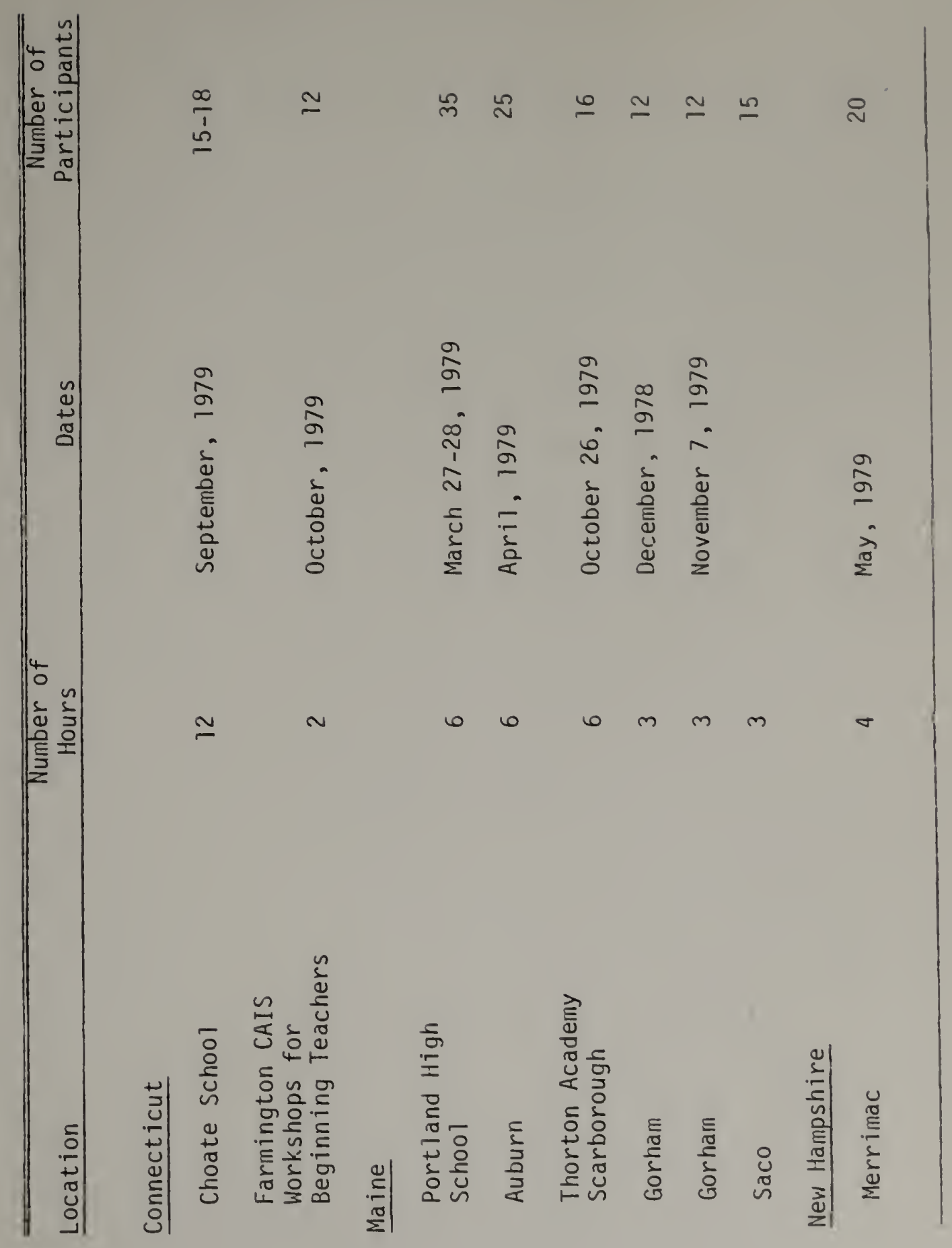




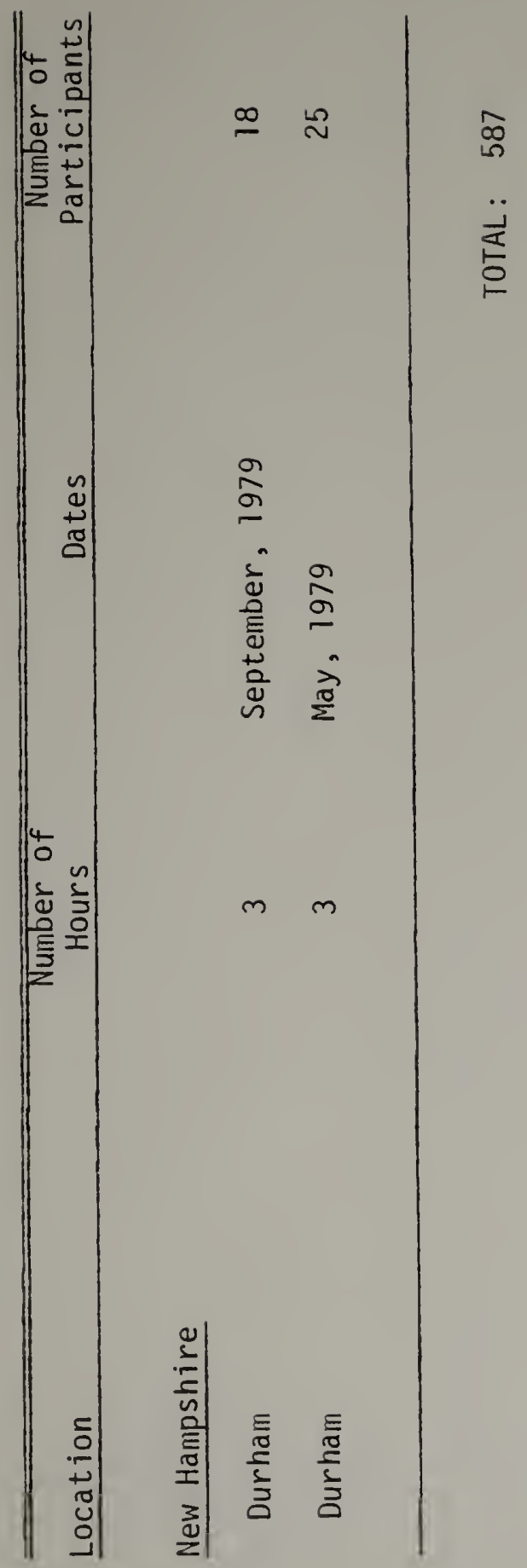


Science Teaching and the Development of Reasoning workshops presented by the Center for the Development of Reasoning, University of Massachusetts, September 1978 to December 1979:

\begin{tabular}{|c|c|c|}
\hline Locations & Dates & Participants \\
\hline $\begin{array}{l}\text { South Hadley Junior and } \\
\text { Senior High School } \\
\text { South Hadley, MA. }\end{array}$ & $\begin{array}{l}\text { December } 9,1978 \\
\text { March 7, } 1979\end{array}$ & 29 \\
\hline $\begin{array}{l}\text { Massachusetts Association } \\
\text { of Science Teachers } \\
\text { Worcester, MA. }\end{array}$ & October 14,1978 & 32 \\
\hline $\begin{array}{l}\text { Hampshire Educational } \\
\text { Coilaborative } \\
\text { Hadley, MA. }\end{array}$ & January 22, 1979 & 18 \\
\hline $\begin{array}{l}\text { Massachusetts Association } \\
\text { of Science Supervisors } \\
\text { Norcester, MA. }\end{array}$ & May 5, 1979 & 28 \\
\hline $\begin{array}{l}\text { Amherst Area Teachers } \\
\text { Center ( } 3 \text {-Credit Course } \\
\text { for Junior High Teachers) }\end{array}$ & Fall, 1979 & 15 \\
\hline $\begin{array}{l}\text { A Chemical Colloquium } \\
\text { Connecticut Valley } \\
\text { Section of American } \\
\text { Chemical Society } \\
\text { Springfield, MA. }\end{array}$ & March 31, 1979 & 57 \\
\hline $\begin{array}{l}\text { Spring Forum } \\
\text { School of Education } \\
\text { University of } \\
\text { Massachusetts/Amherst }\end{array}$ & March 29, 1979 & 32 \\
\hline $\begin{array}{l}\text { Workshop for Science } \\
\text { Education Leaders and } \\
\text { Decision Makers } \\
\text { University of } \\
\text { Massachusetts/Amherst }\end{array}$ & March 22, 1979 & 25 \\
\hline
\end{tabular}


Springfield Technical

Community College

One Armory Square

Springfield, MA.

$$
\begin{gathered}
\text { May } 1,3,10, \\
15,1979
\end{gathered}
$$

Southeastern

Massachusetts

University

Dartmouth, MA.

May 22, 1979

Deerfield Academy Deerfield, MA.

September 8, 1979

Wi11 iston Academy

Easthampton, MA.

September 7 and

September 27, 1979

Regional National

Science Teachers

Association Meeting

Hartford, CT.

October $25-27,1979$

Amity Regional Junior High School

Orange, CT.

November 1, 7, 1979

Pittsfield Junior and Senior High School

Pittsfield, MA. 


\title{
DEVELOPMENT OF REASONING CONFERENCE
}

\author{
November $6-8,1978$ \\ Willits-Hallowell Center \\ Mount Holyoke College \\ South Hadley, Massachusetts
}

\section{PARTICIPANTS}

Russel Agne

Michael Andrew

Michael Burke

William Cobbett

F. Donald Dorsey

Peter Glanz

Deborah A. Hudson

John W. Jones

Joseph Jordan

Irving Marsden
Waterman Building

University of Vermont

Burlington, Vermont 05401

Department of Education

University of New Hampshire

Durham, New Hampshire 03824

Worcester State College

486 Chandler Street

Worcester, Massachusetts 01602

Marblehead High School

Marblehead, Massachusetts 01945

University of Southern Maine Gorham, Maine 04038

Rhode Island College

Providence, Rhode Island 02332

Playback Association

708 Third Avenue

New York, New York 10017

34 Eagles West Road

Duxbury, Massachusetts 02332

Weston High School

444 Wellesley Street

Weston, Massachusetts 02193

Weston High School

Weston, Massachusetts 02193 
Harold T. Neuberger

Edward North

Paul Peknik

Russ Stanhope

Frank Sullivan

Kenneth Taylor

Robert Viens

George Weygand

Mary Worth

Ralph Yuro
College of Education

University of Southern Maine

Gorham, Maine 04038

The Taft School

watertown, Connecticut 06795

Hoyt Schocl

High Ridge Road

Stamford, Connecticut 06903

Curriculum Center

31 Elizabeth Street

Worcester, Massachusetts 01605

Department of Biology

Salem State College

Salem, Massachusetts 01970

Department of Biology

Westfield State College

Westfield, Massachusetts 01085

Department of Physical Science

Rhode Island College

Providence, Rhode Island 02908

Department of Fhysics

Bridgewater State College

Bridgewater, Massachusetts 02324

Center for Cognitive Studies

University of Vermont

Burlington, Vermont 05401

Eastern Connecticut State College

83 Windham Street

Willimantic, Connecticut 06226 


\section{DEVELOPMENT OF REASONING CONFERENCE/WORKSHOP SCHEDULE \\ November $6-8,1978$}

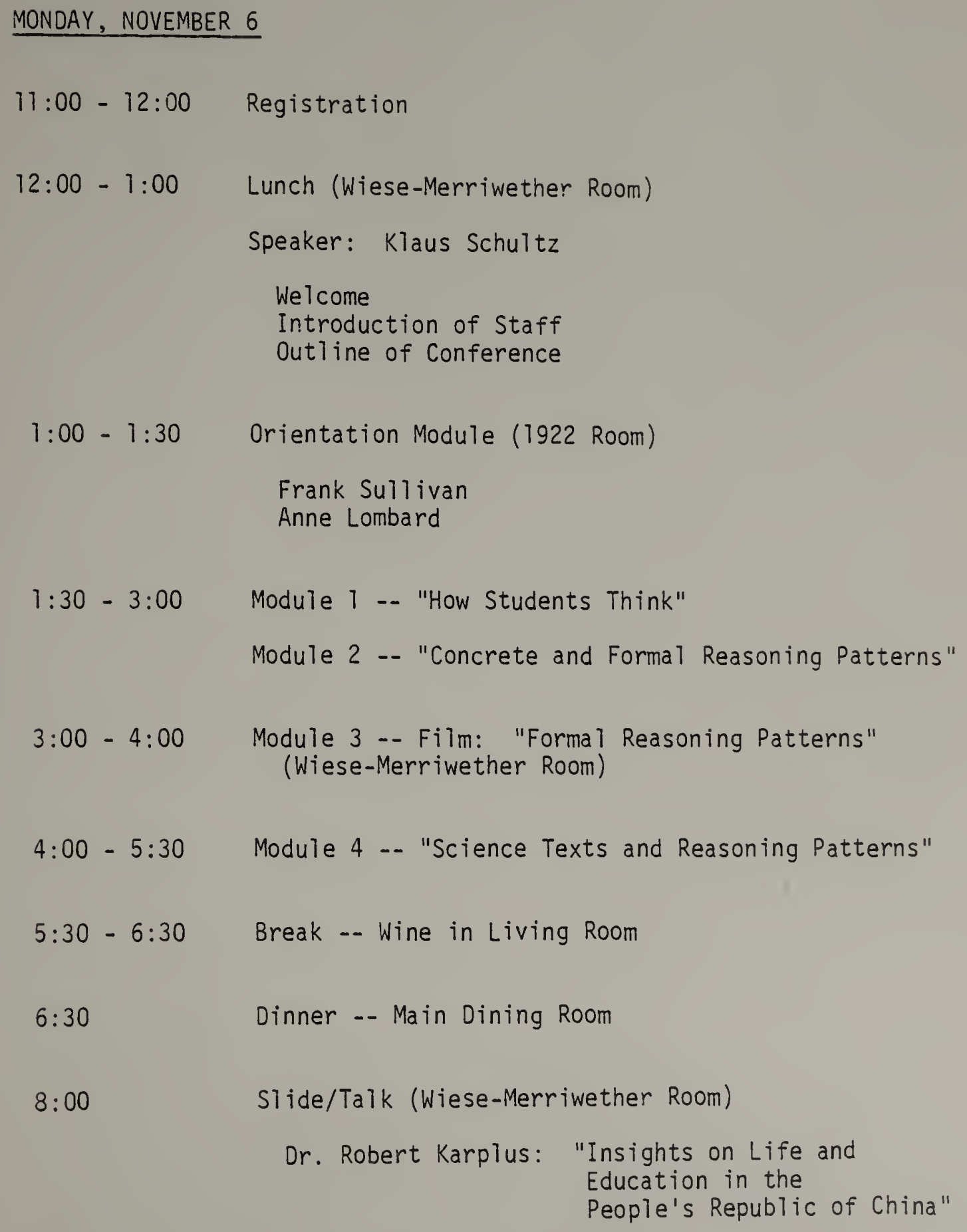

STide/Talk (Wiese-Merriwether Room)

Dr. Robert Karplus: "Insights on Life and Education in the People's Republic of China" 
TUESDAY, NOVEMBER ?

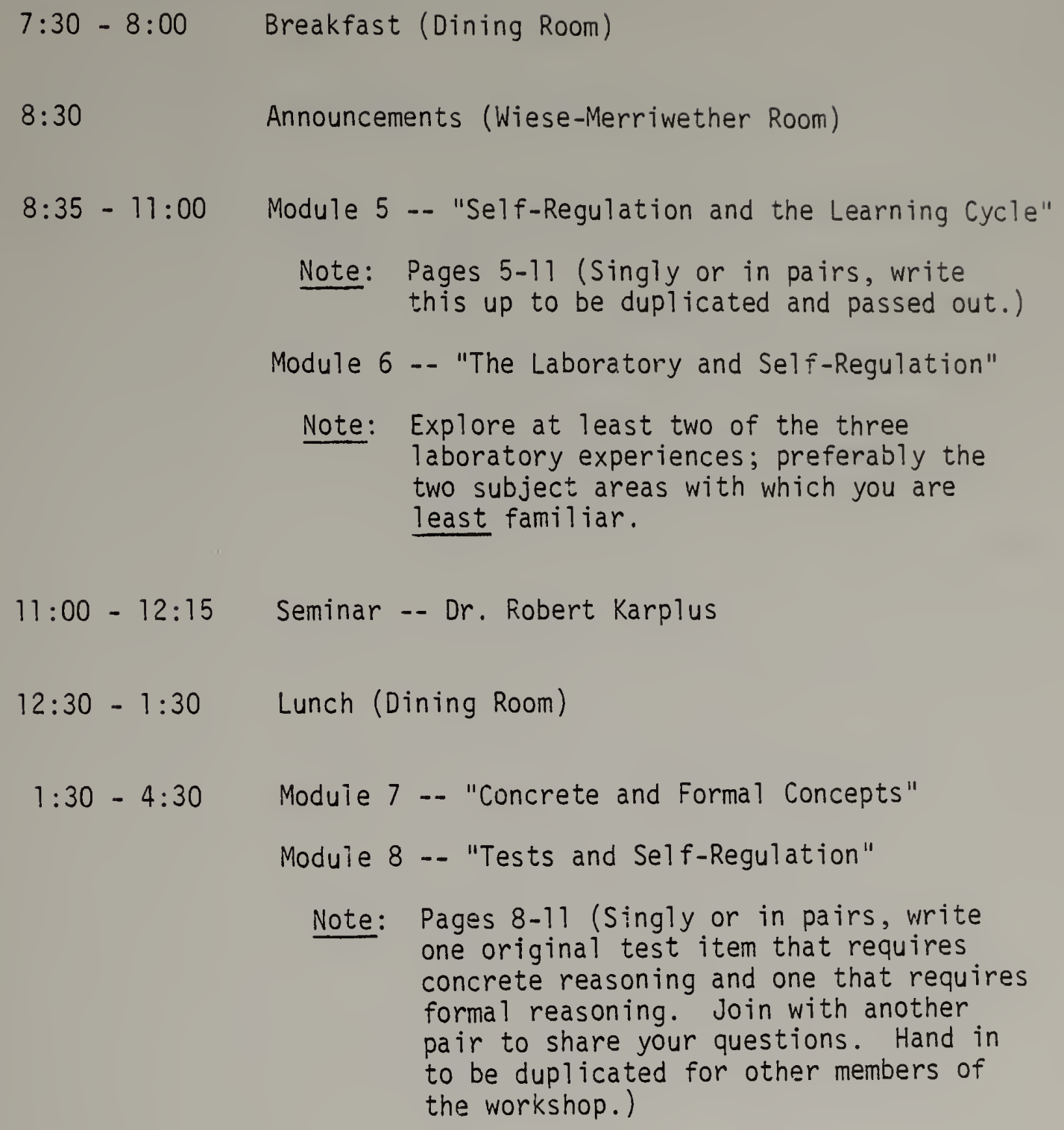
one original test item that requires concrete reasoning and one that requires formal reasoning. Join with another pair to share your questions. Hand in to be duplicated for other members of the workshop.)

4:30 - 5:30 "A Cartoonist Looks at Piaget" -- Dr. Richard Konicek (Wiese-Merriwether Room)

5:30 - 6:30 Wine and Cheese in Living Room

$6: 30$ Dinner (Dining Room) 
WEDNESDAY, NOVEMBER 8

$7: 30-8: 00 \quad$ Breakfast (Dining Room)

8:30 - 10:00 Module 9 -- "Teaching Strategies and Goals"

Summary and Application of Workshop Materials

10:00 - 10:30 Interviewing Techniques

What Follows This Workshop?

Irv Marsden

Frank Sullivan

$10: 30-10: 45 \quad$ Coffee Break

10:45 - 12:15 Module 10 -- "Workshop Planning and Management"

Workshop Models

That First Workshop

$12: 30-1: 30 \quad$ Lunch (Wiese-Merriwether Room)

$1: 30-3: 30 \quad$ Dissemination Plans

Publicity

Support Systems

$3: 30-4: 00 \quad$ Summary and Evaluation

Distribution of Materials

APRIL 6, 1979: SET ASIDE THIS DATE FOR A ONE-DAY CONFERENCE TO EXCHANGE IDEAS AND ASSESS PROGRESS! 
APPENDIX B

WORKSHOP EVALUATION QUESTIONNAIRE

RESPONSES TO WORKSHOP EVALUATION QUESTIONNAIRE

PERMISSION LETTER

WORKSHOP INTERVIEW QUESTIONNAIRE

CONCERNS QUESTIONNAIRE 
Apri1 1, 1980

Dear Workshop Participant:

I am writing to you because you have been a participant in a Science Teaching and the Development of Reasoning workshop or class within the past two years.

We are now doing an evaluation of the effectiveness of these workshops and request your assistance. We would like to find out whether or not the workshops were useful to you, and what might be done to improve them. Our goal is to help teachers and schools develop inservice programs which are what teachers want and need, conducted in such a way so as not to impose more unnecessary demands on an already heavy schedule.

We are asking you to fill out the attached questionnaire and return it to us by April 15th. Please place the completed questionnaire in the envelope included and either return it to the person who gave it to you or mail it back to us directiy.

Thank you for your help.

Sincerely,

Anne Lombard

Anne Lombard, Project Director

Center for the Development of Reasoning 


\section{SCIENCE TEACHING AND THE DEVELOPMENT OF REASONING WORKSHOP}

\section{EVALUATION QUESTIONNAIRE}

1. The location of the Science Teaching and the Development of Reasoning workshop or class you attended was

2. What were the total number of hours of the workshop or class which you attended?

$$
\text { 3-4 hours _ 5-6 hours__ More than } 6
$$

3. How many months have passed since you attended the workshop?

$$
\text { 0-3 months _ 4-6 months__ More than } 6
$$

4. Present grade/teaching level:

5. Total yeạrs teaching:

6. Female:

Male:

7. In what subject area is your major teaching responsibility?

8. Highest degree earned:

Bachelor's

Master's

Doctorate

Other

9. The size of the classes you teach could best be described as clustering around:
15
20
25
30 and up

10. Check all the phrases which describe your participation in the workshop you attended.

a. Voluntary participation

b. Mandatory participation

c. Released time to attend workshop

d. Attended because you were interested

NAME (Optional): 
PLEASE CIRCLE THE APPROPRIATE RESPONSE TO EACH STATEMENT

$1=$ Strongly Agree

2 = Agree

$3=$ Disagree

4 = Strongly Disagree

5 = Irrelevant or Unsure

11. As a result of this workshop, I have become more aware of the reasoning processes of my students.

12. Most of the secondary school science teaching is appropriate for the developmental

level of the students taught.

13. The "learning cycle," as described in the workshop (exploration, concept introduction, and concept application), can be an effective way to teach secondary school science.

14. I was involved in the decision to have the the Science Teaching and the Development of Reasoning workshop at my school.

15. The teachers generally have input into making decisions about inservice programs in my school.

16. The workshop addressed my individual concerns as a teacher.

17. I had the opportunity to actively participate during the workshop.

18. I felt I could not incorporate the ideas of the workshop into my teaching.

19. The workshop provided the opportunity to work and discuss with other participants.

SA A $\quad D \quad S D$ I

i 2345

$\begin{array}{lllll}1 & 2 & 3 & 4 & 5\end{array}$

$\begin{array}{lllll}1 & 2 & 3 & 4 & 5\end{array}$

$\begin{array}{lllll}1 & 2 & 3 & 4 & 5\end{array}$

$\begin{array}{lllll}1 & 2 & 3 & 4 & 5\end{array}$

$\begin{array}{lllll}1 & 2 & 3 & 4 & 5\end{array}$

$123 \quad 3 \quad 4 \quad 5$

12345

$\begin{array}{lllll}1 & 2 & 3 & 4 & 5\end{array}$

$\begin{array}{lllll}1 & 2 & 3 & 4 & 5\end{array}$

20. I feel I should plan or teach some of my classes differently as a result of the workshop. 


\section{SA A $\quad$ D $\quad$ SD I}

21. The ideas of the workshop did not fit with what I already bel ieved about teaching and learning.

22. After the workshop, I agreed with the approach to teaching and learning presented in the workshop.

23. I feel that some change in my teaching has occurred as a result of participating in this workshop.

24. The morale in my school is high.

25. My administration does not support changes I make in the direction of increased emphasis on reasoning development.

26. I need more planning time during school hours if I am going to make any innovations in my science teaching.

27. The issue of job security prevents me from being as innovative as I would like.

12345

12345

12345

$\begin{array}{lllll}1 & 2 & 3 & 4 & 5\end{array}$

$\begin{array}{lllll}1 & 2 & 3 & 4 & 5\end{array}$

$1 \quad 2 \quad 3 \quad 4 \quad 5$

12345

28. To what extent have you applied the ideas of the workshop in the following areas:
a. Laboratory
Design
b. Use of
Textbook
c. Introducing New Topics
d. Tests
e. Presentation of Concepts
f. Other (Explain)

\begin{tabular}{|l|l|l|l|l|}
\hline $\begin{array}{l}\text { Not at } \\
\text { All }\end{array}$ & $\begin{array}{l}\text { Very } \\
\text { Little }\end{array}$ & $\begin{array}{l}\text { Mod- } \\
\text { erately }\end{array}$ & $\begin{array}{l}\text { Con- } \\
\text { Siderably }\end{array}$ & $\begin{array}{l}\text { A Great } \\
\text { Deal }\end{array}$ \\
\hline & & & & \\
\hline & & & & \\
\hline & & & & \\
\hline & & & & \\
\hline & & & & \\
\hline & & & & \\
\hline
\end{tabular}


29. If you have applied the ideas of the workshop in any of the above areas, please describe one or more examples below. Use the other side of the page if necessary.

We will be conducting a small number of interviews with interested teachers to collect more detailed impressions of the workshops. Please place your name, address, and phone number below if you are interested in being contacted regarding this.

Name

Address

Phone

THANK YOU!

Those who return this form and include name and address somewhere on the form will receive an article describing the results of this study. 


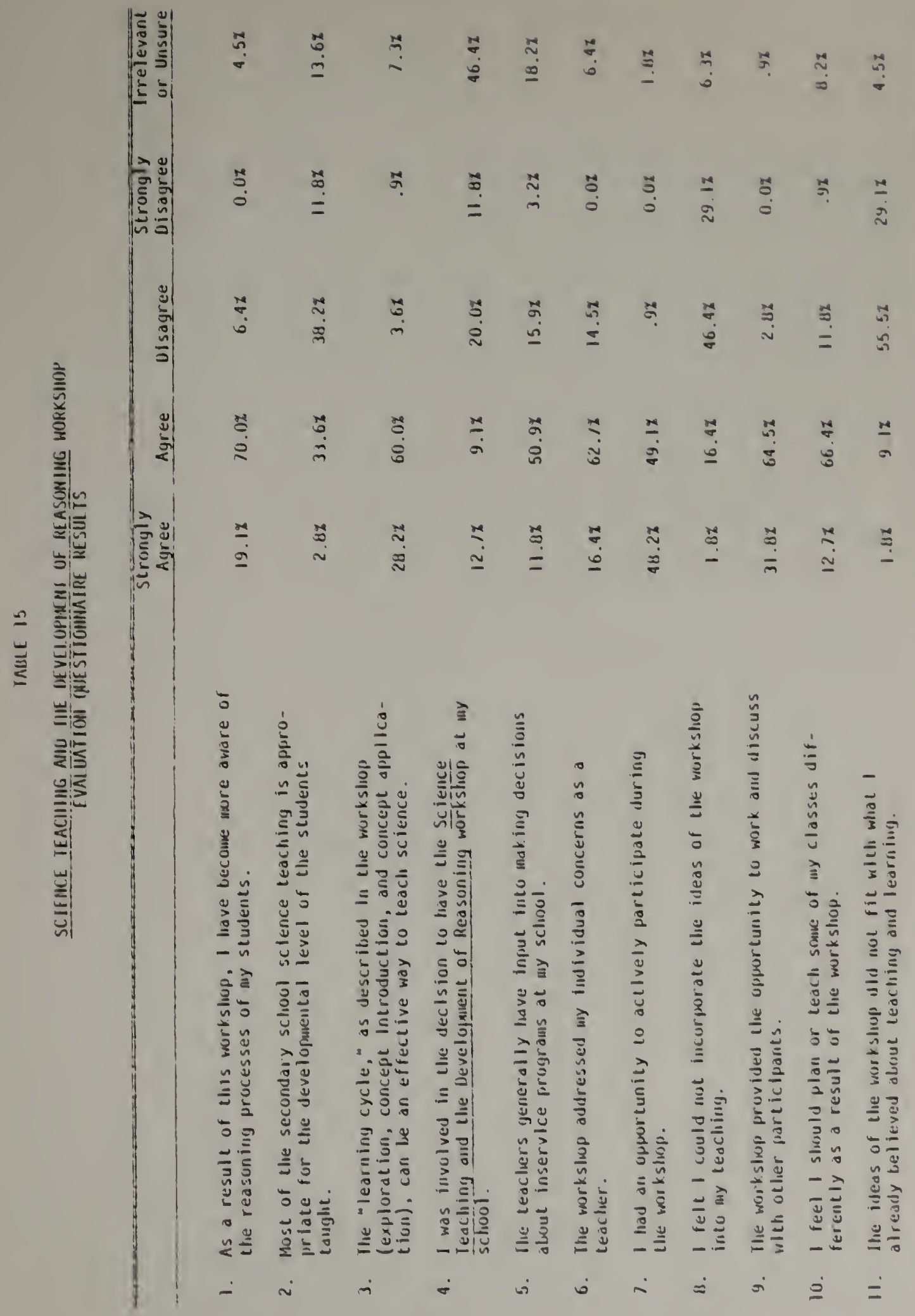




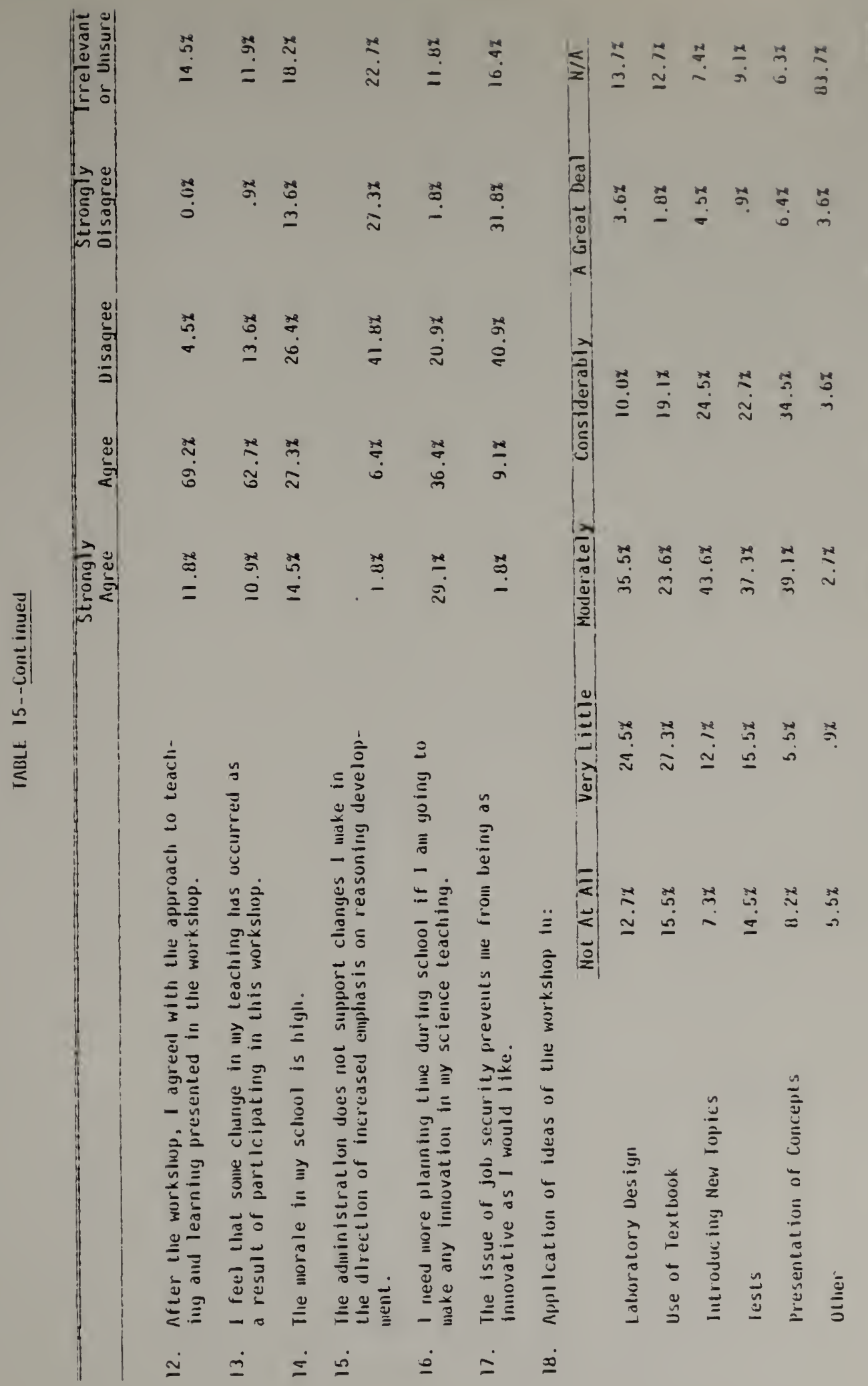




\section{EVALUATION}

1. Things found most useful about the Development of Reasoning workshop were:

a. Which moduies were particularly instructive?

b. Which ideas appeared most relevant to your teaching?

2. Things found least useful about this workshop were:

3. Suggestions for improvement of future workshops:

4. Do you have any ideas at present for utilizing the information and suggestions presented in the workshop? 


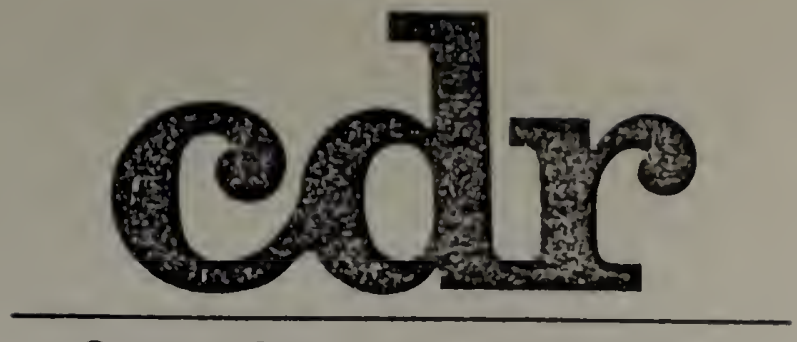

\section{Center for the Development of Reasoning}

May 1,1980

To teachers interested in participating in a study determining the effect of reasoning workshops on the teaching strategies of secondary science teachers.

The purpose of the interview in which you have volunteered to participate is to determine whether teachers who have taken part in reasoning workshops have used the ideas of the workshop in changing teaching style and methods. It is also to determine the nature and extent of changes made and to identify what factors you think either facilitated or hindered your ability to make changes.

Schools with funding for inservice training continue to seek outside resources to provide one or a series of workshops for their teachers. It is important to clarify what changes are possibie as a result of workshops provided by outsiders, so schools can assess whether funds spent in this manner are accomplishing their goals.

All responses will be kept confidential and you are free to withdraw from the interview at any time. Data will be reported in aggregate to assure anonymity, and wi 17 be destroyed or returned. Any questions you have concerning the study are welcome.

Thank you for your help and cooperation.

Sincerely,

Anne S. Lombard

Anne S. Lombard

I, , am willing to participate in the above described interview regarding the reasoning workshop which I attended. 


\section{WORKSHOP QUESTIONNAIRE}

(For Users)

1. What is your overall reaction to the Science Teaching and the Development of Reasoning Workshop as you reflect back on it at this time?

Did you feel any differently immediately after you attended it?

2. Are you currently using the ideas and methods from the workshop? YES NO

3. Please describe ways you have used it.

4. What did you feel about the results when you used it?

5. Did you find that variations of the ideas of the workshop, or going beyond the ideas of the workshop, worked for you?

6. In what ways do you feel you have adapted the workshop ideas to your own use and style?

7. Have you talked with others and shared information regarding the workshop ideas? YES NO What did you share?

8. Have you worked with others on matters related to the workshop?

9. What do you see as the strengths of the workshop?

10. What do you see as the weaknesses of the workshop? Have you done anything about the weaknesses? 
Users (Continued)

11. Have you explored any further information related to the subject matter of the workshop?

What kinds?

For what purposes?

12. What are the most important points which you got out of the workshop?

13. What do you see as your major concerns about the workshop and its ideas at the present time?

14. Have you had any feedback from students about your use of the workshop ideas?

Have you noticed any impact on the students?

15. If the workshop were to be given again, do you have any suggestions for changes or additions?

16. What factors in your school situation helped you to use the ideas of the workshop?

17. What prevents you from making more changes?

18. Did you attend the workshop voluntarily? YES NO Did that factor have any effect on your use of the workshop ideas? 
Users (Continued)

19. What is your general opinion regarding new approaches to teaching that appear periodically in workshops and conferences?

20. What have been your prior experiences with inservice workshops in your school?

Have you been able to use the ideas? YES NO

Are you involved in the decisions about them? YES NO

Who plans and conducts them?

Is participation required? YES NO

21. What degree of trust and administrative support is there when you try out new ideas?
Actively Negates
Passive Support
Without interference
Active
Support

22. Can you summarize for me where you see yourself right now in relation to the use of the ideas of the workshop? 


\section{WORKSHOP INTERVIEW QUESTIONNAIRE \\ (For Non-Users)}

1. What is your overall reaction to the Science Teaching and the Development of Reasoning Workshop as you reflect back on it at this time?

Did you feel any differently immediately after you attended it?

2. Are you currently using ideas or methods from the workshop?

YES NO

3. Have you used it at all in the past?

$$
\text { YES NO }
$$

4. Why did you stop?

5. Do you or did you have any serious reservations about the workshop, either its content or how it was given?

6. What do you see as the strengths of the workshop?

7. What prevented you from using the ideas of the workshop?

8. What do you see as the weaknesses of the workshop? In your situation?

9. What are your major concerns about the workshop and its ideas at the present time?

10. What are the most important points which you got out of the workshop? 
Non-Users (Continued)

11. Have you looked for or asked about any further information related to the subject matter of the workshop?

What kind?

For what purposes?

12. Did you attend the workshop voluntarily? YES NO Did that factor have any effect on your use of the workshop ideas?

13. What is your general opinion regarding new approaches to teaching that appear periodically in workshops and conferences?

14. What have been your prior experiences with inservice workshops in your school?

Have you been able to use the ideas? YES NO

Are you involved in the decision about them? YES NO Who plans and conducts them?

Is participation required? YES NO

15. What degree of trust and administrative support do you get when you try out new ideas?

$$
\begin{array}{lll}
\text { Actively Negates } & \text { Passive Support } & \text { Active } \\
& \text { Without Interference } & \text { Support }
\end{array}
$$

16. Can you summarize for me where you see yourself right now in relation to the use of the ideas of the workshop? 


\section{Center for the Development of Reasoning}

PLEASE COMPLETE THE FOLLOWING:

1. Present Grade/Teaching Level:

2. Total Years Teaching:

3. Sex: Female Male

4. In what subject area is your major teaching responsibility:

5. Highest Degree Earned:

Bachelor's _ Master's _ _ Doctorate __ Other

6. In your use of "The Learning Cycle Approach," do you consider yourself to be a:

Nonuser

Novice

Intermediate

old Hand

Past User

7. Have you received formal training in "The Learning Cycle Approach"? (Workshops, Courses)

Yes _ No 


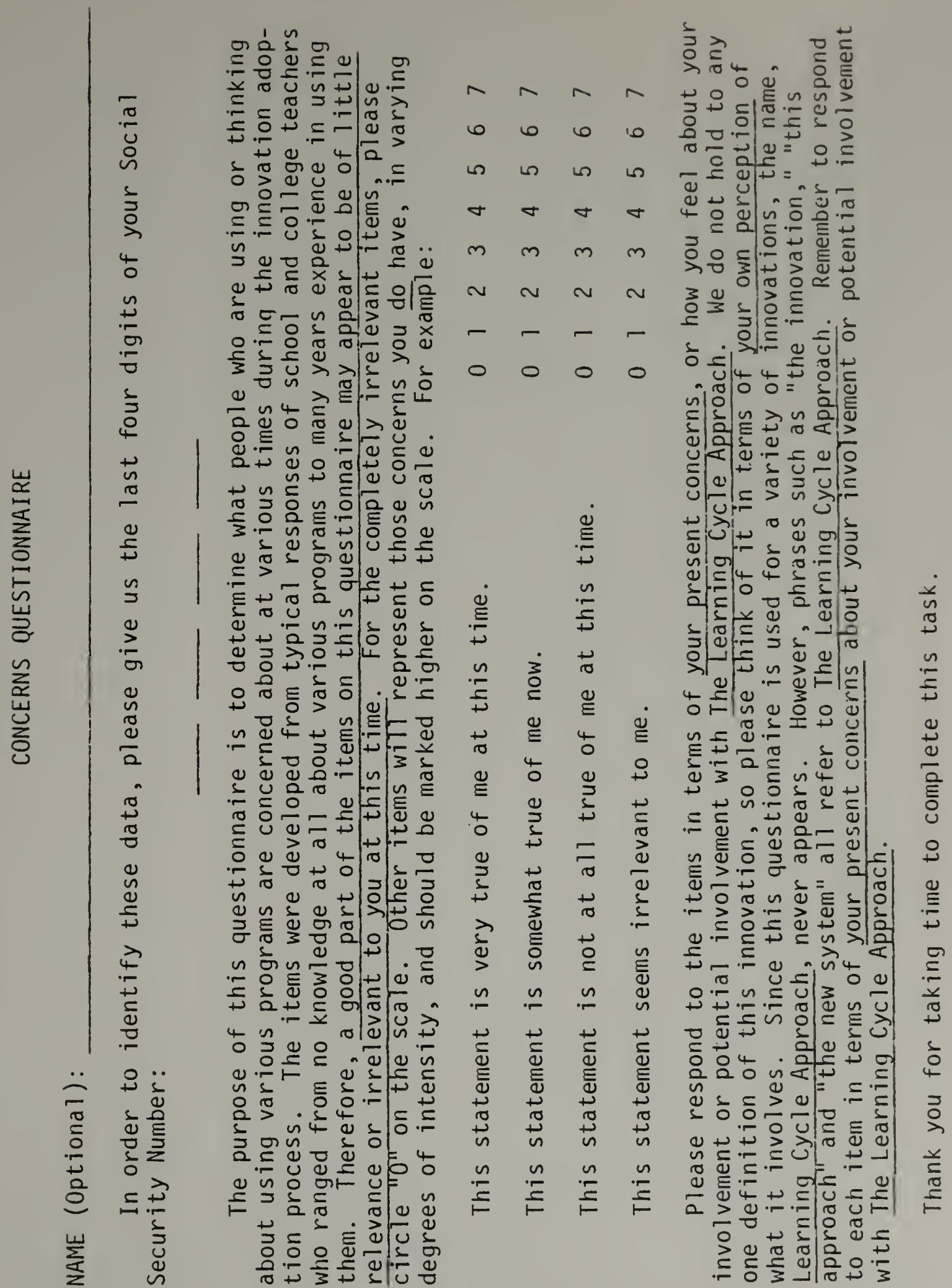




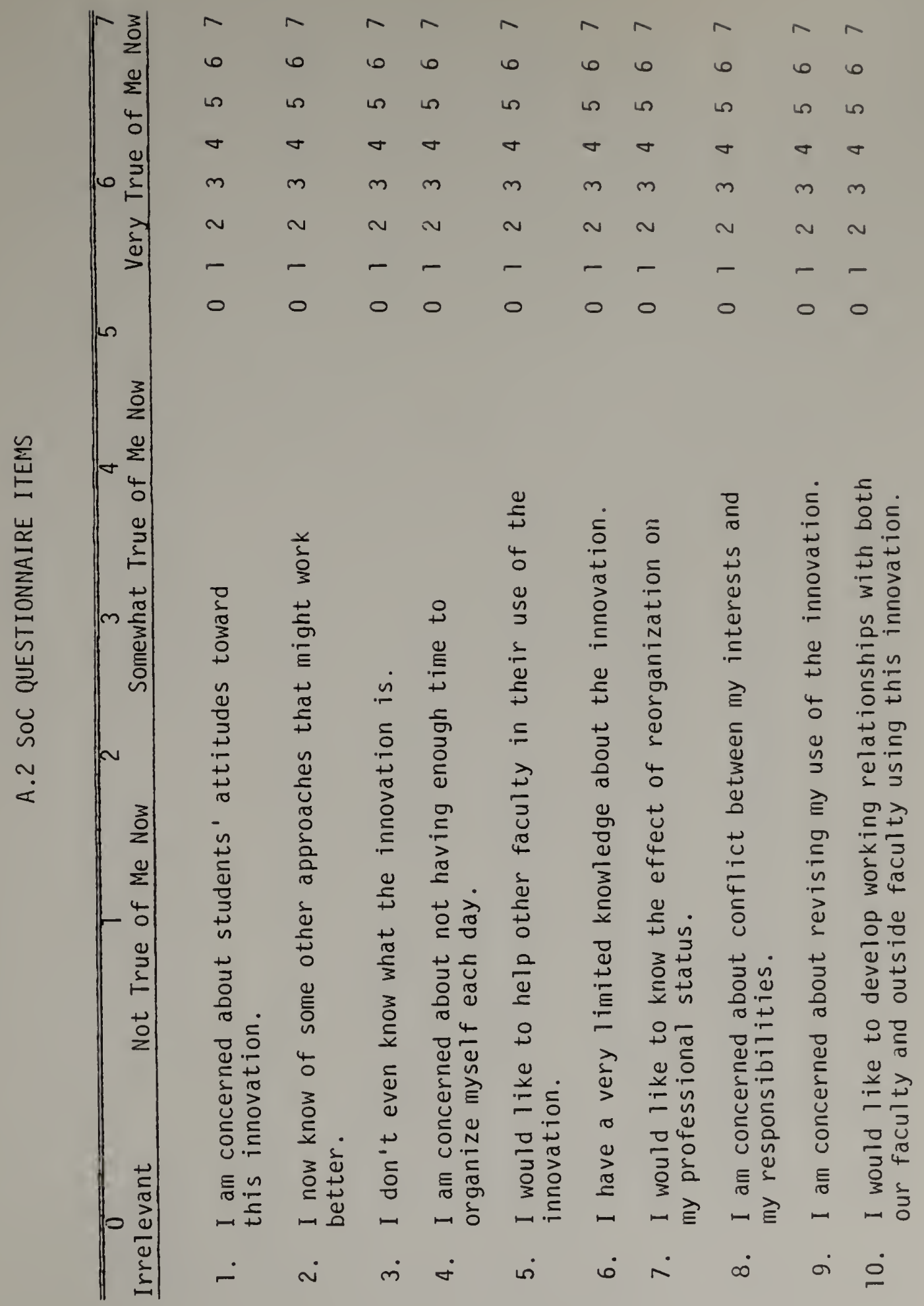




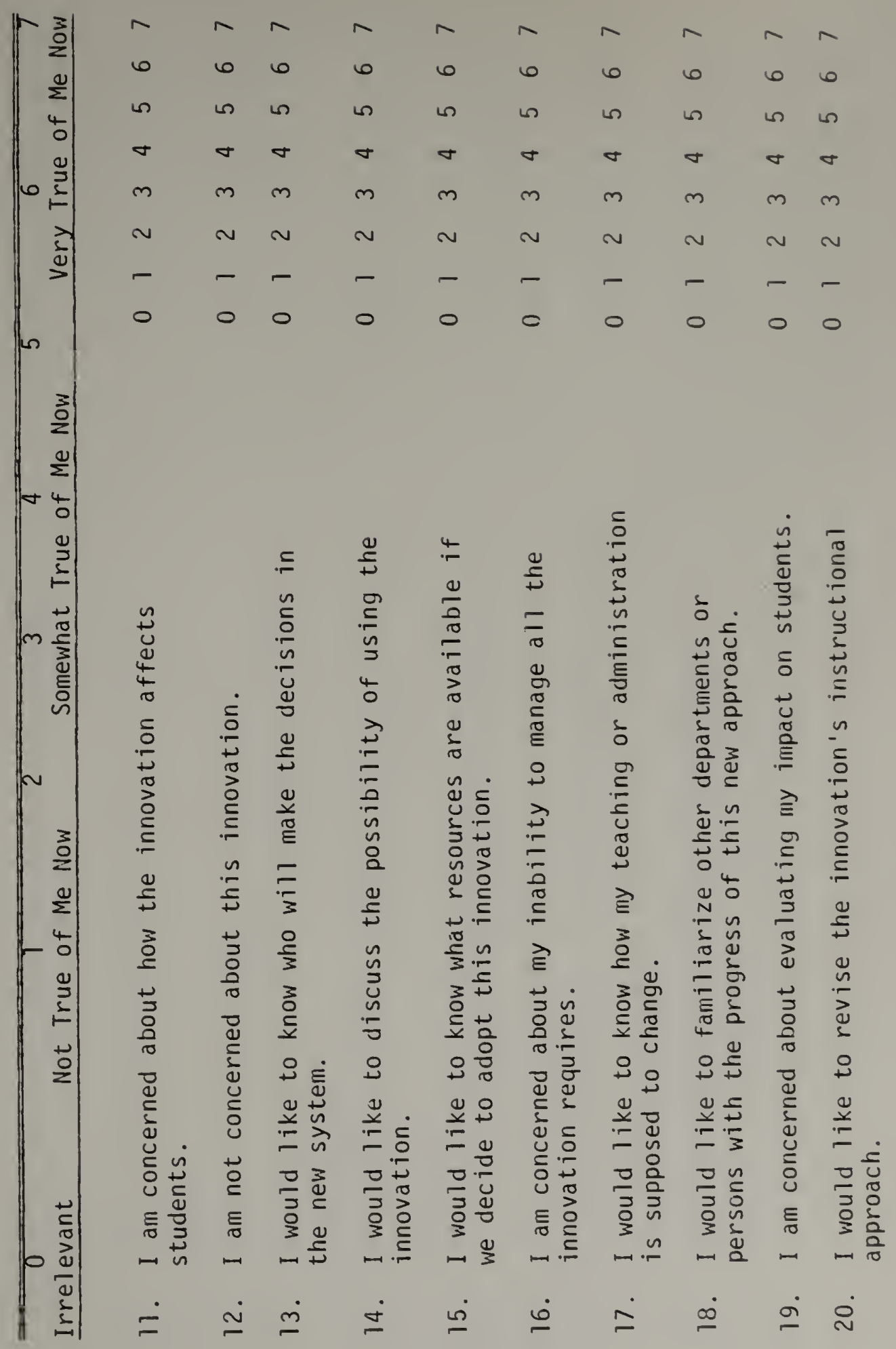




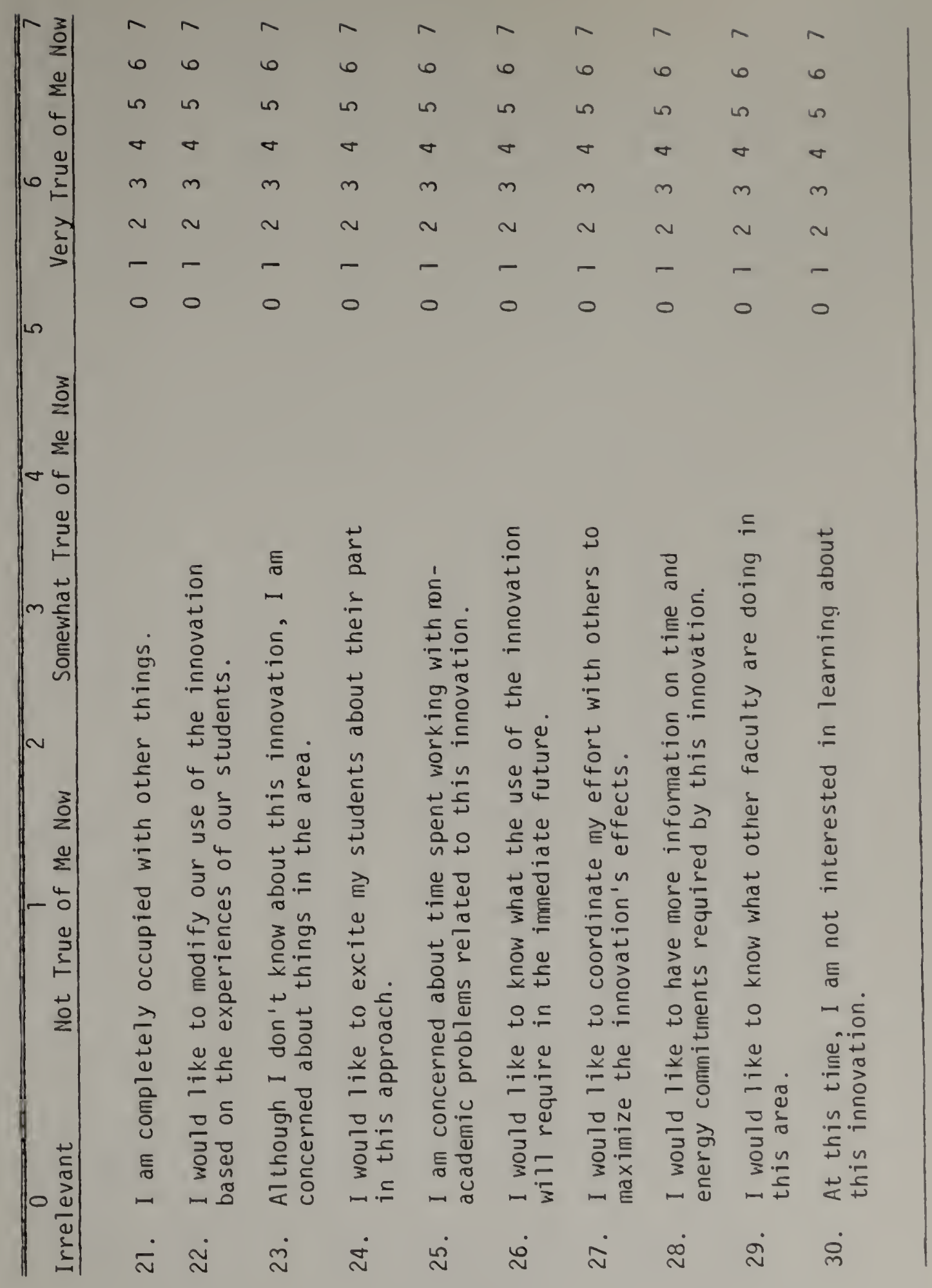




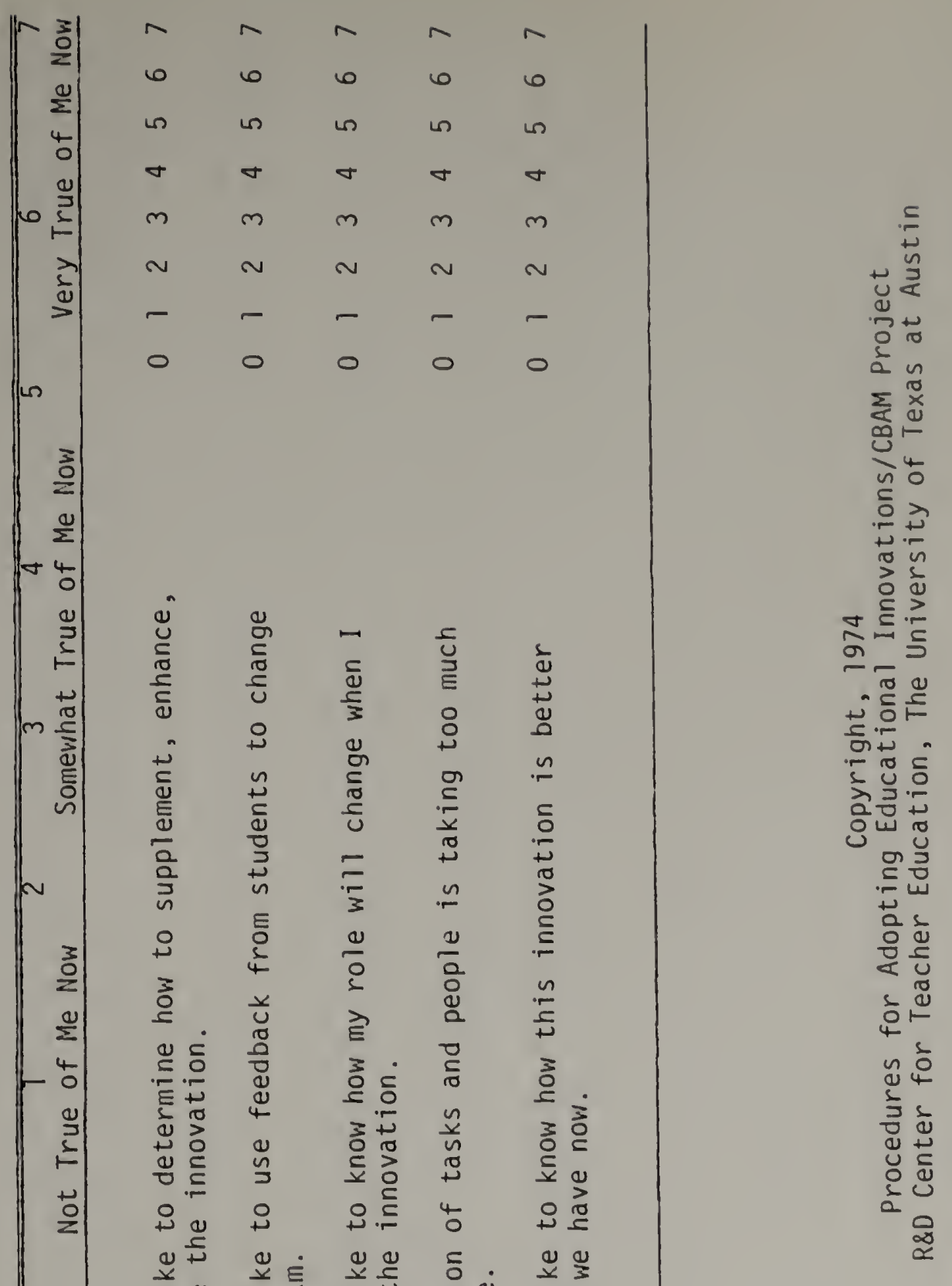




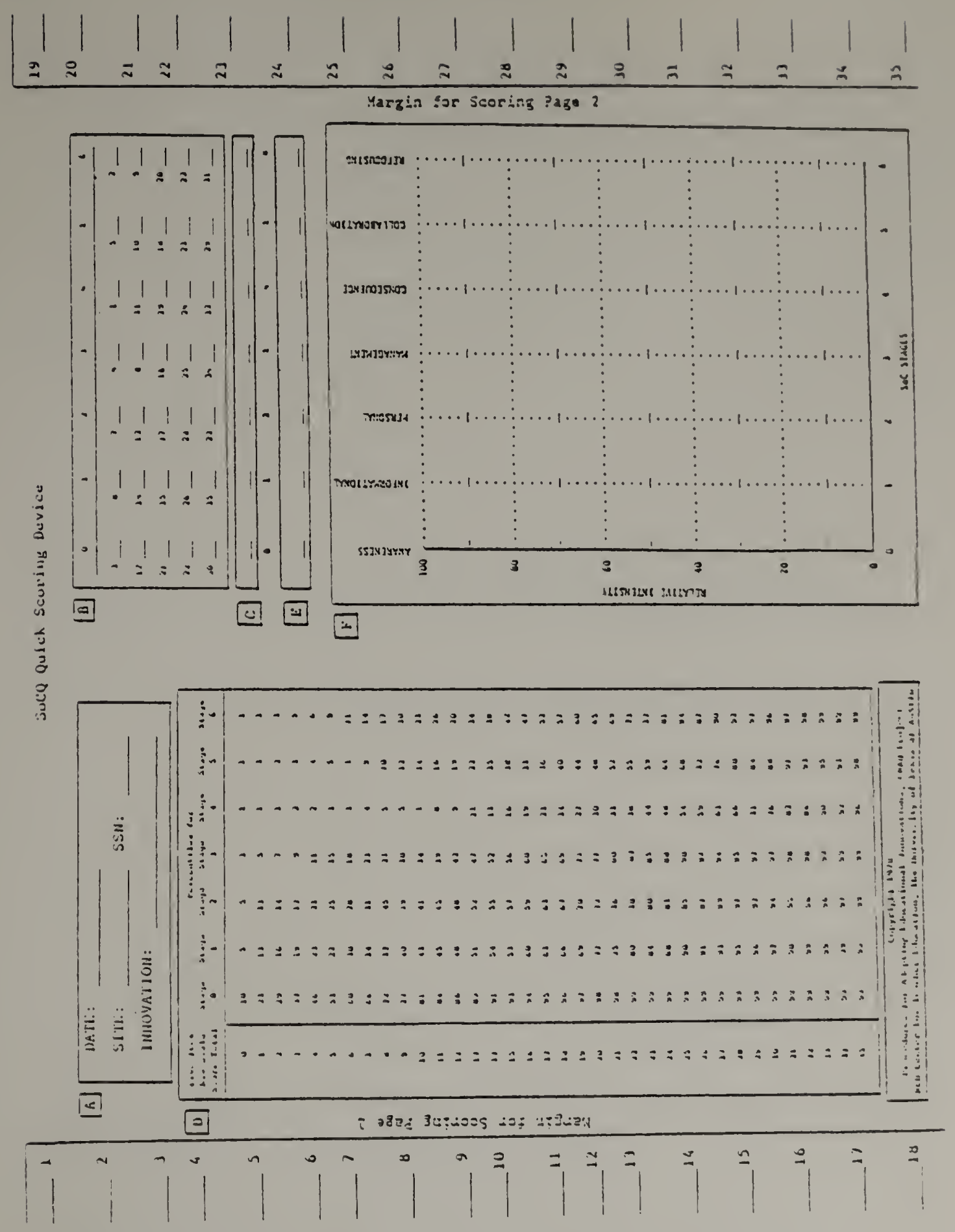


APPENDIX C

EXAMPLES OF "EXPLORATORY" TYPE LABORATORIES

USED BY TEACHERS FOLLOWING SCIENCE TEACHING AND THE DEVELOPMENT OF REASONING WORKSHOPS

(THESE WERE TRANSCRIBEO FROM WORKSHOP EVALUATION INTERVIEWS.) 


\section{EXPLORATORY TYPE LABORATORIES}

Examples of exploratory type laboratories used by teachers following the workshops include the following:

1. Cn testing rocks, looking for similarities and differences, materials for testing were made available with no specific guidelines given. Students decided on their own tests and eventually were able to work out a classification system.

2. Instead of initiating a discussion and listing on the board the characteristics of living things, a two-day exploration was tried, putting out all types of specimens of living and nonliving objects. Students were asked to find patterns and come up with their own groupings.

3. We do five conservation of mass experiments. They see some colors, do some masses, and only later I ask, "What's constant through those five experiments?" That to me is a sort of exploration without really telling them what the purpose of the experiments are until afterward. This is my idea of an exploration with some direction to what is explored. 
4. My students were requested to complete a laboratory on atmospheric pressure given materials and results. They were challenged to devise a procedure which would give the expected results.

5. As a spin-off of the workshop, I used an activity in conjunction with the study of the nervous system. It incorporated several stations using some workshop activities and some activities from an old I.Q. test. Students test themselves and each other and hopefully come to appreciate the difficulty of defining and measuring individual intelligence. This was used successfully at both curriculum levels.

6. My qualitative analysis laboratory is exploratory.

I first give them experience with using the equipment and give them several qualitative anaiysis examples with methods so they have some idea of how to do it. Then they devise their method and bring it up, and I ask them questions to clarify it. They use their own particular method of logic to plan the steps. The students were very enthusiastic.

7. Instead of the usual lecture about different kinds of milk used in cooking, each group was asked to construct a chart listing at least five 
qualities that they would use to compare different kinds of milk. Each group was given four glasses containing evaporated, skim, homogenized, and sweetened condensed milk. They were labeled $A, B, C$, and $D$. The students attempted to identify each kind of milk and filled out their charts according to the qualities they had listed: appearance, taste, color, etc. When they had finished their charts, each group reported their reaction to the class.

8. Instead of the usual lecture-discussion on food groups, we took a walking field trip to the local grocery store. Each student had an imaginary $\$ 25.00$ to spend. Students were asked to record the type of food, product name, ounces or servings, price and reason this package was selected for each product. "I felt that this activity allowed students exposure to an appropriate physical activity, experience, and led to discussion and interaction with others."

9. Laboratory on the process of respiration as it takes place in mitochondria of cells of both plants and animals. Previously, I had provided specific procedures; but this time, I had the students determine the procedure. Once they realized 
that explicit procedures were not available, they proceeded with little difficulty and quickly identified those class members who were able to provide some insight. Now I just provide an overview of the activity and let the students proceed on their own.

10. Formerly, the laboratory I conducted on the skeleton consisted of a laboratory sheet, which essentially stated: "Here's this bone; it works this way." Now I put out the skeleton of ten or twelve different animals. The students entering the laboratory know that the skeleton provides support and muscle attachment, and they are familiar with the names of some of the basic human bones. The laboratory is now in terms of questions rather than statements. "Where is one bone that is different in three types of animals?" "Why do you think it might be different?" I consider this a structured exploration. The laboratory sheets for this type of laboratory look very different from the traditional ones which were filled with information, questions to answer, and items to list.

This laboratory sheet had minimal directions and large empty spaces. 
. 
